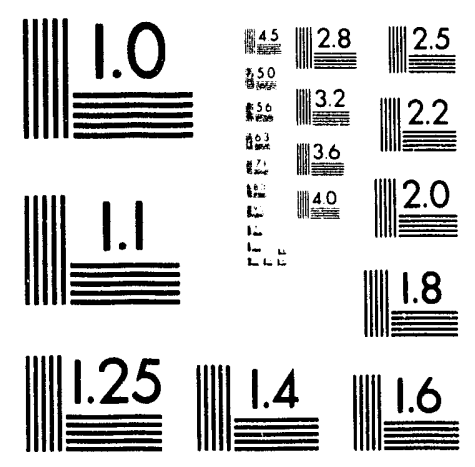



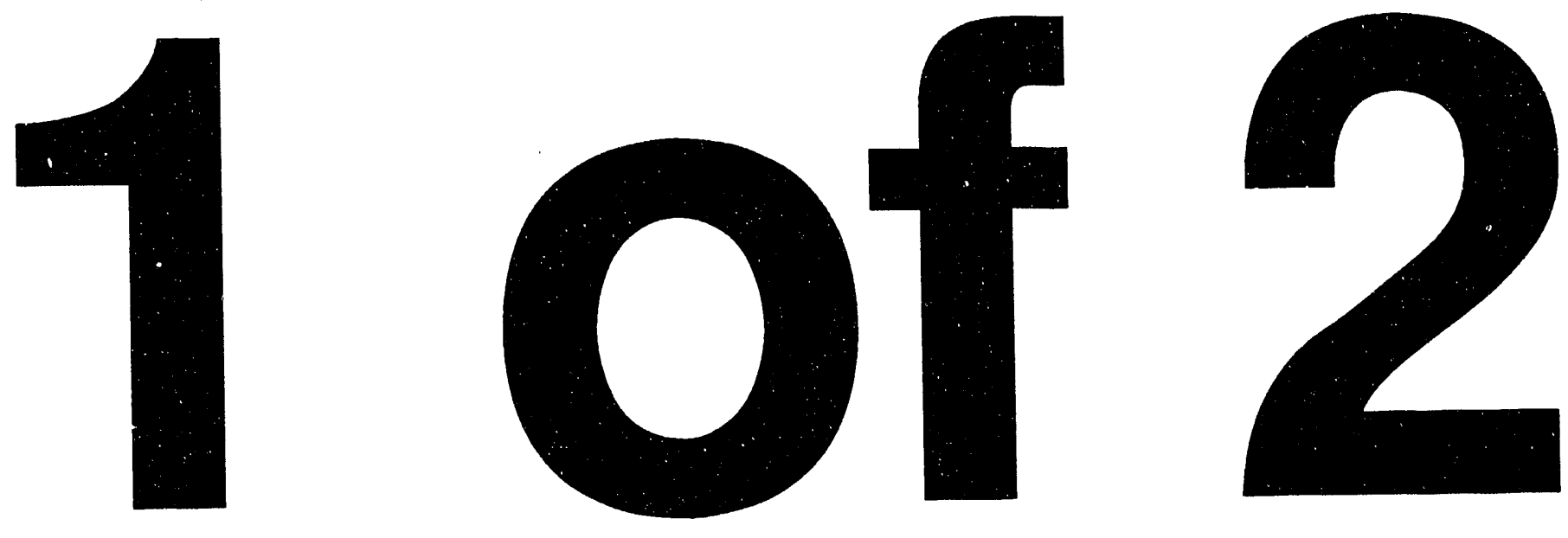


\title{
In Situ Treatment of VOCs by Recirculation Technologies
}

\section{Interim Report}

\author{
R. L. Siegrist 1 \\ O. F. Webb 1 \\ M. R. Ally 1 \\ W. E. Sanford 1 \\ P. M. Kearl 2 \\ J. L. Zutman ${ }^{2}$
}

1 Oak Ridge National Laboratory, Oak Ridge, TN 37831-6038

2 Oak Ridge National Laboratory, Grand Junction, CO 81502-2567

Environmental Sciences Division

Publication No. 4056

Date Prepared: June 1993

Prepared for

U. S. DEPARTMENT OF ENERGY

Office of Technology Development

International Technology Exchange Program

Washington, D.C.

Prepared by the

Environmental Sciences Division

OAK RIDGE NATIONAL LABORATORY

Oak Ridge, Tennessee 37830-6038

\section{Managed by \\ MARTIN MARIETTA ENERGY SYSTEMS, INC. \\ for the}

U. S. DEPARTMENT OF ENERGY

under contract DE-AC05-84OR21400

\section{MASTER}




\section{CONTENTS}

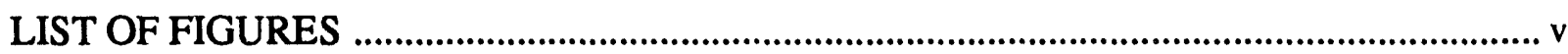

LIST OF TABLES ……….................................................................................................... vii

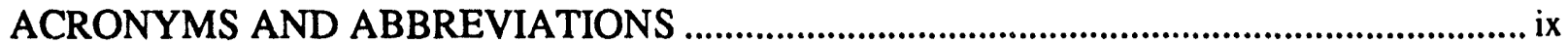

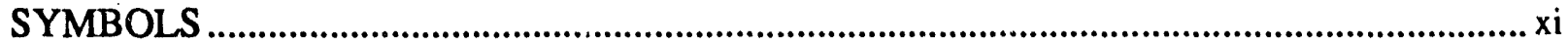

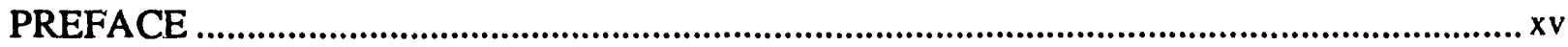

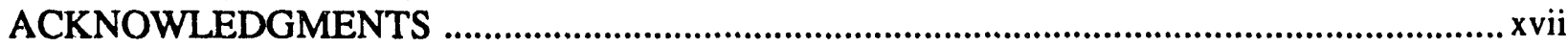

EXECUTIVE SUMMARY ....................................................................................................

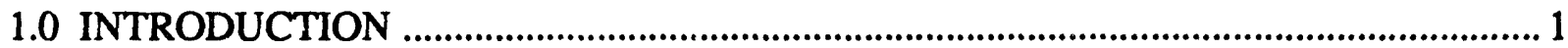

1.1 BACKGROUND ………..................................................................................... 1

1.2 OBJECTIVES AND SCOPE ...................................................................................... 1

1.3 PROJECT ORGANIZATION ............................................................................. 2

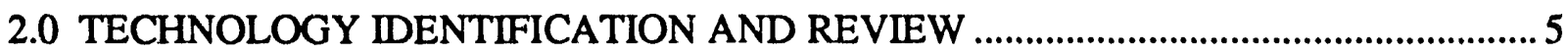

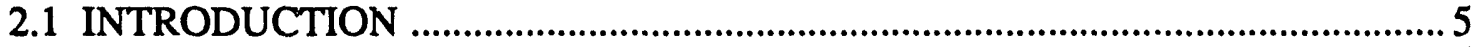

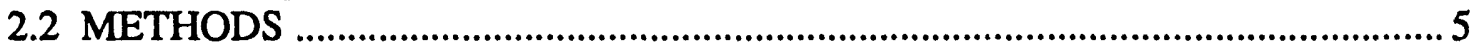

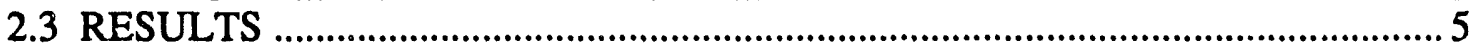

2.3.1 In Situ Treatment of Organics in Subsurface Recirculation .......................5

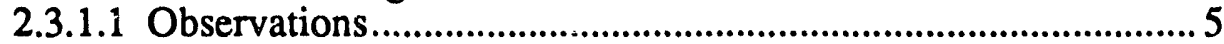

2.3.1.2 Discussion ................................................................................ 9

2.3.2 In Situ Treatment of Organics in Vertical Well Recirculation ................... 10

2.3.2.1 Observations................................................................................... 10

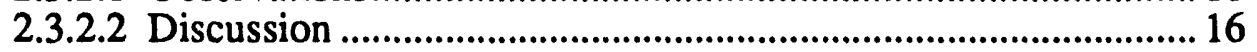

2.3.3 In Situ Treatment of VOCs in Horizontal Wells .......................................... 16

2.3.3.1 Obser vations................................................................................... 16

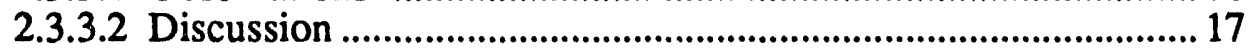

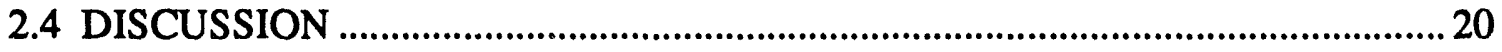

3.0 ASSESSMENT OF IN SITU RECIRCULATION PROCESSES ……...................................2

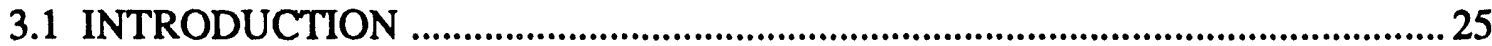

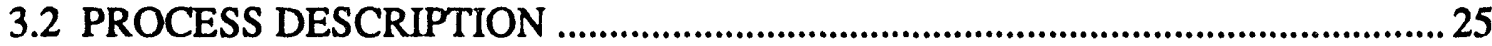

3.2.1 In Situ Recirculation Processes ................................................................ 25

3.2.1.1 Vertical Recirculation Wells (UVB/GZB)............................... 25

3.2.1.2 Porous Pipe Horizontal Recirculation Wells (PP/HW) ............... 25

3.2.2 Baseline Processes ...............................................................................28

3.2.2.1 Vertical Well Pump and Treat Processes ...................................... 28

3.2.2.2 Horizontal Well Pump and Treat Processes................................. 28

3.2.3 Comparison of In Situ Recirculation with Baseline Technologies ............ 29

3.3 Assessment of Recirculation Process Attributes............................................................ 30

3.3.1 Hydrodynamic Performance ................................................................ 30

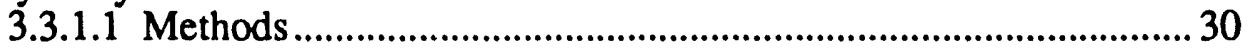

3.3.1.2 Resuits ........................................................................................ 31

3.3.2 VOC Stripping Treatment Efficiency ........................................................ 39

3.3.2.1 Methods ................................................................................... 39

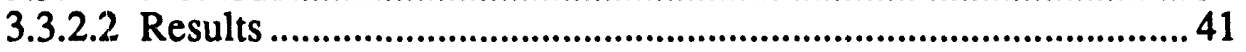

3.3.3 Geochemical Precipitates ........................................................................... 41

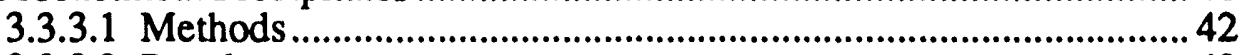

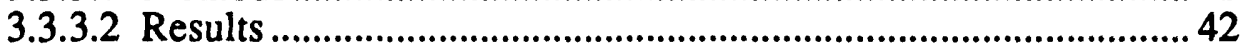




\section{CONTENTS continued}

4.0 PROCESS MODIFICATIONS

4.1 INTRODUCTION

4.2 IMPROVING VOC TREATMENT EFFICIENCY

4.2.1 Improving Stripper Efficiency with a Countercurrent Flow Pattern

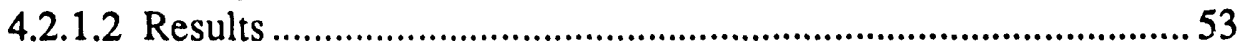

4.2.2 An Alternate Off-gas VOC Treatment Method …................................. 56

4.2.2.1 Methods ............................................................................. 57

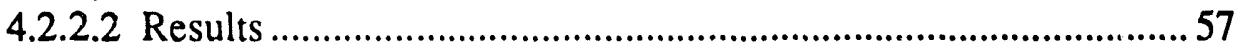

5.0 CONCLUSIONS AND RECOMMENDATIONS .....................................................61

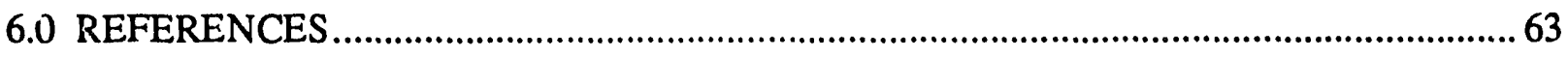

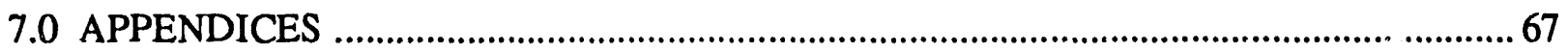

Appendix A. HYDROLOGIC COMPUTATIONS FOR THE UVB/GZB

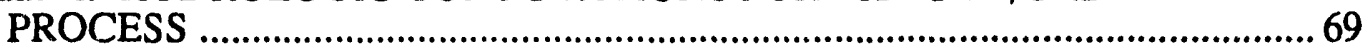

Appendix B. HYDROLOGY OF SELECTED DOE SITES .................................... 81

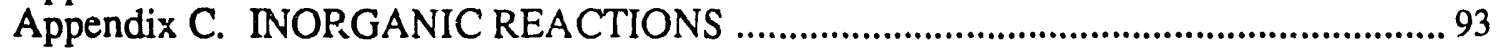




\section{LIST OF FIGURES}

Eigure

1.1. Project organization 3

2.1 Schematic of the UoK ISMFE subsurface recirculation test site 6

2.2. UoK ISMFE subsurface recirculation test site .7

2.3. UoK ISMFE infiltration test area 8

2.4. Schematic of the UVB/GZB vertical well recirculation process ..................................... 11

2.5. UVB/GZB pilot-scale unit ........................................................................................ 12

2.6. Karlsruhe Kneilingen UVB/GZB test site ………….................................................... 13

2.7. Full-scale UVB/GZB unit at GfS in Kircheim, Germany ............................................... 15

2.8. KSK microtunneling equipment in Graben Village, Germany ........................................ 18

2.9. Horizontal pipeline being installed with microtunneling techniques............................... 19

2.10. Relationship between groundwater recirculation and subsurface processes................... 21

2.11. Profile view of an idealized flow field between two parallel PP/HW ........................... 23

2.12. Plan view of a flow field between two parallel PP/HW ............................................... 23

3.1. Major components of the UVB/GZB vertical well for in situ recirculation and treatment of groundwater .......................................................................................... 26

3.2. Major components of the PP/HW system for in situ recirculation and treatment of groundwater ........................................................................................................... 27

3.3 Maximum well spacing as a function of pump rate and hydraulic conductivity for

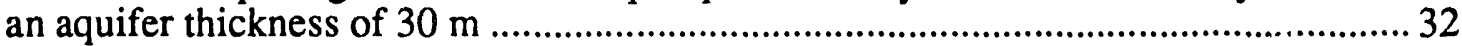

3.4 Maximum well spacing as a function of pump rate and hydraulic conductivity for

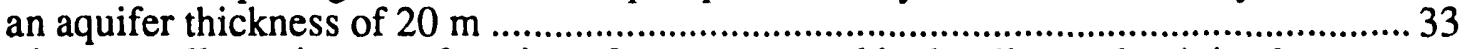

3.5 Maximum well spacing as a function of pump rate and hydraulic conductivity for an aquifer thickness of $10 \mathrm{~m}$.................................................................................... 34

3.6 Maximum well spacing as a function of pump rate and hydraulic conductivity for an aquifer thickness of $5 \mathrm{~m}$

3.7 Maximum well spacing as a function of pump rate and hydraulic conductivity for

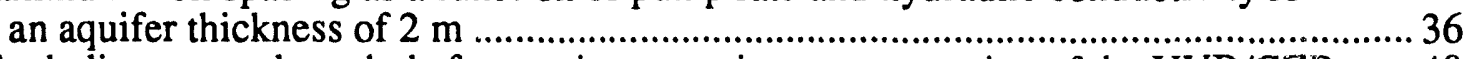

3.8. Block diagram and symbols for a stripper section representative of the UVB/GZB ....... 40

3.9. Predominance of hematite, magnetite, and siderite in aqueous solution under equilibrium conditions containing total dissolved carbonate species of $10-3 \mathrm{M}$ at $25^{\circ} \mathrm{C}$ and $1 \mathrm{~atm}$

3.10. Predominance of hematite, magnetite, and siderite in aqueous solution under equilibrium conditions containing total dissolved carbonate species of 10-2 $\mathrm{M}$ at $25^{\circ} \mathrm{C}$ and $1 \mathrm{~atm}$

3.11. Predominance of hematite, magnetite, and siderite in aqueous solution under equilibrium conditions containing total dissolved carbonate of 1.0 molar, dissolved sulfide at $10-6 \mathrm{M}$, at $25^{\circ} \mathrm{C}$ and $1 \mathrm{~atm}$.

4.1. Diagram of a countercurrent air stripper 50 
3.1. Kansas City Plant UVB/GZB well spacing for various discharge rates ............................38

3.2. Portsmouth Plant UVB/GZB well spacing for a well discharge rate of .......................... 38

4.1. Henry's Law constants for selected VOCs at $25^{\circ} \mathrm{C}$........................................................... 49

4.2. Effect of changing fresh air pipe diameter on stripping processes .....................................5 54

4.3. Effect of changing trichloroethylene liquid feed concentration on required stripping height .........................................................................................................5

4.4. Vapor pressure of TCE at selected temperatures ……………..........................................59

A.1. Maximum well spacing as a function of pump rate, aquifer thickness, and hydraulic conductivity. (Aquifer thickness held constant at $30 \mathrm{~m}$ ) ............................ 71

A.2. Maximum well spacing as a function of pump rate, aquifer thickness, and hydraulic conductivity. (Aquifer thickness was constant at $20 \mathrm{~m}$ ) ................................ 72

A.3. Maximum well spacing as a function of pump rate, aquifer thickness, and hydraulic conductivity. (Aquifer thickness was constant at $10 \mathrm{~m}$ ) ..............................73

A.4. Maximum well spacing as a function of pump rate, aquifer thickness, and hydraulic conductivity. (Aquifer thickness was constant at $5 \mathrm{~m}$ ) ................................. 74

A.5. Maximum well spacing as a function of pump rate, aquifer thickness, and hydraulic conductivity. (Aquifer thickness was constant at $2 \mathrm{~m}$ ) ……....................... 75

A.6. Estimation of possible pumping rates based on drawdown calculations for $\mathrm{H}=30$ $\mathrm{m}(97 \mathrm{ft})$, maximum allowable drawdown $=72 \mathrm{ft}, \mathrm{l}=24 \mathrm{ft}, \mathrm{r}=1 \mathrm{ft}, \mathrm{t}=30$ days........ 76

A.7. Estimation of possible pumping rates based on drawdown calculations for $\mathrm{H}=20$ $\mathrm{m}(97 \mathrm{ft})$, maximum allowable drawdown $=49 \mathrm{ft}, \mathrm{l}=16 \mathrm{ft}, \mathrm{r}=1 \mathrm{ft}, \mathrm{t}=30$ days........ 77

A.8. Estimation of possible pumping rates based on drawdown calculations for $\mathrm{H}=10$ $\mathrm{m}(33 \mathrm{ft})$, maximum allowable drawdown $=24 \mathrm{ft}, \mathrm{l}=8 \mathrm{ft}, \mathrm{r}=1 \mathrm{ft}, \mathrm{t}=30$ days.......... 78

A.9. Estimation of possible pumping rates based on drawdown calculations for $\mathrm{H}=5$ $\mathrm{m}(16 \mathrm{ft})$, maximum allowable drawdown $=11 \mathrm{ft}, \mathrm{l}=4 \mathrm{ft}, \mathrm{r}=1 \mathrm{ft}, \mathrm{t}=30$ days.......... 79

A.10. of possible pumping rates based on drawdown calculations for $\mathrm{H}=2 \mathrm{~m}(6.5 \mathrm{ft})$, maximum allowable drawdown $=4 \mathrm{ft}, \mathrm{l}=1.6 \mathrm{ft}, \mathrm{r}=1 \mathrm{ft}, \mathrm{t}=30$ days

B.1. Range of hydraulic conductivities for aquifer units at the DOE Kansas City Plant 84

B.2. Summary of hydraulic conductivities reported for hydrologic units of the Coastal Plain Sediments (horizontal unless otherwise stated) at the DOE Savannah River Site 88

B.3. Range of hydraulic conductivity values for major lithologies near the DOE Paducah Gaseous Diffusion Plant. 


\section{ACRONYMS AND ABBREVIATIONS}

DCE

DOE

EM

EPA

ESD

IAG

ID

IEG

$\mathrm{IOH}$

IP

ISMFE

ITEP

ORNL

ORNL/ESD

OTD

PAH

PGDP

PORTS

$\mathrm{PP} / \mathrm{HW}$

RCRA

RGA

SGS

SR

SRS

TCE

TOC

UCRS

UoK

UT

UVB/GZB

VOC

VPI
- 1,2-dichloroethylene

- United States Department of Energy

- Environmental Restoration and Waste Management

- United States Environmental Protection Agency

- Environmental Sciences Division

- Institute of Applied Geology

- Integrated Demonstration

- IEG Technologies Corporation

- Institute for Hydromechanics

- Integrated Program

- Institute of Soil Mechanics and Foundation Engineering

- International Technology Exchange Program

- Oak Ridge National Laboratory

- Oak Ridge National Laboratory/Environmental Sciences Division

- Office of Technology Development

- polycyclic aromatic hydrocarbon

- Paducah Gaseous Diffusion Plant

- Portsmouth Gaseous Diffusion Plant

- porous pipe/horizontal well

- Resource Conservation and Recovery Act

- regional gravel aquifer

- shallow groundwater system

- subsurface recirculation

- Savannah River Site

- trichloroethylene

- total organic carbon

- upper continental recharge system

- University of Karlsruhe

- The University of Tennessee

- Unterdruck-Verdampfer-Brunnen/Grundwasser-ZirkulationsBrunnen

- volatile organic compound

- Virginia Polytechnic Institute and State University 


\section{SYMBOLS}

$a \quad$ - Length of screen section [L]

$a_{m t}$ - Gas-liquid inte:facial area for mass transfer [ $\left.\mathrm{L}^{2}\right]$

$A \quad$ - Influx area of the upstream capture zone [ $\left.\mathrm{L}^{2}\right]$

$B$ - Aquifer thickness [L]

$B_{T} \quad$ - Upstream capture zone at the top of the aquifer [L]

$B_{B} \quad$ - Upstream capture zone at the bottom of the aquifer [L]

$c_{i} \quad$ - Concentration of component $i$ in the liquid phase, [M/L3]

$C_{p} \quad$ - Heat Capacity [J/M-T]

$d_{o} \quad$ - Orifice diameter [L]

$d_{p} \quad$ - Particle diameter [L]

D - Maximum well spacing so that contaminated water cannot pass between the two wells [L]

$D_{A B} \quad$ - Diffusion coefficient of component A through B [mol/L 2 ]

$D_{c} \quad$ - Characteristic length [L]

$D_{\text {pipe }}$ - Diameter of pipe [L]

$f \quad$ - Fanning friction factor, dimensionless

$F_{L} \quad$ - Overall liquid side mass transfer coefficient [mol/t L $\left.\mathrm{L}^{2}\right]$

$G$ - Mass flux of fresh air $\left[\mathrm{M} / \mathrm{t} \mathrm{L}^{2}\right]$

$g_{c} \quad$ - Constant $\left[32.2 \mathrm{lb}_{\mathrm{m}}-\mathrm{ft} / \mathrm{lb} \mathrm{b}_{\mathrm{f}} \mathrm{s}^{2}\right]$

$H$ - Henry's constant, dimensionless

$h_{i} \quad$ - Inside Heat Transfer Coefficient [J/L2-K]

$h_{o} \quad$ - Outside Heat Transfer Coefficient $\left[\mathrm{J} / \mathrm{L}^{2}-\mathrm{K}\right]$

$H_{\text {aff }}$ - Effective Henry's constant, dimensionless

$H_{c} \quad$ - Henry's Constant for component $i$, [atm- $\left.\mathrm{L}^{3} / \mathrm{mol}\right]$

$H_{\text {toL }}$ - Height of transfer unit, [L]

I - Hydraulic gradient of the natural groundwater system

J $\quad$ - Joules [J]

$k \quad$ - Thermal conductivity [J/L-T-t]

$K_{h} \quad$ - Horizontal conductivity [L/t]

$K_{v} \quad$ - Vertical conductivity $[\mathrm{L} / \mathrm{t}]$

$\mathrm{L} \quad$ - Length [L]

$l$ - Screened interval in UVB/GZB [L]

$L_{i} \quad$ - Molar flow rate of liquid phase in stripper [mol/t- $\left.\mathrm{L}^{2}\right]$

$L_{\max } \quad$ Maximum allowable length of pipe [L] 


\section{SYMBOLS continued}

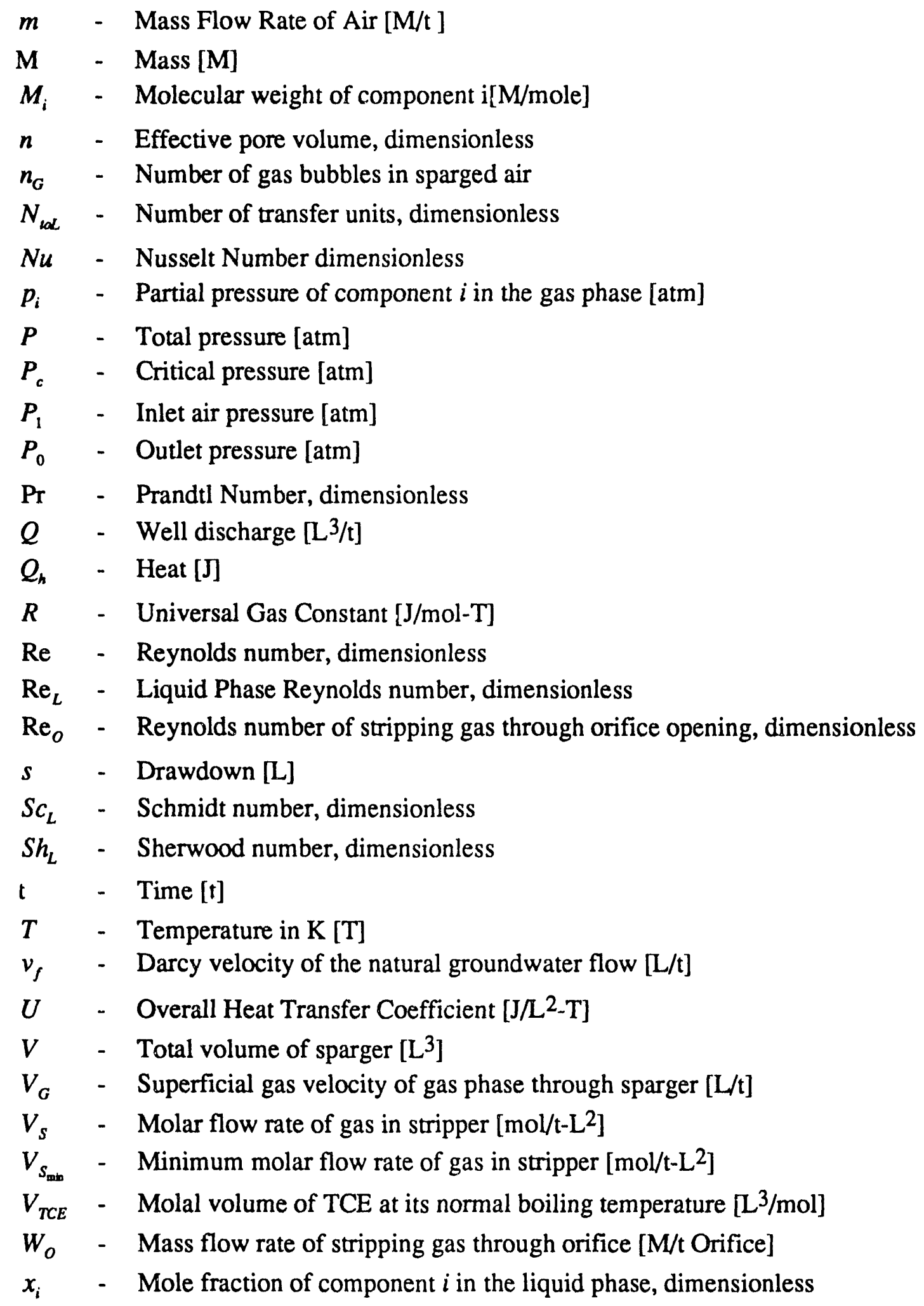




\section{SYMBOLS continued}

$X_{i} \quad$ - Mole ratio of component $i$ in the liquid phase, dimensionless

$y_{i} \quad$ - Mole fraction of component $i$ in the vapor phase, dimensionless

$Y_{i} \quad$ - Mole ratio of component $i$ in the vapor phase, dimensionless

$\phi \quad-2.6$ association factor of water, dimensionless

$\varphi_{G} \quad$ - Gas hold-up, dimensionless

$\mu_{a} \quad-\quad$ Viscosity of liquid [M/t T L]

$\mu_{L} \quad$ - Viscosity of liquid [M/t L]

$\rho_{L} \quad-$ Density of the fluid phase $\left[\mathrm{M} / \mathrm{L}^{3}\right]$ 


\section{PREFACE}

Recognizing the potential gain from research and demonstration activities in foreign countries, an International Technology Exchange Program (ITEP) was initiated within the U. S. DOE Office of Technology Development. As part of this ITEP effort, technical exchange and assessment activities were initiated. The project described herein was conducted by Oak Ridge National Laboratory (ORNL) to identify processes and technologies developed in Germany that appeared to have near-term potential for enhancing the cleanup of volatile organic compound (VOC) contaminated soil and groundwater at DOE sites. Members of the ORNL research team identified and evaluated selected German technologies developed at or in association with the University of Karlsruhe (UoK) for in situ treatment of VOC contaminated soils and groundwater. Project activities included contacts with researchers within three deparments of the UoK (i.e., Applied Geology, Hydromechanics, and Soil and Foundation Engineering) during fall 1991 and subsequent site visits to UoK and private industry collaborators during February 1992. Subsequent analyses consisted of engineering computations, groundwater flow modeling, and treatment process modeling. As a result of these project efforts, two processes were identified as having near-term potential for DOE: (1) the vacuum vaporizer well/groundwater recirculation well (German: Unterdruck-Verdampfer-Brunnen/Grundwasser-Zirkulations-Brunnen, or $\mathrm{UVB} / \mathrm{GZB})$ and (2) the porous pipe/horizontal well (PP/HW).

This document was prepared to summarize the methods and results of the assessment activities completed during the initial year of the project. All project activities were completed except the development of a finite element model for predicting three-dimensional flow and pollutant transport within a groundwater system as affected by a recirculation system. Completion of the modeling of representative DOE conditions is scheduled for later this year. In this document, findings are provided that incorporate as much information as possible. Recommendations for laboratory and field experiments are included. However, it should be emphasized that the project is still ongoing and not all facets of the effort are complete as of this writing. 


\section{ACKNOWLEDGMENTS}

Since the inception of this project in late fall 1991, scientists and engineers from Oak Ridge National Laboratory (ORNL), from collaborating universities, and from private industries have contributed to it. The International Technology Exchange Program within the U. S. Department of Energy (DOE) in Washington, D.C., provided project sponsorship and oversight. The following organizations and individuals have contributed to the effort:

Oak Ridge National Laboratory

R. L. Siegrist

O. F. Webb

M. R. Ally

W. E. Sanford

T. L. Donaldson

P. M. Kearl

Tommy J. Phelps

J. L. Zutman

Westinghouse Savannah River Company

B. B. Looney

\section{Universities}

J. C. Parker

B. Herrling

H. Hoetzl, M. Nahold

G. Gudehus, N-Ch. Lund, J. Swinianski

\section{Private Industries}

M. R. Sick, E. J. Alesi

Martin Marietta Energy Systems, Inc.

T. L. Mayfield

\section{U. S. Department of Energy}

D. Gieser

J. O. Moore
Environmental Sciences Division

Environmental Sciences Division

Chemical Technology Division

Environmental Sciences Division

Chemical Technology Division

Environmental Sciences Division

Environmental Sciences Division

Oak Ridge Associated Universities
Savannah River Site

- Virginia Polytechnic Institute State University and Environmental Systems \&

Technologies, Inc.

University of Karlsruhe

University of Karlsruhe

University of Karlsruhe

IEG Technologies Corporation

Technology Transfer, Martin Marietta Energy Systems, Inc.

DOE Headquarters, Washington, D.C.

DOE Field Office, Oak Ridge 


\section{EXECUTIVE SUMMARY}

Considerable research and development in environmental restoration and waste management (EM) have occurred in several foreign countries, most notably the former West Germany. Confronted with contaminated land from the world wars and postwar industrialization period, German researchers and practicing professionals have worked to develop and test processes and technologies for effective environmental restoration. Recognizing the potential gain from research and demonstration activities in foreign countries, an International Technology Exchange Program (ITEP) was initiated within the U. S. Department of Energy (DOE) Office of Technology Development. The ITEP project described herein was conducted by Oak Ridge National Laboratory (ORNL) to identify processes and technologies developed in Germany that appeared to have near-term potential for enhancing the clean-up of volatile organic compound (VOC) contaminated soil and groundwater at DOE sites.

The objectives of the project were to (1) identify German technologies potentially appropriate for demonstration of in situ recirculation and treatment of groundwater at DOE sites, (2) assess their current performance and identify modifications for use at specific sites, and (3) provide ad hoc technical support to DOE sites for planning and implementing field demonstration and testing activities. In accordance with the intent of the ITEP program, and with guidance from DOE, the project was limited in scope to identification and preliminary evaluation of technologies that appeared to have near-term application to DOE environmental restoration projects. Within ITEP it was envisioned that promising technologies would be transferred to an integrated program (IP) or integrated demonstration (ID) for further research and development or demonstration, testing, and evaluation, respectively. Thus this project involved a literature review, personal inquiries, site visits, and a conceptual analysis. Members of the ORNL research team identified and evaluated selected German technologies developed at or in association with the University of Karlsruhe (UoK) for in situ treatment of VOC contaminated soils and groundwater. Subsequent analyses consisted of engineering computations, groundwater flow modeling, and treatment process modeling. As a result of these project efforts, two processes were identified as having near-term porential for DOE: (1) the vacuum vaporizer well/groundwater recirculation well (German: Unterdruck-Verdampfer-Brunnen/Grundwasser-Zirkulations-Brunnen, or UVB/GZB) and (2) the porous pipe/horizontal well (PP/HW).

The UVB/GZB technology induces a spherical recirculation flow field about a large diameter dual-screened well. In the UVB system, this is accomplished by imposing a negative pressure on the well head and inducing an air lift pump effect. Contaminated groundwater typically enters the well through a lower screened interval, rises vertically within the well, and then is reintroduced into the aquifer through a higher screened interval. In the GZB system, a pump is used to enhance the recirculation flow rate. The groundwater remains below ground and VOCs are air stripped from it and treated aboveground. The UVB/GZB technology enables simultaneous treatment of aquifers and unsaturated zones. Because of the flow fields created, the methoi may also be applicable to recovery of dense nonaqueous phase liquids (DNAPLs). UoK researchers have demonstrated the UVB/GZB technology in shallow aquifers with moderately high saturated thicknesses and hydraulic conductivities. The technology has also been implemented full-scale at several sites with reported success. However, demonstration has not occurred at sites with a wide range of conditions (e.g., at sites with deep aquifers, thin aquifers, highly or poorly conductive aquifers, or aquifers with significant heterogeneities) nor with treatment processes other than air stripping and carbon adsorption.

The use of shallow directional drilling and porous piping ( $\mathrm{PP} / \mathrm{HW}$ ) has been developed in Germany for vapor extraction of VOCs from unsaturated soils. Use of this technology for in situ recirculaticn of groundwater zones offers potential for treatment of VOCs in sites with thin 
aquifers or those with heterogeneities. However, there has been limited testing of this PP/HW technology. Evaluation of the utility and effectiveness of these processes for solving DOE problems requires continued investigation.

Standard engineering analysis shows that significant improvements can be made in the stripping efficiency of the UVB/GZB by changing the contact pattern between liquid and gas phases in the stripping section. Using typical liquid and gas phase flow rates supplied by Dr. B. Herrling of the University of Karlsruhe, the stripper design will at best under ideal conditions reduce plume concentrations by an order of magnitude per each pass through the stripper. Trial estimates indicate that an approximate two orders of magnitude decrease in plume concentration is possible by changing the stripper design. The stripper efficiency is very important because subsurface recirculation will occur at low flow rates resulting in very long treatment times and high energy costs.

Pourbaix plots indicate that changes in Eh and $\mathrm{pH}$ may significantly increase precipitate formation that will result in premature fouling of equipment and the well-aquifer interface. Recycling of the stripping gas (with a purge stream) might be effective in reducing detrimental precipitates caused by recirculation processes.

Ongoing activities include development of a finite difference model for predicting multiphase flow and pollutant transport in thre: dimensions surrounding in situ recirculation systems. The model will be used to assess technology application at representative DOE sites and to facilitate design of laboratory testing and field demonstration activities. Pertinent issues that might be addressed by laboratory and field tests for both the UVB/GZB and PP/HW systems include: (1) verification of recirculation zone geometries and sensitivities to aquifer properties, (2) fouling of well materials and aquifer sediments by precipitates, (3) evaluation of VOC stripping efficiencies, (4) evaluation of alternative in situ treatment processes, and (5) direct comparison of operation and performance features with conventional pump and treat systems. 


\subsection{INTRODUCTION}

\subsection{BACKGROUND}

Considerable research and development in environmental restoration and waste management (EM) has occurred in several foreign countries, most notably the former West Germany. Confronted with contaminated land from the world wars and the postwar industrialization period, German researchers and practicing professionals have worked to develop and test processes and technologies for effective environmental restoration. The International Technology Exchange Program (ITEP) was established within the Department of Energy (DOE) Office of $\Gamma$ echnology Development (OTD) in an attempt to identify and facilitate infusion of foreign techrology into the Uniied States to help solve the pressing environmental problems within the DOE. Similarly, the ITEP sought export opportunities for U. S. technology to solve environmental problems in Europe and Asia as well as to help U. S. competitiveness.

The DOE ITEP initiated a project that included collaborative exchange with researchers and private industry in the Karisruhe, Germany, area. This area of Europe was selected because it appeared to have a concentration of processes and technologies with potential for application at DOE sites. These processes and technologies were focused on in situ remediation of soil and groundwater contaminated by volatile organic compounds (VOCs), a pressing need within DOE. In situ remediation of subsurface VOC contamination has been a desirable goal within DOE, but continues to present formidable challenges. New, reliable methods are needed to increase cleanup efficiency and reduce associated treatment time and costs of subsurface contamination. Factors that complicate effective in situ treatment include the heterogeneous sature of the subsurface and the contaminants distributed therein. The potential benefits of an international collaboration included (1) improvement of EM programs by importing foreign technical information, (2) improvement of U. S. technology by importing foreign technical information, (3) introduction of foreign cooperative technology in EM-30 or EM-40, and (4) introduction of foreign cooperative technology into an integrated demonstration (Bonano, 1991).

\subsection{OBJECTIVES AND SCOPE}

The overall goal of this project was to identify processes and technologies in Germany that appeared to have near-term potential for enhancing the cleanup of VOC contaminated soil and groundwater at DOE sites. Achieving this goal would also facilitate technology exchange between Germany (i.e., researchers and private industry) and DOE for in situ remediation of VOCs. Target VOCs included chlorinated aliphatic compounds, aromatic compounds, and hydrocarbon compounds. These compounds are posing major challenges at DOE sites including Hanford, Savannah River, and Portsmouth. Specific objectives of the project were to (1) identify German technologies for in situ recirculation and treatment of VOC contaminated soil and groundwater potentially appropriate for demonstration at DOE sites, (2) assess their current performance and identify modifications for use at specific sites, and (3) provide ad hoc technical support to DOE sites for planning and implementation of field demonstration and testing activities. Within the DOE ITEP it was envisioned that promising technologies would be transferred to an integrated program (IP) or demonstration (ID) for further research and development or demonstration, testing, and evaluation, respectively. Thus this project involved a literature review, personal inquiries, site visits, and a conceptual analysis. 


\subsection{PROJECT ORGANIZATION}

Several organizations were involved in this project (Fig. 1.1). DOE provided project guidance and funding while researchers from Oak Ridge National Laboratory (ORNL) conducted and coordinated investigative activities. Experts from Virginia Polytechnic Institute and State University (VPI) developed numerical algorithms for modeling subsurface processes. Experts from the University of Tennessee (UT) provided review and guidance on subsurface processes.

The University of Karlsruhe (UoK), Germany, provided opportunities for collaboration as they conduct significant research on in situ treatment processes and have dedicated facilities. In situ treatments increase treatment efficiency, reduce regulatory requirements, and reduce generation of secondary waste streams. Three institutes within the UoK conducted research on subsurface recirculation with in situ treatment-the Institute of Hydromechanics, the Department of Applied Geology, ard the Soil Mechanics and Foundation Engineering Department. UoK facilities included a well-equipped large-scale test facility for conducting remediation, bioremediation, and advanced oxidation field-scale experiments. Facilities were also available for testing and evaluating VOC measurement and sensor technologies and treatment by means of horizontal wells. The UoK also had ties to German industry that could potentially benefit DOE. 


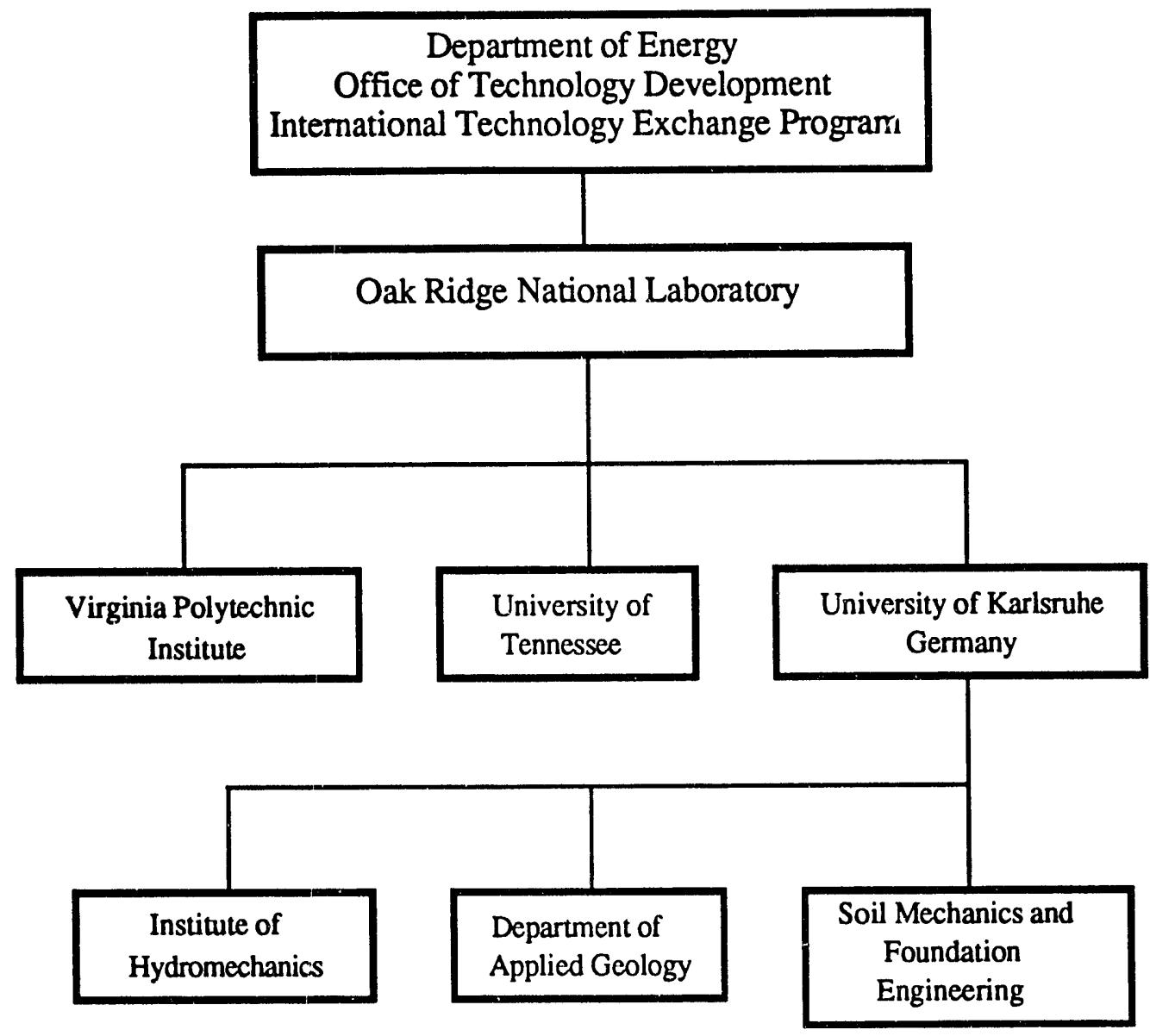

Fig. 1.1. Project organization. (ORNL Drawing 93-10191) 


\subsection{TECHNOLOGY IDENTIFICATION AND REVIEW}

\subsection{INTRODUCTION}

Researchers identified and evaluated selected German technologies for in situ treatment of VOC contaminated soils and groundwater. In accordance with the intent of the ITEP program, and with guidance from DOE, the project approach was to (1) identify potential collaborators; (2) investigate processes to determine potential strengths, weaknesses, and benefits; and (3) inform interested agencies as to the results.

\subsection{METHODS}

The technology identification and review process consisted principally of telephone and written communications with researchers in the United States. and Germany during fall 1991 and subsequent site visits to UoK and private industry collaborators during February 1992. For the site visit to the UoK and private industry, the travelers from the United States included Dr. R. L. Siegrist of ORNL, Dr. T. J. Phelps of UT, Dr. J. C. Parker of VPI, and Dr. B. B. Looney of the Savannah River Site (SRS). This team was selected based on their areas of expertise and their representation of sites where laboratory and field testing could readily occur. The agenda included technical presentations and discussions at the University of Karlsruhe, field test site and laboratory tours at the UoK, and visits to several private industry vendors and their field sites. The individuals contacted included representatives from three potential collaborating Institutes at the UoK (Institute of Soil Mechanics and Foundation Engineering, Institute of Applied Geology, and Institute of Hydromechanics) and five private industries (KSK Microtunneling, FlowTex Directional Drilling, Schumacher Environmental, IEG Technologies, and GfS Site Remediation). The discussions held and review of the literature and information gained during this visit were to be used in identifying and evaluating selected German technologies for inclusion in the DOE ITEP project on in situ destruction of VOCs (Siegrist 1992).

\subsection{RESULTS}

\subsubsection{In Situ Treatment of Organics in Subsurface Recirculation}

\subsubsection{Observations}

Subsurface recirculation (SR) research is ongoing at the UoK Institute of Soil Mechanics and Foundation Engineering (ISMFE). ISMFE facilities included a field test site for testing of the SR technology and companion laboratory facilities for treatability testing with large soil cores.

The purpose of the research was development and demonstration of cost effective methods for treating contaminated soil located at gas works sites. Two projects were ongoing: (1) biological treatment that uses air infiltration for oxygen delivery and water re-infiltration for nutrient delivery and (2) removal of large soil cores by ground-freezing techniques followed by treatment in the laboratory (Lund et al., 1991; Swinianski et al., 1991).

The field test site was designed and implemented by N.-Ch. Lund (1991) of ISMFE and some private industry partners at an old gas works site in Karlsruhe (Fig. 2.1 through 2.3). The field test facility was established in a contaminated area of the gas works site. The contaminated soil consists of sand and gravel. A grout curtain extending from ground surface to underlying bedrock isolated a portion of the contaminated site and enabled control of the site groundwater 


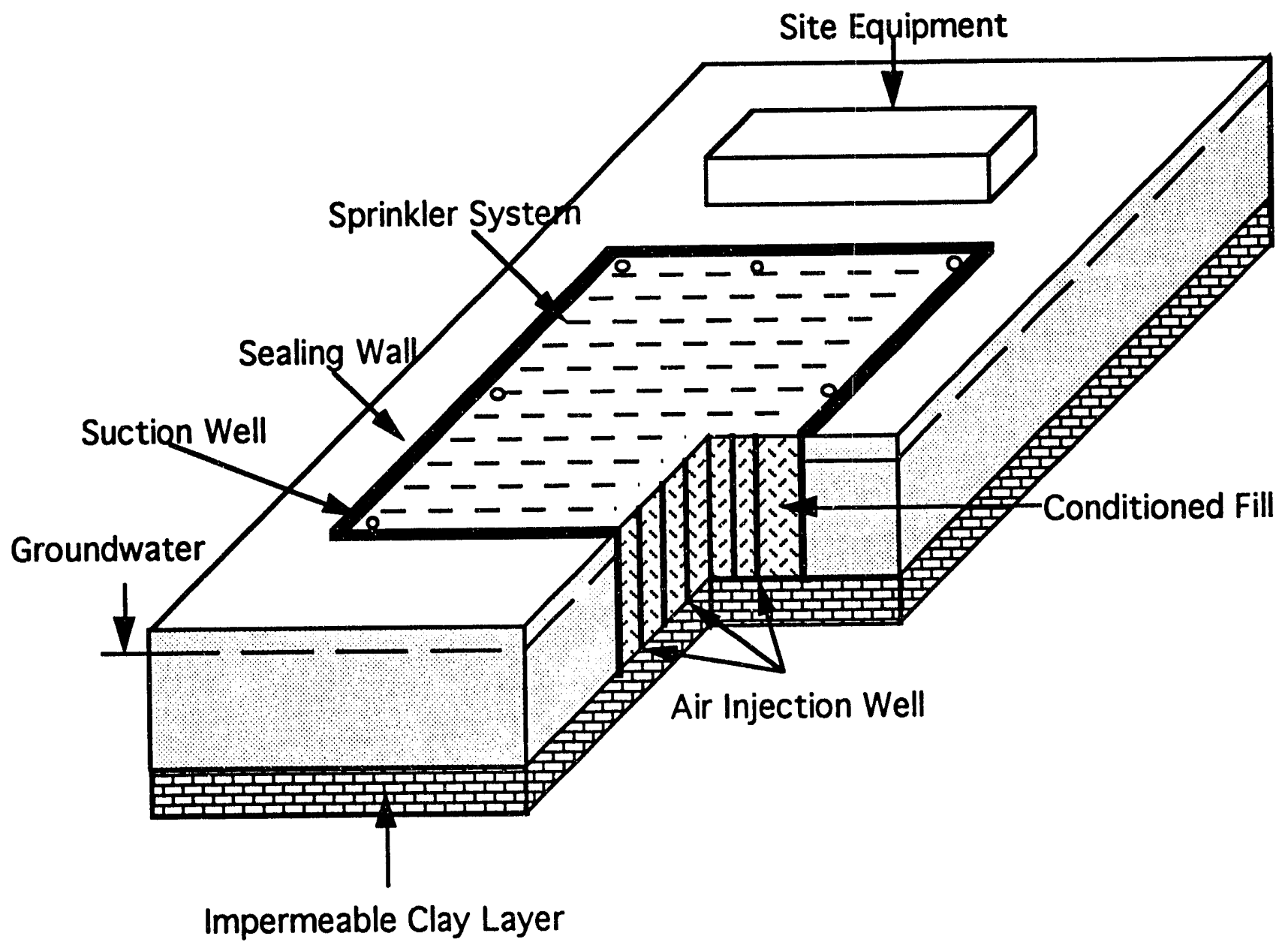

Fig. 2.1 Schematic of the UoK ISMFE subsurface recirculation test site (Adapted from Lund et al. 1991; ORNL Drawing 93-10192). 


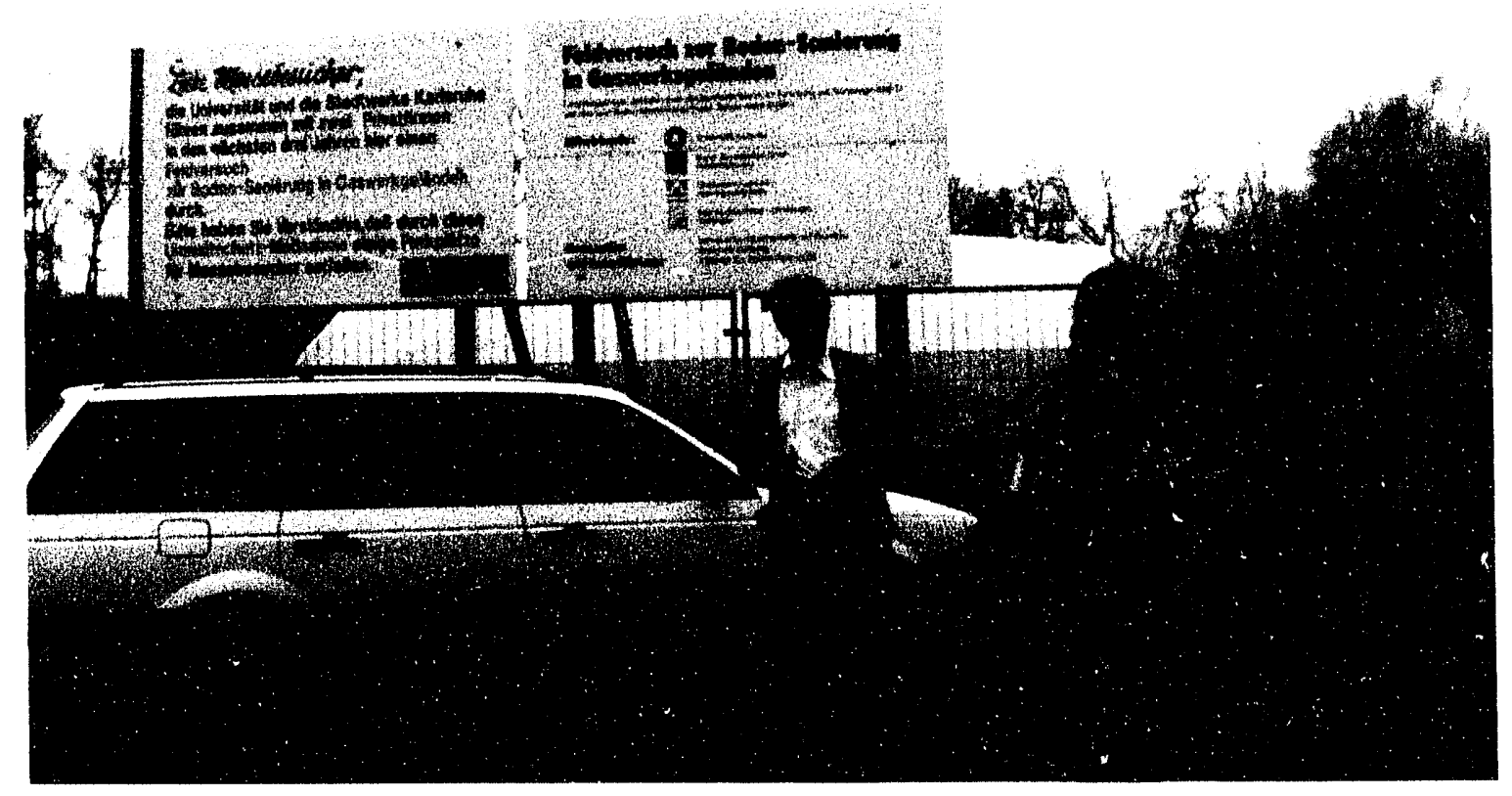

Fig. 2.2. UoK ISMFE subsurface recirculation test site (ORNL site visit during February 1992; ORNL Photo 2878-92). 


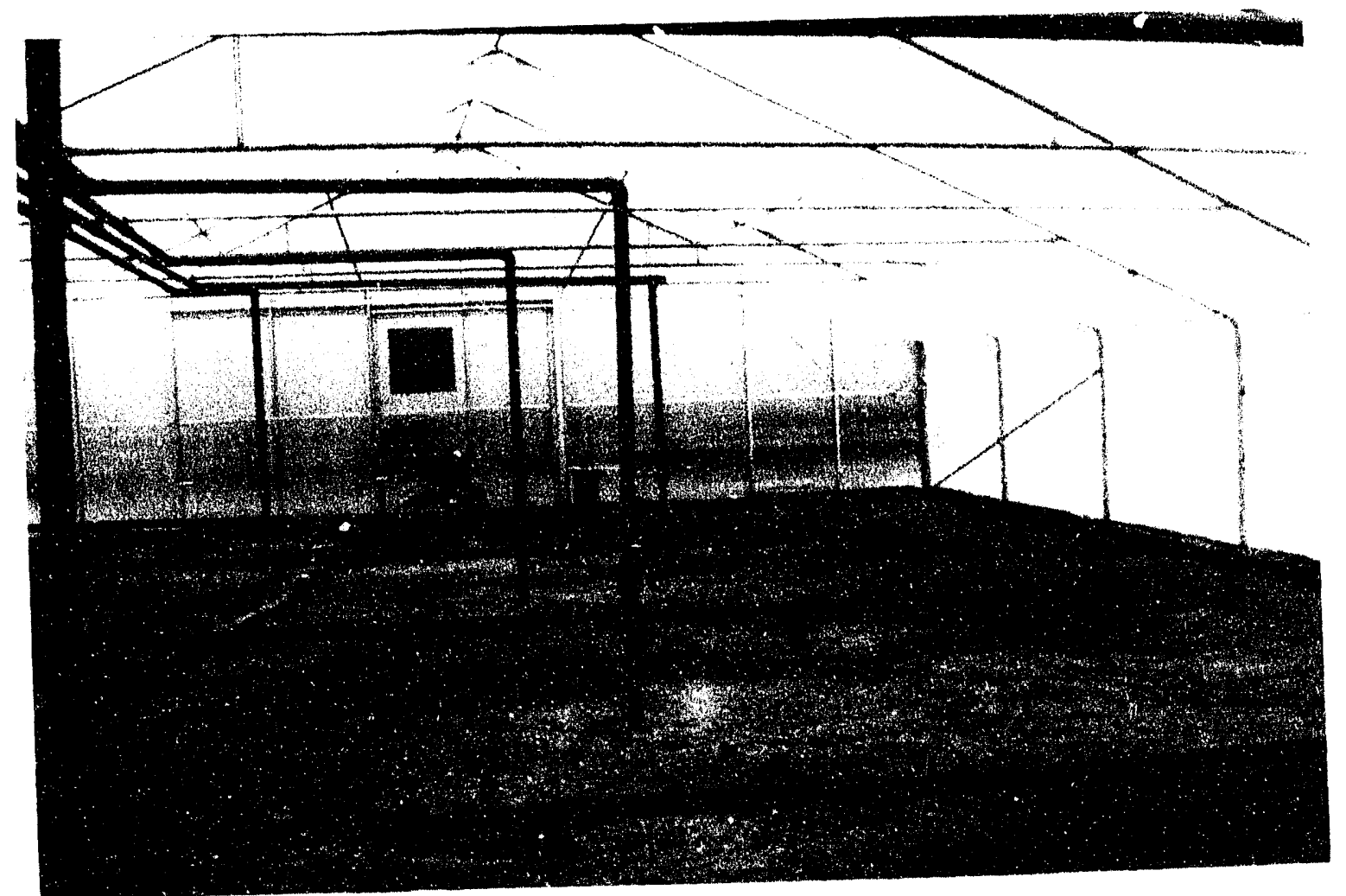

Fig. 2.3. UoK ISMFE infiltration test area (ORNL site visit during February 1992; ORNL Photo 2879-92). 
level. The grout curtain also enabled capture of percolating water resulting from the water infiltration and nutrient delivery (i.e., nitrogen and phosphorus). Oxygen is delivered by a series of air injection pipes, which penetrate the contaminated soil in the test facility. As part of the facility, a real-time monitoring system was developed to continuously record system flows, temperatures, and oxygen and carbon dioxide concentrations. These gas measurements were used to estimate respiratory quotients and the biodegradation rates. To date, respiratory quotients of 0.66 have been measured, compared with 0.60 to 0.85 expected. The oxygen consumption rates for coal gas organics are anticipated to be 1.5 to $3.5 \mathrm{~kg} \mathrm{O} 2$ per $\mathrm{kg}$ of hydrocarbon. Consumption rates for the test site were initially $4 \mathrm{~kg} / \mathrm{d}$ but increased to $20 \mathrm{~kg} / \mathrm{d}$ after 1 year of operation. The biodegradation rates were more difficult to calculate because quantifying the pretreatment and posttreatment concentrations of organics was difficult. Approximately 20 to $50 \%$ of the organics were degraded. Wuerdemann estimated that the 16 polycyclic aromatic hydrocarbons (PAHs) included on the U. S. Environmental Protection Agency (EPA) priority pollutant list comprised only 10 to $20 \%$ of the total mass of organics present. This stimulated discussion regarding methods to measure and assess soil contaminated by complex mixtures of organics. Periodically, water containing nutrients (warmed by solar energy) has been infiltrated to temporarily submerge the contaminated soil within the test facility in an effort to disperse nutrients throughout the region and enhance bioactivity. This has proved effective in enhancing biodegradation rates. Also, it has been observed that the aqueous concentrations of organics following this treatment have been declining, suggesting that biodegradation is reducing the concentration of mobile organics. The temperature in the test facility rose to $25^{\circ} \mathrm{C}$ compared with 12 to $14{ }^{\circ} \mathrm{C}$ in the natural material. Heat balance calculations are planned to determine whether the temperature increase is the result of bioactivity.

Companion laboratory facilities at ISMFE include large undisturbed soil cores $(60 \mathrm{~cm}$ diameter by $1 \mathrm{~m}$ length) collected from the gas works site by using ground freezing techniques. This was been accomplished by driving a hollow delivery tube to the depth desired and then running liquid nitrogen through the tube for $24 \mathrm{~h}$. The soil core is then removed from the site and transported to the laboratory, where it is placed into a flexible membrane reactor. After thawing, the core receives nutrients and oxygen. The reactor system is equipped with leachate and off-gas collection lines and instruments for real-time monitoring of gas temperature, pressure, and offgas concentrations. Several series of experiments have been conducted with the laboratory cores over periods of about 5 to 6 months. Starting with an initial total organic concentration of about $5 \%$ by weight, about 15 to $20 \%$ of the organics are washed out during initial treatment, followed by a biodegradation of an estimated 20 to $50 \%$ over the next 5 to 6 months. Even though the extent of biodegradation appeared to be low, the biodegradation rates have been about $2 \mathrm{mg} \mathrm{kg}^{-1}$ day $^{-1}$, which is quite high for PAH compounds. Attempts to use ozone injection to further enhance biodegradation rates have been ineffective. It was noted that these attempts have not been rigorous or comprehensive, and further studies might be appropriate.

\subsubsection{Discussion}

The ISMFE in situ restoration approaches and test facilities were well-conceived and executed. The laboratory- and field-scale test facilities of ISMFE mad it possible to do controlled experiments of in situ bioremediation. The SR technique under investigation at the field test site has application to in situ treatment of VOCs, but it is perhaps more appropriate for relatively immobile organic contaminants such as PAHs. The SR technique requires shallow sites underlain with an impermeable zone. For example, the ISMFE field test site was established at an abandoned coal-gasification site. This was a relatively concentrated source of contamination with a shallow groundwater table and underlain by a clay layer. This site might be considered ideal for use of this technique. SR equipment includes vertical wells for injection and removal of soil air, a groundwater recirculation system, and sealing walls for isolating the contaminated site (Lund et al., 1991). The SR produces a horizontal movement of air and a vertical percolation of 
water through the soil and encourages biological degradation of contaminants. Subsurface organisms receive nutrients as the water table moves vertically. The fresh air supplies bacteria with oxygen and strips VOC. Treatment of VOC in the gaseous SR waste stream occurs aboveground.

In conclusion, this technique may demonstrate only limited applicability for DOE problems because of more complex hydrology and deeper contamination. The technique is appropriate for contaminants strongly adsorbed to soil.

\subsubsection{In Situ Treatment of Organics in Vertical Well Recirculation}

\subsubsection{Observations}

Within the Institute for Hydromechanics (IOH), Dr. B. Herrling et al. have studied groundwater circulation wells developed by IEG $\mathrm{mbH}$ of Reutlingen, Germany. These specially designed groundwater wells use an airlift effect (vacuum vaporizer well or Unterdruck-VerdampferBrunnen. UVB) or electric pump (Grundwasser Zirkulations Brunnen GZB) to pull water through a screened interval at the bottom of a $15-$ to $40-\mathrm{cm}$ diameter well casing and move it upwards and back into the aquifer via a screened interval at the top of the well casing (Figs. 2.4 and 2.5). The system has application for inducing recirculation in relatively homogenous aquifers. Treatment techniques included air stripping, adsorption, and bioremediation processes. Apart from the groundwater recirculation and in situ VOC treatment potential, the tech ology also has potential for inducing strong vertical and horizontal gradients and may aid in remo al of nonaqueous phase liquids (NAPLs).

Research of this technology was initiated about 2 years ago with support of the German developer, IEG Technologies. Dr. Herrling's research has focused on numerical modeling of the capture and release zone of the UVB/GZB systems used for stripping VOCs from contaminated groundwater. The "typical" capture/release zone is estimated to be about five times the thickness of the aquifer when the horizontal to vertical conductivity is 10:1. Numerical simulations indicate that when the horizontal to vertical conductivity approaches 100 , application of this technology may no longer be feasible. Dr. Herrling is involved in modeling for design and evaluation of the UVB/GZB systems at numerous sites in Germany and has proposals pending for further joint research with the developer, IEG Technologies, and a prominent consulting firm, GfS. GfS is reported to have the most field experience with UVB/GZB application in Germany.

During the visit to Karlsruhe in February 1992, a site visit was made to several locations where the UVB/GZB technology had been implemented. At Karlsruhe Kneilingen there was a research site for study of the in situ groundwater treatment using IEG Technologies UVB/GZB recirculation wells (Fig. 2.6). At the site, we met Dr. W. Buermann, a colleague of Dr. Herrling who was directing the field research while B. Herrling conducted the numerical modeling. We also met Dr. Alesi, President, and Dr. Sick, Project Manager, of GfS mbH. This test site was characterized by a 1 to $2 \mathrm{~m}$ silt cap overlying a sand aquifer. VOCs (chlorinated aliphatics) were present at concentrations of 100 to $1000 \mathrm{mg} / \mathrm{L}$. Two UVB/GZB recirculation systems, one subsequent to the first, were installed at the site in an attempt to reduce the groundwater VOC concentrations to $25 \mathrm{mg} / \mathrm{L}$ or less. The UVB/GZB systems are installed in $150 \mathrm{~mm}$ boreholes. The existing groundwater dissolved oxygen was near zero. The airflow introduced via the airlift effect is approximately 10 to 20 times the water flow. The system has been operating for approximately 3 months, and various monitoring points are installed in the aquifer to measure temperature, pressure, flow direction, and VOC concentrations. An on-site laboratory facilitated data collection and analyses. 


\section{Fresh Air}

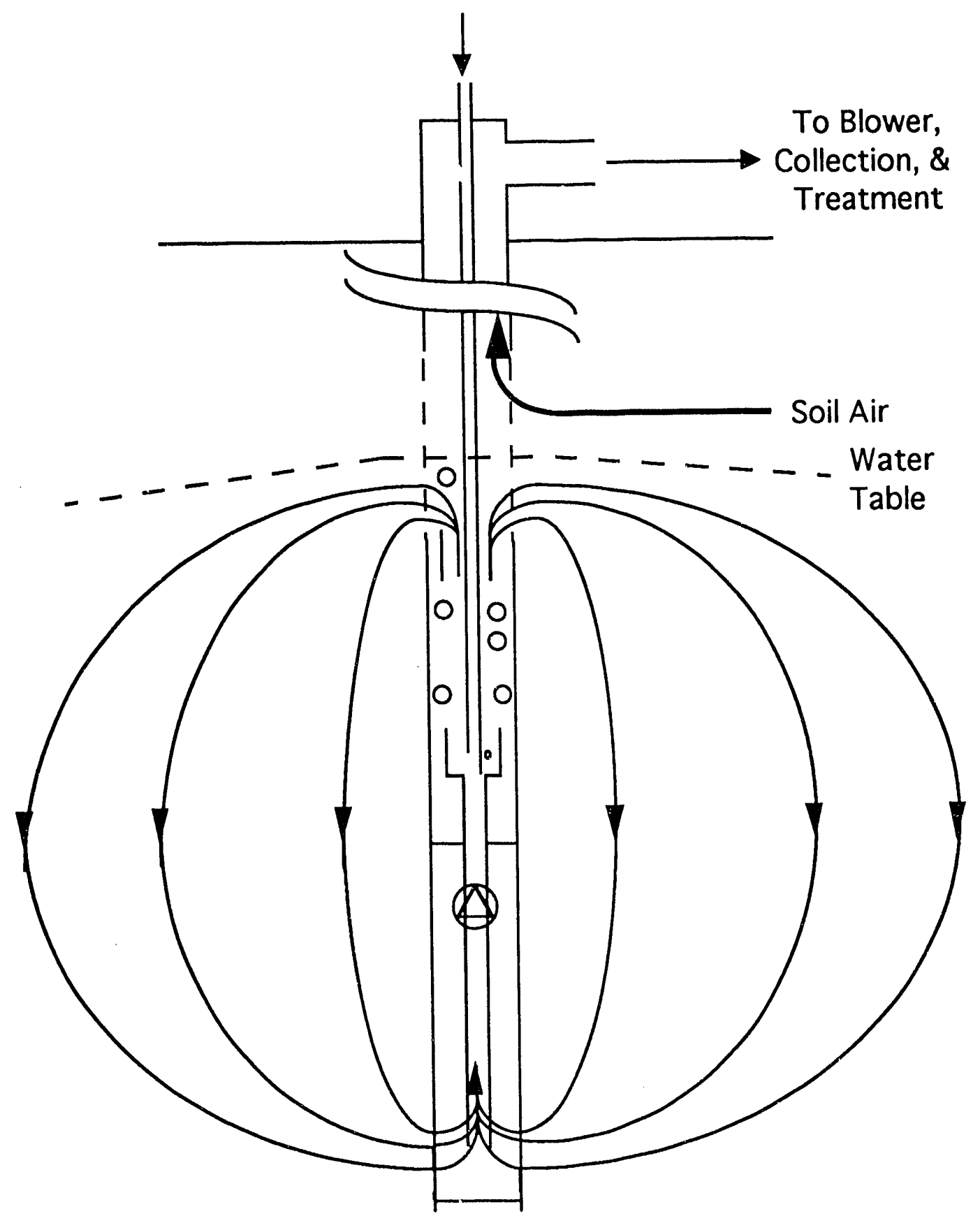

Fig. 2.4. Schematic of the UVB/GZB vertical well recirculation process. (ORNL Drawing 9310193) 


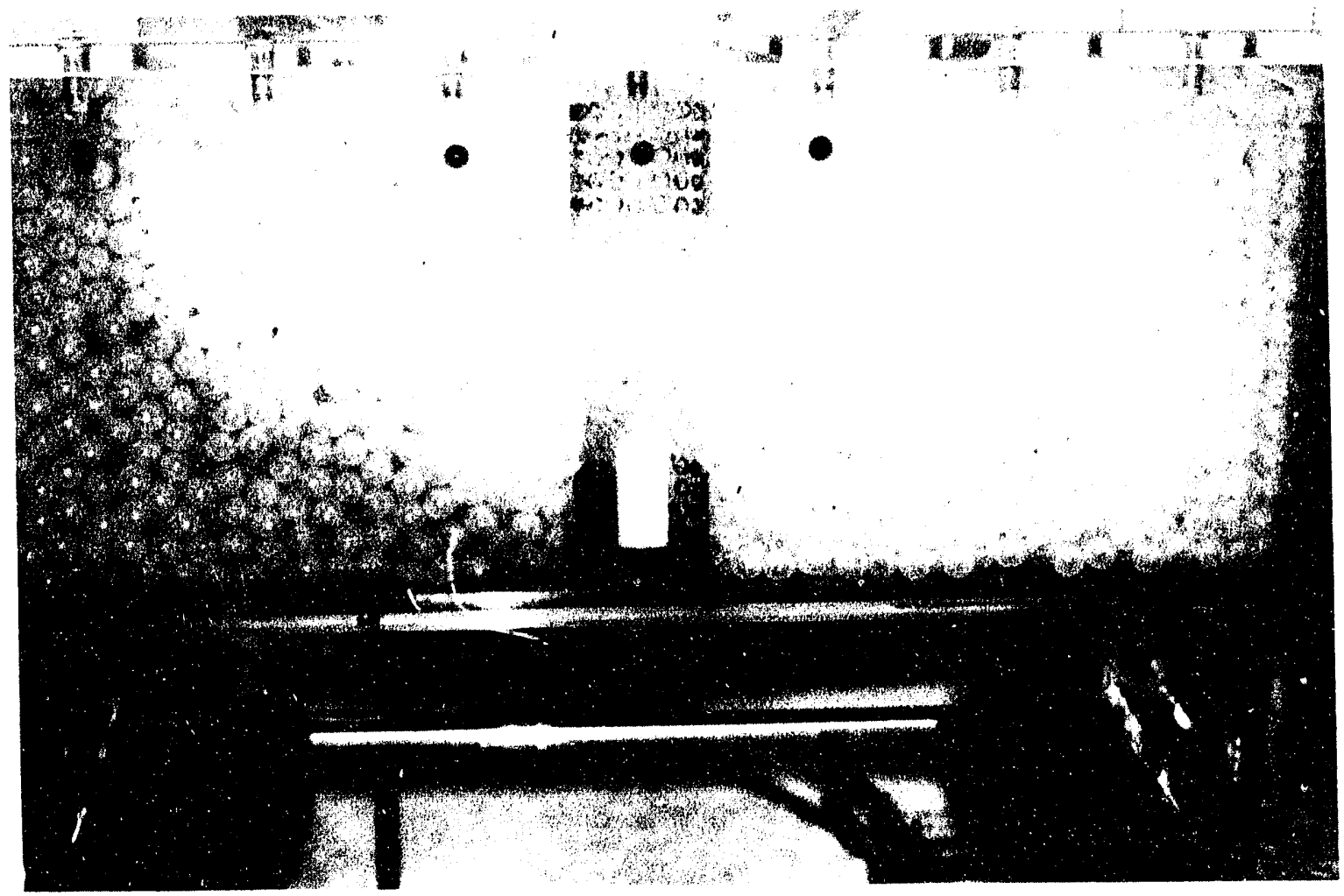

Fig. 2.5. UVB/GZB pilot-scale unit (ORNL site visit during February 1992; ORNL Photo 287492). 


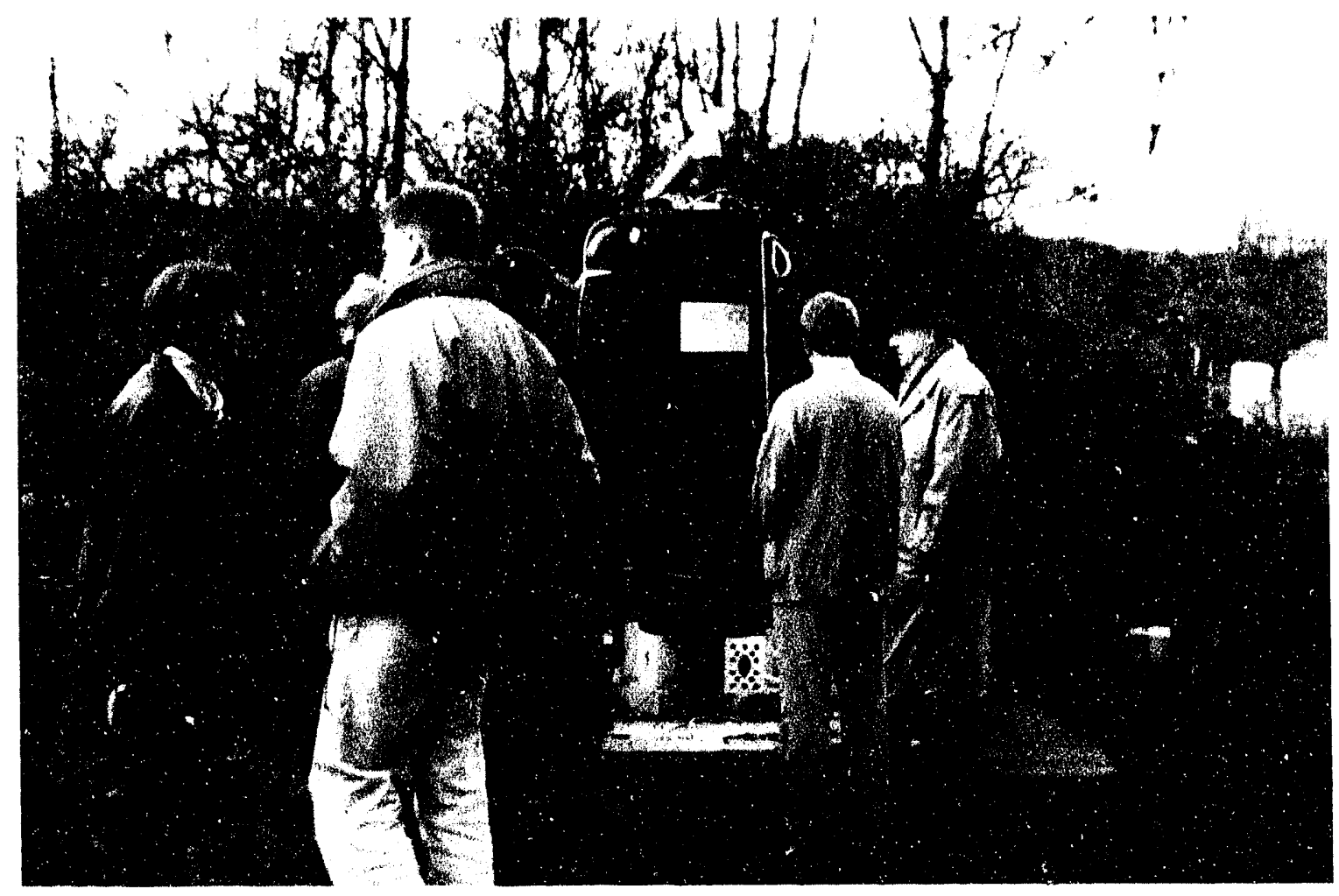

Fig. 2.6. Karlsruhe Kneilingen UVB/GZB test site (ORNL site visit during February 1992; ORNL Photo 2875-92). 
After the field site tour, further discussions were held at the UoK IOH with B. Herrling, J. Stamm, Alesi, and Sick. Dr. Sick provided a detailed presentation regarding the development and application of the IEG recirculation well system and various configurations employing different in situ and ex situ treatment techniques. This was reported to reduce off-gas treatment costs. Dr. Sick described several installations of recirculation wells for groundwater and soil air treatment to remove VOCs and pesticides.

Treatment techniques included air stripping, adsorption, and bioremediation processes. Process performance was reported to be quite good, in some cases far better than that of previously installed pump and treat systeris. The cost of a UVB/GZB system installation (one well and a stripper) was reported to range from $\$ 35,000$ to $\$ 90,000$.

Dr. Sick also described another IEC. development, a double-cased screen material. This product was being utilized for soil air recirculation (SAR) and venting. Between the double screens (60\% open area), there was a hydrophobic material that precluded the passage of water through the screen. This was reported to minimize off-gas water content and enable high soil air movement at very low vacuum (e.g., 50 mbar). The screened sections are about $1 \mathrm{~m}$ long and come in ditferent diameters, each section costing about \$2,500. Dr. Sick reported that there are about 20 SAR systems in operation in Germany, 1 year being the longest period of operation. The SAR system can be combined with the UVB/GZB system to achieve soil air and groundwater treaiment.

Site visits were alco made to two private industry locations where GfS was responsible for fullscale remediation of soil and groundwater contamination by VOCs. The first was in a relatively small site in Denkendorf, where a UVB/GZB system was installed to remove VOCs from groundwater. The second was in Ebersbach, where an SAR system was installed beneath an asphalt parking lor to remove VOCs (mostly trichloroethylene) from soil surrounding an abandoned site for disposal of rludge from carpet processing.

After visiting the field sites, meetings were held in the offices and laboratory of GfS in Kirchheim, Germany. A full-scale working model of a UVB/GZB system was inspected as well as a section of the dosble-cased screen (Fig. 27). Following the viewing, discussions with Alesi, Sick and Herrling continued regarding the operation and performance of the recirculation systems, including the different types of down-hole treatment techniques that have been developed and tested, the limitations of the system application (e.g., thickness, heterogeneity), nature and extent of any in situ tioremediation that might be occurring in the aquifer affected $b y$ the recirculation systems, and so forth. It :ipeared that there had been considerable development and iesting of these products and that performance was gerierally good. However, it also appeared that the major thrust to date had been on the hydrodynamics of the recirculation system in which the primary VOC removal process was in-well air stripping. The Germans were claiming some degree of bindegradation based on carbon dioxide evolution. 


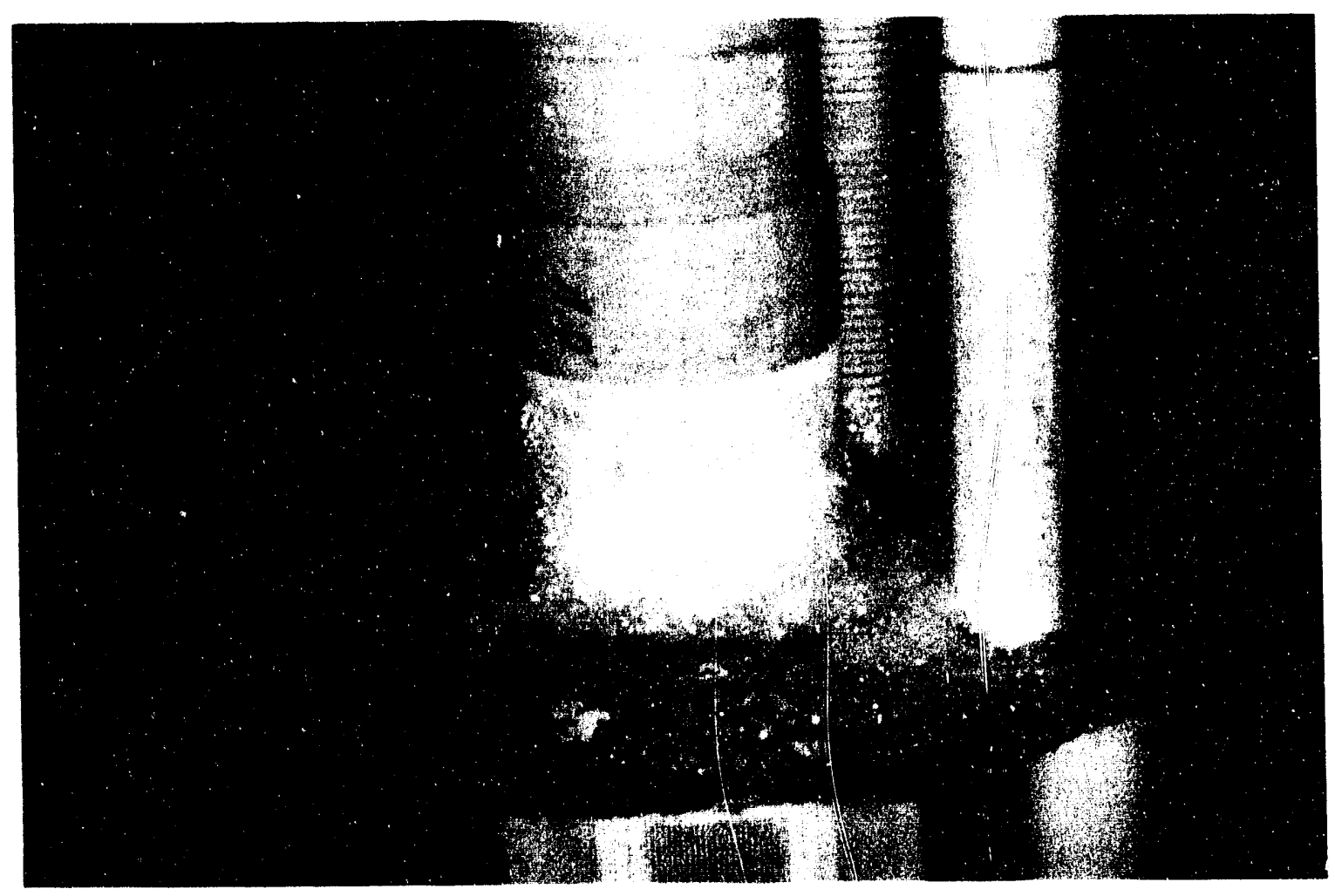

Fig. 2.7. Full-scale UVB/GZB unit at GfS in Kirchheim, Germany. (ORNL site visit during February 1992; ORNL Photo 2871-92) 


\subsubsection{Discussion}

The UVB/GZB method appears most applicable to in situ treatment of VOCs present in the subsurface (Herrling et al., 1991). Concurrent treatment of aquifers and unsaturated zones to 60 $\mathrm{ft}$ is claimed possible (Herrling et al., 1991). The method may also be applicable to recovery/treatment of dense non-aqueous phase liquids (DNAPLs). UoK researchers have not rigorously tested the UVB/GZB method in aquifers with significant heicrogeneities, but have had some success in the tests that they have done. For example, the UVB/GZB reduced VOC levels to regulatory limits at a German site during an 1.5 year operating period. Subsurface characteristics limit the global utility of the UVB/GZB process and may dictate pumping rates and well spacing (Beurmann, 1990; Herrling et al., 1990; Herrling et al., 1991). In conclusion, the UVB/GZB is applicable to DOE problems. Evaluation of the utility and effectiveness of the process for solving DOE problems requires continued investigation.

\subsubsection{In Situ Treatment of VOCs in Horizontal Wells}

\subsubsection{Observations}

In situ treatment technologies were being developed and tested by researchers in the UoK Institute of Applied Geology (IAG) in collaboration with several private industries. Dr. H. Hoetzl of IAG provided an overview of their work on infiltration/transport of organics, fracture flow characterization and modeling, geophysical techniques for site characterization, waste deposit caps and barriers, and groundwater treatment techniques for VOCs. Dipl. M. Nahold provided a description of a test site south of Karlsruhe where he was evaluating air injection/extraction techniques for removal of trichloroethylene from NAPLs in fractures beneath an old government run animal hide processing plant. Dipl. I. Sass described a proposed project to study extraction of VOCs from soil and groundwater by using horizontal drilling techniques and porous piping systems. This is a very exciting 3-year, $\$ 4.5$ million dollar effort which will include laboratory and field testing at one or more sites in Germany. This is a joint project between the IAG and several private industries (KSK, FlowTex, and Schumacher et al.) with sponsorship by private industry and the German research agency.

Following the morning presentations, Dr. H. J. Byer of FlowTex, met us at the UoK and escorted us along with M. Nahold and I. Sass, to KSK Microtunneling Technologies in Rastatt, where we met with Erhard Kracht, Director of Sales and Marketing for KSK. Discussions focused on directional drilling in Germany and environmental applications for site remediation. KSK and FlowTex were joint participants in the UoK IAG project described earlier by I. Sass. KSK manufactures guided microtunneling technologies while FlowTex designs and carries out the actual installations in Germany. With the KSK equipment, water-driven jets in a steel head cut a pilot hole of $52 \mathrm{~mm}$ to lengths of about $50 \mathrm{~m}$. Then a backream is pulled through up for diameters up to $160 \mathrm{~mm}$. Applications can occur in fine soils, whereas rocks and gravel can be a problem. Typical production rates are 80 to $120 \mathrm{~m} / \mathrm{d}$. The cost of the shallow horizontal drilling is about $\$ 100$ per meter for installations less that $10 \mathrm{~m}$ deep. Environmental applications by KSK/FlowTex began about 2 years ago with a system installed at the Frankfort airport to vapor extract aviation fuels. A series of center wells were installed with 8 to 10 horizontal wells radiating out 40 to $60 \mathrm{~m}$ from the center well. The KSK technology was uncomplicated and attractive because it was up-scaled from the utility industry, rather than down-scaled from the oil exploration industry. There were companies in the United States manufacturing similar equipment. 
On Thursday morning, February 13, a KSK/FlowTex horizontal drilling installation (Figs 2.8 and 2.9) was observed at Graben Village, south of Karlsruhe. At this site, FlowTex was installing a $10 \mathrm{~cm}$ diameter gas line. The operation was quite simple and uncomplicated and was being carried out with minimal disruption in a densely populated residential area. Potential applications to in situ treatment of VOCs at DOE sites were obvious.

From Graben Village, we proceeded to the test site at Schwabehall, where M. Nahold was studying the removal of VOCs in fractured media by air injection/air extraction. The system was in operation with the off-gas VOCs being treated by activated carbon adsorption.

Meetings were held at Schumacher Environmental and Separation Technologies located in Crailsheim, Germany, with Dr. Duest, Head of Research and Development, and Dr. Freude, Head of Quality Assurance. Schumacher is an old German company that manufactures porous ceramic materials, including silicate, clay, glass, silicon carbide, and aluminum oxide, plus other products, including some with membrane coatings. The company has subsidiaries in several countries, including the United States. The majority of their products are used in liquid and gas filtration systems, although they have recently entered the environmental restoration market and have initiated some joint research with the University of Karlsruhe IAG and KSK/FlowTex. Two particularly interesting Schumacher products included porous plastic and sintered activated carbon. The porous plastic is made in various shapes (e.g. $1 \mathrm{~m}$ by $1 \mathrm{~m}$ tiles and 10 to $120 \mathrm{~mm}$ cylinders) with pore sizes of 10 to $100 \mu \mathrm{m}$ and thickness of 2 to $20 \mathrm{~mm}$. The cylinder material costs about $\$ 100$ per meter. The sintered activated carbon also comes in various shapes and sizes. The use of porcus piping installed with horizontal drilling techniques for soil vapor extraction of VOCs was being studied as part of a joint project being implemented by UoK IAG, Schumacher, and KSK/Flow Tex.

\subsubsection{Discussion}

The shallow directional drilling and porous piping system approach to in situ treatment of VOCs was attractive. The cylindrical plastic sections can be joined to create piping that is flexible enough to be implanted with directional drilling techniques. This material could then be used to extract VOCs from the subsurface or to introduce treatment agents; however, the technology is limited to relatively well sorted, unconsolidated sediments. 


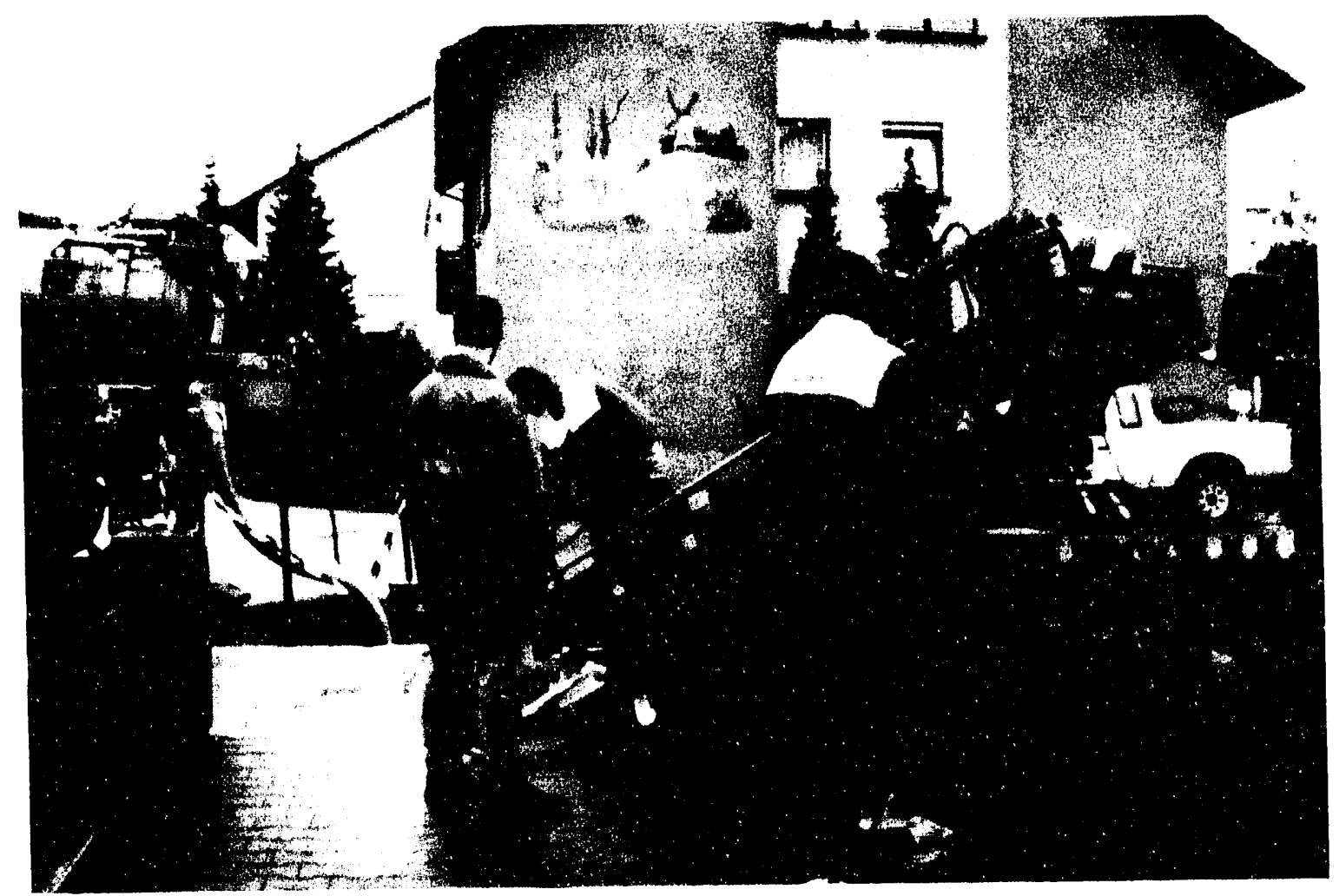

Fig. 2.8. KSK microtunneling equipment in Graben Village, Germany (ORNL site visit during February 1992; ORNL Photo 2876-92). 


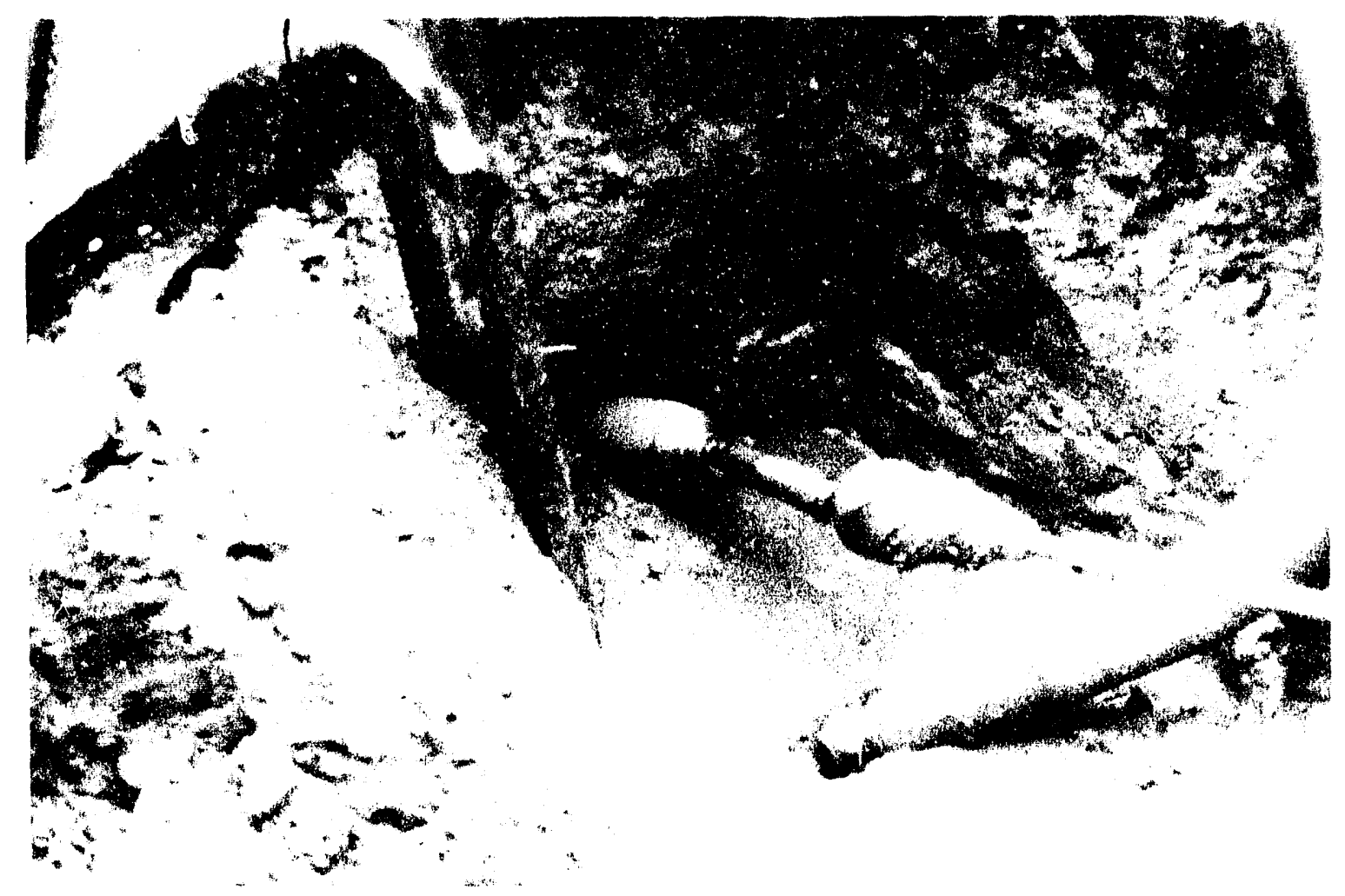

Fig. 2.9. Horizontal pipeline being installed with microtunneling techniques (ORNL site visit during February 1992; ORNL Photo 2877-92). 


\subsection{DISCUSSION}

The vertical recirculation well (i.e., UVB/GZB) and the porous piping horizontal well (PP/HW) technologies were judged to offer the greatest near-term benefits to DOE. These two technologies were originally designed to remove VOCs from the subsurface by vapor stripping processes. However, their use to support implementation of other treatment processes, such as chemical oxidation or bioremediation, is also possible. The UVB/GZB has been used for fullscale air stripping of VOCs at a number of sites in Germany and the process performance is reported to be good. The PP/HW technology has not been demonstrated or tested to any extent there.

Recirculation technologies can be used to strip VOCs from the groundwater and soil air and produce a gaseous waste stream only. Moving a gas (by using UVB/GZB and PP/HW) from the subsurface poses fewer operational problems than moving a dense liquid from the subsurface (by using a pump and treat method). The recirculation technologies are capable of treating two soil phases simultaneously (soil air and groundwater), whereas traditional technologies treat single phases. In situ sparging technologies have been developed to varying degrees and applied at sites in the U. S. For example, Looney et al. (1991) have demonstrated groundwater sparging and stripping of VOCs at the SRS by using a set of slotted pipe, horizontal wells.

Recirculation technologies must be evaluated by including subsurface interactions, merits of the process, and coupling between processes. Fig. 2.10 indicates the relationships between operation and subsurface processes. An arrow pointing from the top left block to the top right block indicates the effects of the treatment processes on aquifer chemistry/biology. The aeration of groundwater, injection of nutrients for stimulation of biological growth, addition of chemicals, or side products of treatment reactions may change the aquifer chemistry and biology. Changes in aquifer chemistry (e.g., precipitation or dissolution) and aquifer biology (e.g., microbial growth) may influence the aquifer characteristics (e.g., permeability). The lower arrow from the top right block indicates the effects of aquifer processes on equipment operation. For example, microbes may foul equipment.

A schematic drawing of the UVB/GZB system with idealized capture zone geumetry is depicted in Fig. 2.6. The UVB/GZB develops a spheroid capture zone; however, capture zone geometry depends upon a number of factors. Relationships between operation, aquifer characteristics, and capture zone geometries are indicated in the three bottom blocks of Fig. 2.10. The vertical/horizontal conductivities and local hydraulic gradient control the horizontal radius of the capture zone. Inlet and outlet screen placement control the capture zone vertical radius. The bottom right block represents aquifer characteristics such as conductivity's and groundwater flow rates. The arrows pointing from the bottom right block indicate the effects of aquifer characteristics on equipment operation and capture zone geometry. The UVB/GZB capture zone geometry is dependent on other factors, including pump rates, screen placement, aquifer thickness, confining zones, and groundwater flow. Aquifer characteristics also dictate maximum aquifer pump rates. 


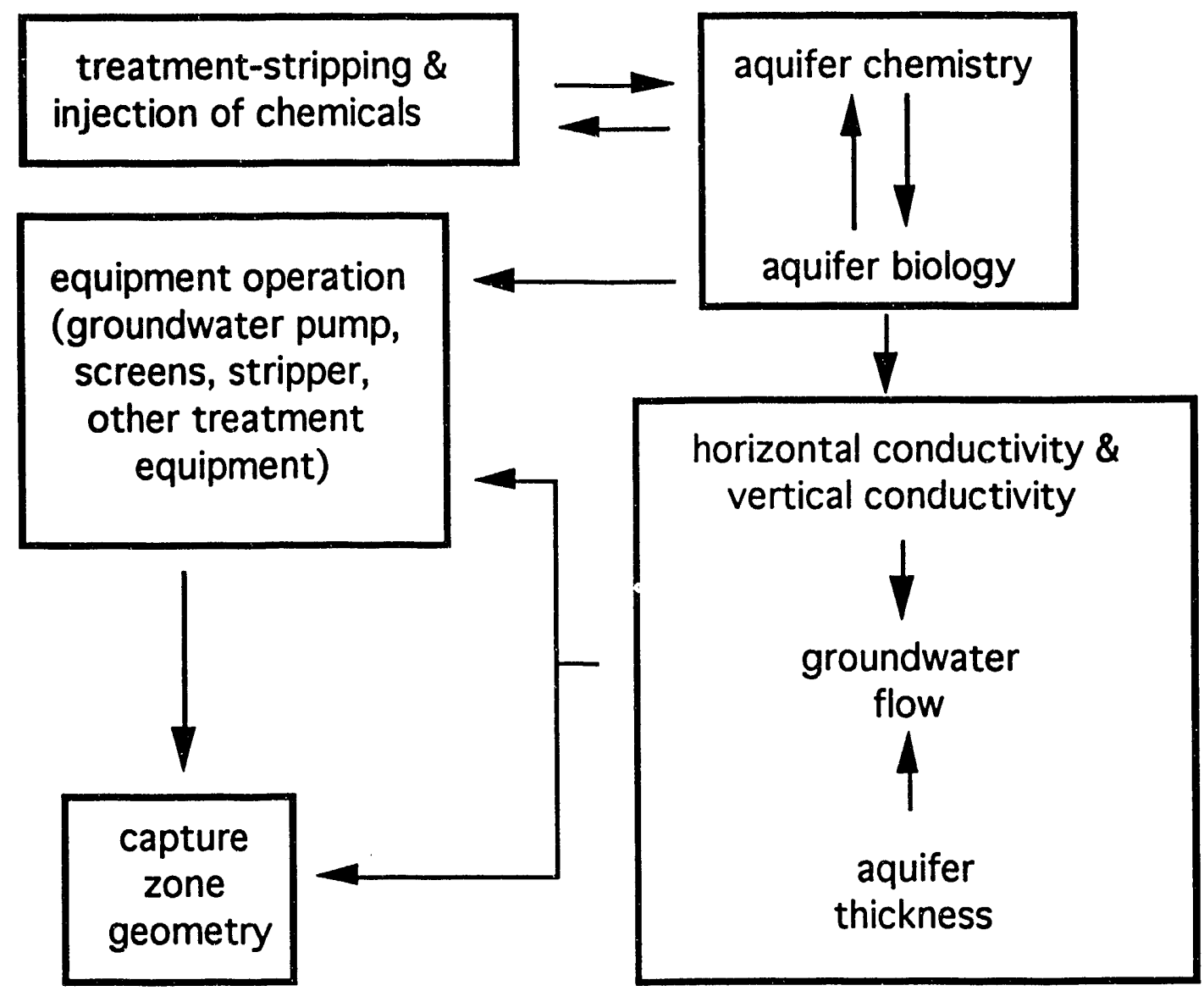

Fig. 2.10. Relationship between groundwater recirculation and subsurface processes. (ORNL Drawing 93-10194) 
Although the UVB/GZB equipment is simple and appears easy to maintain, the overall robustness and reliability of the process depends on the processes depicted in Fig. 2.10. For the UVB/GZB technology, (1) its operation has been limited to depths no greater than $60 \mathrm{ft}$ (assuming simultaneous treatment of soil air and groundwater), (2) its sphere of influence is a function of subsurface conductivity's and geometry's and may be limited to relatively small areas at some sites, and (3) short circuiting between the inlet and outlet screen sections may significantly reduce treatment efficiency at some sites. Several methods are available for evaluating the reliability/robustness and cost to benefit ratio of the UVB/GZB technology, including simulations, laboratory tests, and previous operating records; however, installation and direct on-site evaluation are needed to evaluate full-scale process performance to account for site conditions and subsurface heterogeneities.

The PP/HW subsurface interactions are expected to be similar to UVB/GZB-subsurface interactions. Fig. 2.10 indicates the relationships between recirculation operation and subsurface processes. Figs. 2.11 and 2.12 illustrate an idealized capture zone produced by the PP/HW. The axial length of the surface is a function of the $\mathrm{PP} / \mathrm{HW}$ pump rate and the interstitial resistance to flow between the inlet and outlet pipe. The vertical axis dimension is a function of the horizontal and vertical conductivity's. The PP/HW capture zone geometry also depends on PP/HW placement, aquifer thickness, confining zones, and groundwater flow. Short-circuiting between injection and extraction wells may affect capture zone geometry; however, negative effects are expected to be less significant when using the PH/WW system than when using the UVB/GZB system.

PP/HW equipment appears simple and easy to maintain; however, the overall robustness and reliability of the process depends on the processes depicted in Fig. 2.10. As with the UVB/GZB technology, several methods are available for evaluating the reliability/robustness and cost to benefit ratio of the PP/HW system; however, final evaluation requires installation and direct onsite evaluation. 


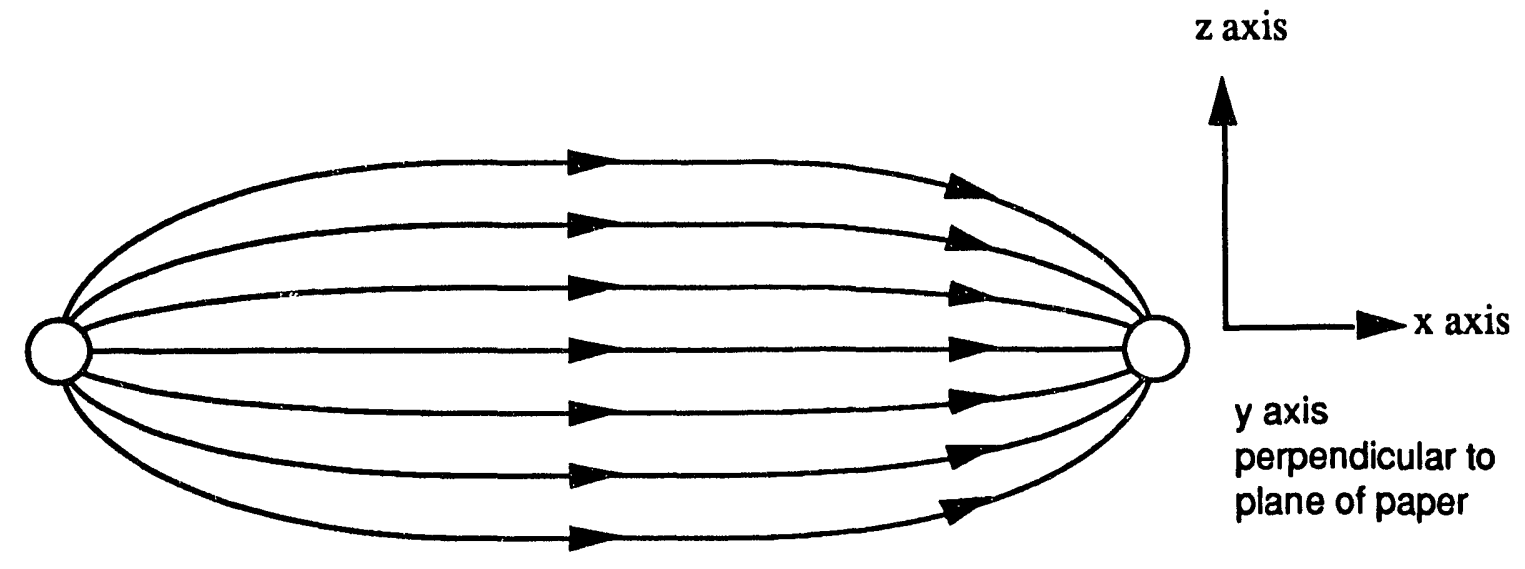

Fig. 2.11. Profile view of an idealized flow field between two parallel PP/HW. (ORNL Drawing 93-10195).
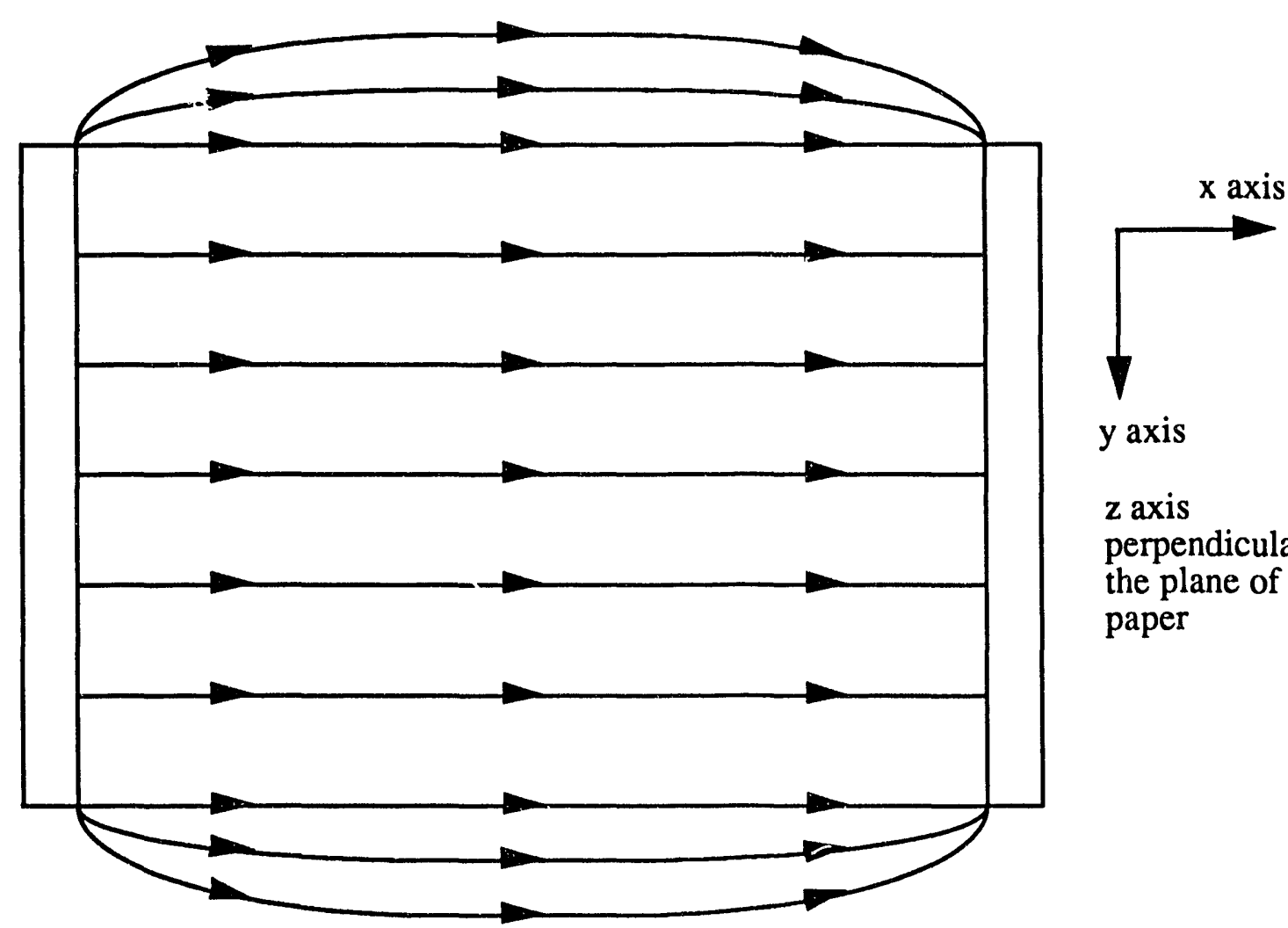

$z$ axis

perpendicular to the plane of the paper

Fig. 2.12. Plan view of a flow field between two parallel PP/HW. (ORNL Drawing 93-10196) 


\subsection{ASSESSMENT OF IN SITU RECIRCULATION PROCESSES}

\subsection{INTRODUCTION}

This section contains a more in depth description of the in situ recirculation processes and a comparison of their attributes with typical pump ind treat technology, a baseline technology for treatment of subsurface VOC contamination.

\subsection{PROCESS DESCRIPTION}

\subsubsection{In Situ Recirculation Processes}

\subsubsection{Vertical Recirculation Wells (UVB/GZB)}

As indicated in preceding sections, the UVB/GZB technology consists of a vertical well with screened sections below and above the water table, a groundwater pump, and an aboveground air blower. Fig. 3.1 depicts the major components of the UVB/GZB. A pump moves groundwater from the bottom entrance section through the UVB/GZB to the top screened section for reinjection into the aquifer. A separation plate prevents back-mixing of the treated groundwater with contaminated water entering the UVB/GZB. A blower, mounted on the outlet side of the $\mathrm{UVB} / \mathrm{GZB}$, moves fresh air through the UVB/GZB and induces a slight vacuum inside the UVB/GZB stripping section. Fresh air, supplied from the surface, strips VOC from the contaminated groundwater. Soil air may also enter the UVB/GZB at the stripping section. The VOC treatment occurs in situ or aboveground in the gaseous UVB/GZB waste stream.

\subsubsection{Porous Pipe Horizontal Recirculation Wells (PP/HW)}

The porous piping horizontal well (PP/HW) system consists of horizontal wells connected to a caisson. PP/HW major components, depicted in Fig. 3.2, consist of pairs of horizontal wells used for withdrawal and injection of groundwater and possibly soil air. A caisson houses treatment and pumping equipment. The groundwater (and/or soil air) enters through the far well, passes through the caisson, and then is reinjected into the aquifer through the second well. Treatment efficiency may be increased by using parallel sets of horizontal wells. A pump housed in the caisson moves groundwater through the PP/HW. Control variables include groundwater and soil air pump rates, and the number and placement of wells. The caisson may also house in situ treatment equipment. For example, the caisson might house an adsorber or air stripper. Horizontal wells installed in the unsaturated zone may also recirculate soil air. 


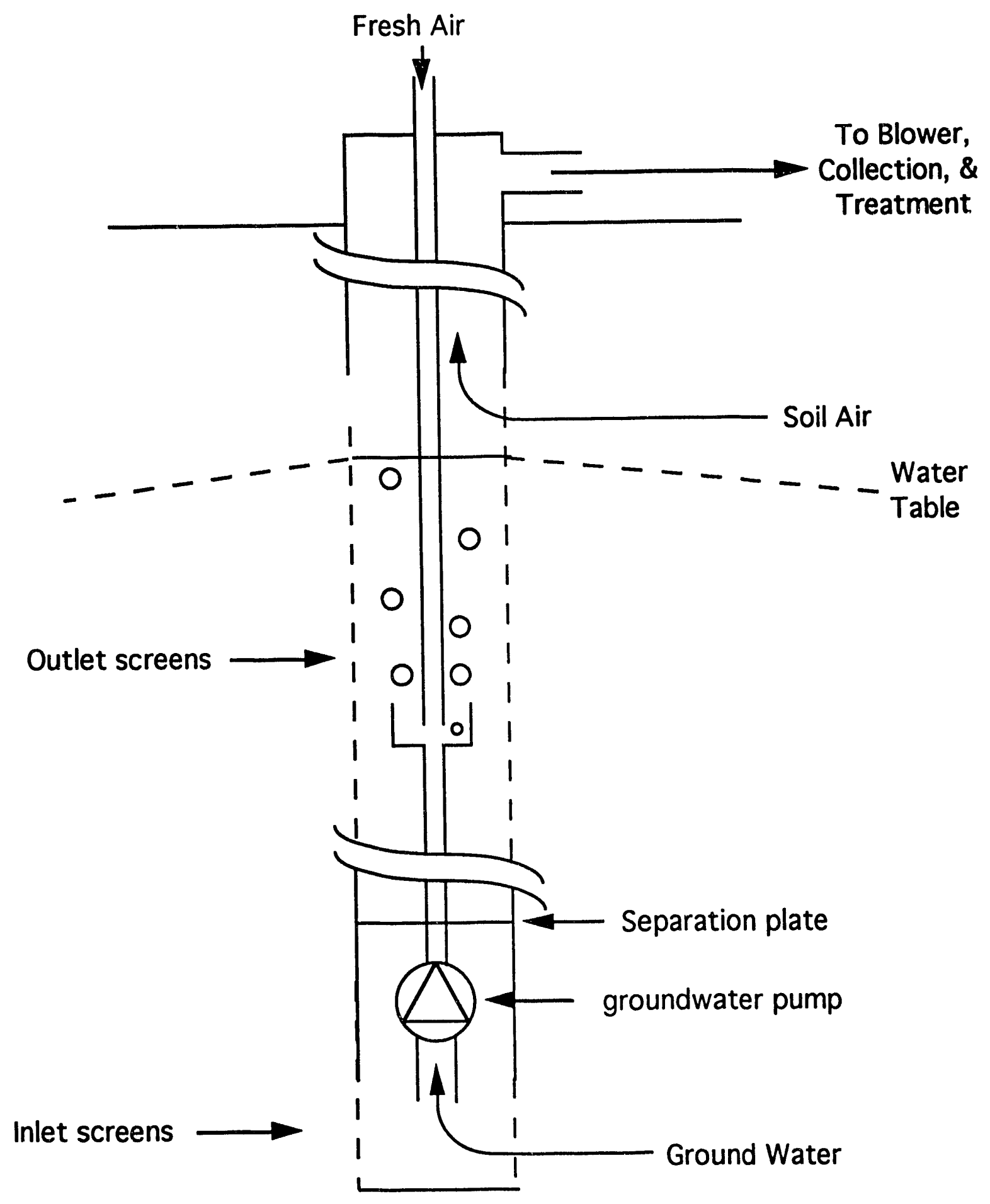

Fig. 3.1. Major components of the UVB/GZB vertical well for in situ recirculation and treatment of groundwater. (ORNL Drawing 93-10197) 

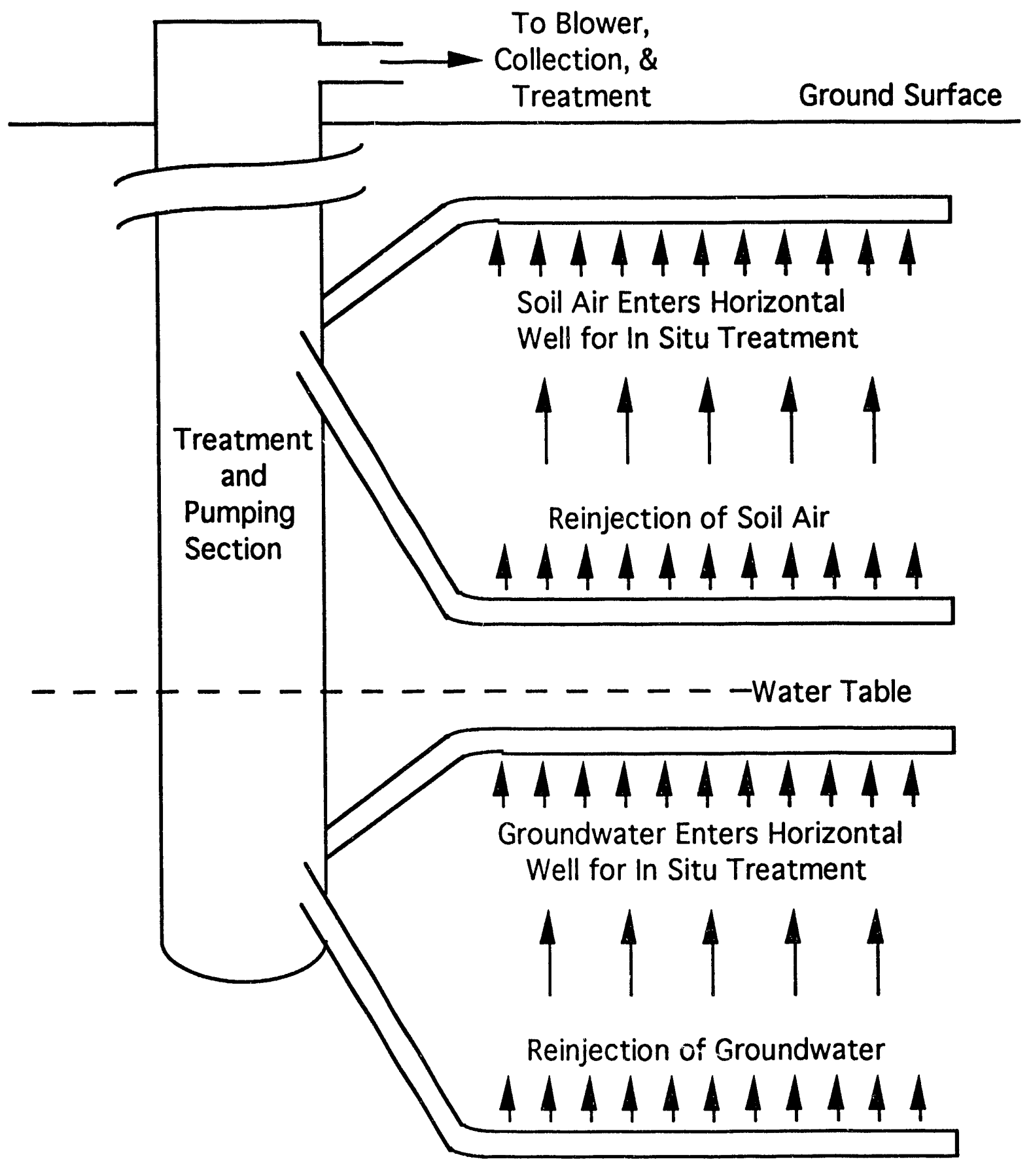

Fig. 3.2. Major components of the PP/HW system for in situ recirculation and treatment of groundwater (ORNL Drawing 93-10198). 


\subsubsection{Baseline Processes}

\subsubsection{Vertical Well Pump and Treat Processes}

Pump and treat remediation technology refers to extraction of contaminated groundwater and subsequent treatment above the land surface. Vertical wells, completed within or downgradient of the groundwater plume, extract groundwater. Treated water is typically disposed of and/or reinjected upgradient of the source area.

Conventional pump-and-treat technologies are among the most widely used systems for the remediation of contaminated groundwater (Palmer and Fish 1992). Studies by Keely (1989) and Mercer et al. (1990) have pointed out the limitations of pump and treat systems which are the result of the complexity of the subsurface porous media and the physical behavior of the contaminant such as NAPLs. An article by Travis and Doty (1990) points to a recent EPA study involving 19 sites where pump and treat has continued for up to ten years. The study concluded that although significant mass removal of contaminants had been achieved, there had been little success in reducing concentrations to target levels. Some of the authors participating in a recent National Research Council report suggest that a restoration of quality in many aquifers might not be achieved in less than 100 to 200 years of pumping (Abelson 1990).

Currently, it is widely recognized that conventional pump and treat technology is plume control technology (Nyer 1990). In other words, the spread of groundwater contamination can be controlled but source reduction is beyond the capabilities of conventional pump and treat systems. Several investigators including Lepore et al. (1990), Palmer and Fish (1992), and Russell et al. (1992) have discussed emerging technologies for the enhancement to pump and treat systems in order to decrease treatment time. Palmer and Fish (1992) discussed in situ chemical enhancements such as co-solvents and surfactants for the removal of immiscible contaminants in source areas. For both techniques, additional research is needed experience in their application is limited.

Existing systems and operating issues are discussed in papers by Thomsen et al. (1989) and Doherty (1992). For a pump and treat system installed under the direction of the Michigan Department of Natural Resources, capital costs of $\$ 3,000,000$ and annual operating and maintenance costs of $\$ 145,000$ were incurred. If this system is operated for 20 to 30 years, substantial additional costs will also occur.

\subsubsection{Horizontal Well Pump and Treat Processes}

Horizontal wells can replace conventional vertical wells in pump and treat systems. Although limited applications of horizontal wells have occurred in groundwater remediation programs, horizontal wells have been used extensively in the oil field industry. In a comparison study of horizontal versus vertical well performance, Gilman and Jargon (1992) reported that for homogeneous reservoirs with moderate permeability, the horizontal well produces more than three times the cumulative oil of a vertical well during the first five years. For more permeable reservoirs, a horizontal well accelerates production while ultimate recovery is only slightly higher. Horizontal wells can be expected to provide higher rates and significant incremental recovery.

In Taber \& Seright (1592), a horizontal well recirculation system that involved injection of water for oil recovery increaseci production on a per well basis from about 100 to $400 \mathrm{bbl}$ per day - the highest production rate in the life of the 45 year old field. Taber and Seright (1992) concluded that combinations of horizontal injectors and producers increased production rates by as much as 10 times (with no increase in pressure) and improved areal sweep efficiencies. 
A unique application of recirc dlation horizontal wells for the remediation of groundwater contamination is currently underw dy at the SRS (Kaback 1989). The system consists of two horizontal wells. One well is completed in an aquifer containing substantial quantities of chlorinated solvents. A mixture of air and methane is injected into this well and bubbles upward through the contaminated groundwater. The idea is to strip the volatile chlorinated solvent and enhance microbial action. A second horizontal well is completed in the overlying vadose zone. This well is connected to a vacuum system that removes the contaminated vapor produced by bubbling gas through the aquifes. Initial reports indicate that substantial quantities of chlorinated solvents have been removed, but the overall efficiency of the system has yet to be evaluated. Various designs and recirculation schemes have yet to be evaluated.

\subsubsection{Comparison of In Situ cecirculation with Baseline Technologies}

Single-well vertical recirculation systems developed in Germany are an emerging technology that may provide enhanced treatment efficiency and lower costs associated with groundwater remediation. Each individual well has screened sections at both the top and bottom. Groundwater can be drawn into the well through the bottom section, pumped vertically through the well casing, and injected back into the aquifer through the top section (if desired, the direction can be reversed). The upper and lower screened sections can be in different layers but the layers need to be hydraulically connected in order for a circulation cell to form. This design produces vertical flows that under ideal conditions can encompass the entire thickness of the aquifer.

Two types of vertical recirculation wells have been developed. The UVB is used to strip volatile contaminants from groundwater and soil by using air that is below atmospheric pressure. Clean air is bubbled into the well and the volatile contaminants dissolved in the groundwater are transferred to the gaseous phase. The upper portion of the well is kept under vacuum, and the contaminated air is cleaned on the surface by using activated carbon (Herrling et al. 1991). With this method, no water is brought to the surface, thereby eliminating some of the problems associated with treatment, disposal, or reinjection. The groundwater circulation well GZB utilizes vertical recirculation for in situ bioremediation by addition of nutrients and/or electron acceptors as the groundwater passes through the well casing. The GZB method can also be used for the removal of heavy metals by pumping the water for treatment at the surface and then reinjecting the water back into the aquifer (Herrling et al. 1991).

The proponents of the vertical recirculation techniques suggest that it has several advantages when compared with typical pump and treat systems. These proposed advantages are:

- horizontal layers of lower permeability are penetrated vertically

- there is no groundwater extraction and no waste water produced (for the UVB/GZB method)

- nutrients and electron acceptors can in theory be evenly distributed throughout the aquifer (GZB)

- no regional lowering of the groundwater level and hence reduced effect on the regional flow system

- the entire thickness of the aquifer may be included in the circulation

- soil air extraction is possible at the same time as treatment of the groundwater and

- investment and operating costs are lower.

The UVB/GZB method has been reported as an effective remediation tool at several sites in Germany (Herrling et al., 1991). The contaminants treated inciude trichioroethyiene (TCE), 
trichloroethane, perchloroethylene, benzene, toluene, and xylene. The costs of construction and treatment were reported to be significantly less than the same levels of treatment by more traditional methods.

The vertical recirculation wells can be installed for both plume control and source remediation. Nomographs for determining radius of influence and well spacing have been published by Herrling et al. (1991). The radius of influence and well spacing are influenced by the same parameters that affect the same calculations for conventional wells. The nomographs, however, were produced for the ideal conditions of radial symmetry in an homogeneous, anisotropic, confined, aquifer with the horizontal to vertical hydraulic conductivity ratios, between 1 and 10 . This leaves open the question of how aquifer heterogeneities influence the effectiveness of the technology. The technology also does not address the situation where transport is dominated by diffusion processes. The technique mentioned above was successfully applied in locations in which the aquifers were fairly homogeneous and the horizontal hydraulic conductivity's ranged from $10^{-1}$ to $10^{-3} \mathrm{~cm} / \mathrm{s}$.

The available literature on the UVB/GZB technology suggests that this treatment method may be a substantial improvement over traditional technologies. On the other hand, little information exists on the effectiveness of the technology in a wide variety of hydrologic conditions and in the presence of aquifer heterogeneity. The fact that vertical flows are developed, though, warrants further research into the technology to determine the conditions for which UVB/GZB are best suited (e.g., DNAPLs, bioremediation). Extensive field testing in different hydrogeological settings, computer simulations, and detailed cost comparisons to other methods need to occur before the vertical recirculation well technology can be implemented on a broad scale. Computer modeling is needed as the basis of comparisons of the UVB/GZB terhnology with other groundwater treatment technologies. Because of the lack of information on the effects of heterogeneities, the vertical recirculation wells may be best used in conjunction with other technologies. One example would be to use the UVB/GZB well in the source area of a TCE spill and pump and treat wells downgradient to control the contaminant plume.

\subsection{Assessment of Recirculation Process Attributes}

\subsubsection{Hydrodynamic Performance}

\subsubsection{Methods}

The procedure for determining the spacing of UVB/GZB wells given in Herrling et al. (1991) was developed for simplified conditions of the wells pumping from bottom to top in a confined, homogeneous aquifer with or without the presence of natural groundwater flow. The only anisotropy allowed is in the ratio of horizontal to vertical hydraulic conductivity. This discussion will concentrate only on situations in which a natural groundwater flow is present. No equations are given for the calculation of spacing, rather nomographs are presented that use dimensionless variables. Development of a finite difference algorithm for predicting pollutant transport in a three phase system in three dimensions is currently under development by J. C. Parker of VPI. The algorithm will be used as an independent check of flow predictions reported by Herrling et al. (1991).

The nomographs of Herrling et al. were developed for the condition in which the length of the screened sections of the well at both the top and bottom are equal to one quarter the thickness of the aquifer. In other words, a total of one-quarter of the aquifer is screened. The nomographs are available for horizontal-to-vertical hydraulic conductivity ratios of 1,5 , and 10 . 
To test the nomographs and to determine the relationships between aquifer thickness, pumping rate, and hydraulic conductivity, a simplified analysis was conducted. For illustration purposes the gradient and the following parameters were kept constant for each trial:

$$
\begin{aligned}
& I=0.005 \quad \text { (hydraulic gradient of the natural groundwater system), } \\
& n=0.20 \quad \text { (effective porosity), } \\
& K_{h} / K_{v}=10 \quad \text { (ratio of horizontal to vertical hydraulic conductivity), and } \\
& a=0.25 * \mathrm{~B} \quad \text { (length of screened section). }
\end{aligned}
$$

This procedure was applied to aquifer thicknesses of $30,20,10,5$, and $2 \mathrm{~m}$. For each thickness, six values of horizontal hydraulic conductivity's, ranging from $0.0001 \mathrm{~m} / \mathrm{h}\left(3 \times 10^{-6}\right.$ $\mathrm{cm} / \mathrm{s})$ to $10 \mathrm{~m} / \mathrm{h}(0.3 \mathrm{~cm} / \mathrm{s})$, were used. For each value of hydraulic conductivity, 18 pumping rates, ranging from $0.01 \mathrm{~m}^{3} / \mathrm{h}$ to $100 \mathrm{~m}^{3} / \mathrm{h}$, were used. The Darcy velocity $v_{f}$ was calculated by multiplying the horizontal hydraulic conductivity by the natural hydraulic gradient. These terms were used to calculate the dimensionless term.

\subsubsection{Results}

Evaluation of the Nomographs and General Site Application. The dimensionless terms determined for each aquifer thickness, hydraulic conductivity, and pumping rate are given in Tables A.1 through A.5 in Appendix A. The well spacing $D$ is also given. The spacing $D$ was determined by using the nomographs presented in the article by Herrling et al. (1991). The nomographs are limited to a dimensionless value $\left(\frac{Q}{B^{2} v_{f}}\right)$ of 50 . Well spacings of less than $1 \mathrm{~m}$ were not considered.

The data from Tables A.1 through A.5 in Appendix A are represented graphically in Figs. 3.3 through 3.7. Each represents data for a specific aquifer thickness and relates the pumping rate to well spacing for the various hydraulic conductivities. The kinks in some of the lines are the result of uncertainties associated with picking numbers off the nomograph.

Before interpreting the plots, it was necessary to determine if the pumping rates used in the calculations can actually be sustained by an aquifer with the various thicknesses and hydraulic conductivity's. This was estimated by using the Theis method of estimating aquifer parameters. The equations and the table of $W(u)$ values used are given in Davis \& De Wiest (1966, pp. 215217).

It was assumed that the maximum drawdown that could occur would be to a depth of $1 \mathrm{ft}$ above the top of the bottom screened interval at a radius of $1 \mathrm{ft}$ from the well after steady pumping for a period of 30 days. The transmissivity was calculated by multiplying the thickness of the screened interval by the hydraulic conductivity. The coefficient of storage was taken to be equal to the effective porosity, 0.20 . The drawdown was calculated for each pumping rate and hydraulic conductivity. If the calculated drawdown exceeded the maximum allowed drawdown, then that pumping rate was not deemed feasible. The calculated drawdowns are presented in Tables A6 through A10 in Appendix A. 


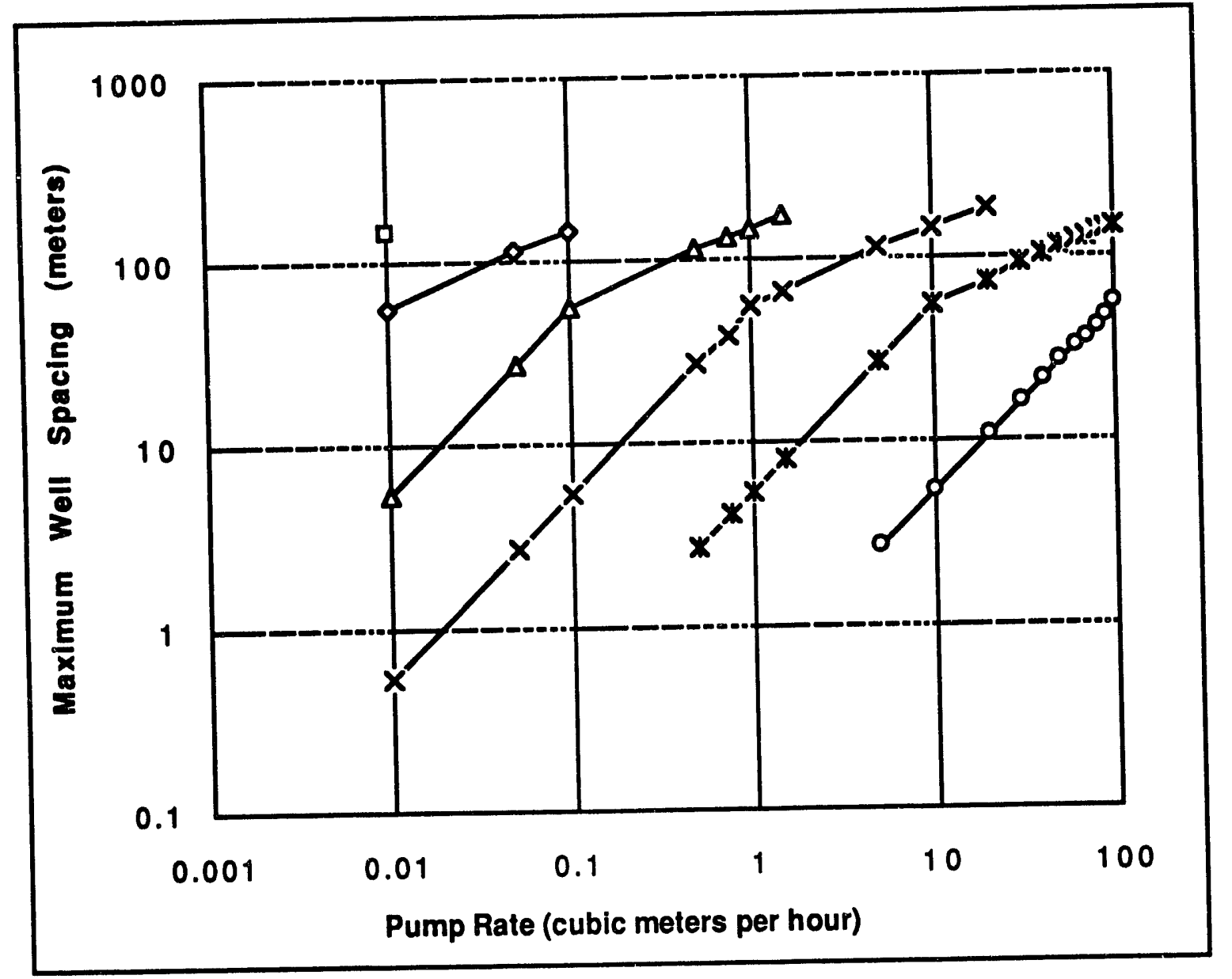

Fig. 3.3 Maximum well spacing as a function of pump rate and hydraulic conductivity for an aquifer thickness of $30 \mathrm{~m}$. Horizontal conductivities are indicated by the following symbols, $\square K_{h}=0.0001 \mathrm{~m} / \mathrm{h}, \diamond K_{h}=0.001 \mathrm{~m} / \mathrm{h}, \Delta K_{h}=0.01 \mathrm{~m} / \mathrm{h}, \times K_{h}=0.1 \mathrm{~m} / \mathrm{h}, \times K_{h}=$ $1.0 \mathrm{~m} / \mathrm{h}, \circ K_{h}=10.0 \mathrm{~m} / \mathrm{h}$. (ORNL Drawing 93-10199)

(Note: $K_{h} / K_{v}=10 ; 4.4 \mathrm{gal} / \mathrm{min}$ is approximately equal to $1 \mathrm{~m}^{3} / \mathrm{hour}$ ). 


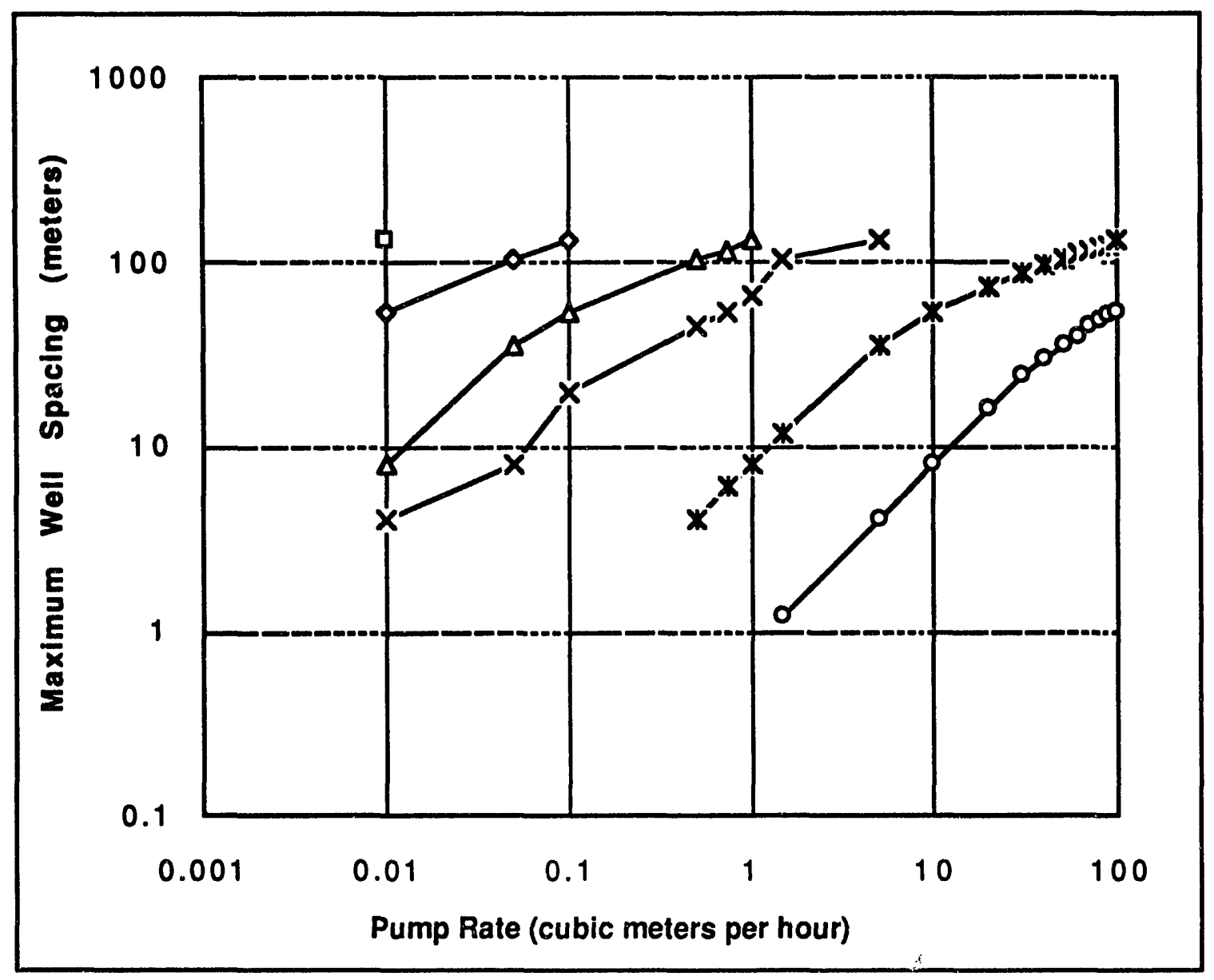

Fig. 3.4 Maximum well spacing as a function of pump rate and hydraulic conductivity for an aquifer thickness of $20 \mathrm{~m}$. Horizontal conductivities are indicated by the following symbols, $\square K_{h}=0.0001 \mathrm{~m} / \mathrm{h}, \diamond K_{h}=0.001 \mathrm{~m} / \mathrm{h}, \Delta K_{h}=0.01 \mathrm{~m} / \mathrm{h}, \times K_{h}=0.1 \mathrm{~m} / \mathrm{h}, \mathbf{x} K_{h}=$ $1.0 \mathrm{~m} / \mathrm{h}$, ० $K_{h}=10.0 \mathrm{~m} / \mathrm{h}$. (ORNL Drawing 93-10200) (Note: $K_{h} / K_{v}=10 ; 4.4 \mathrm{gal} / \mathrm{min}$ is approximately equal to $1 \mathrm{~m}^{3} /$ hour). 


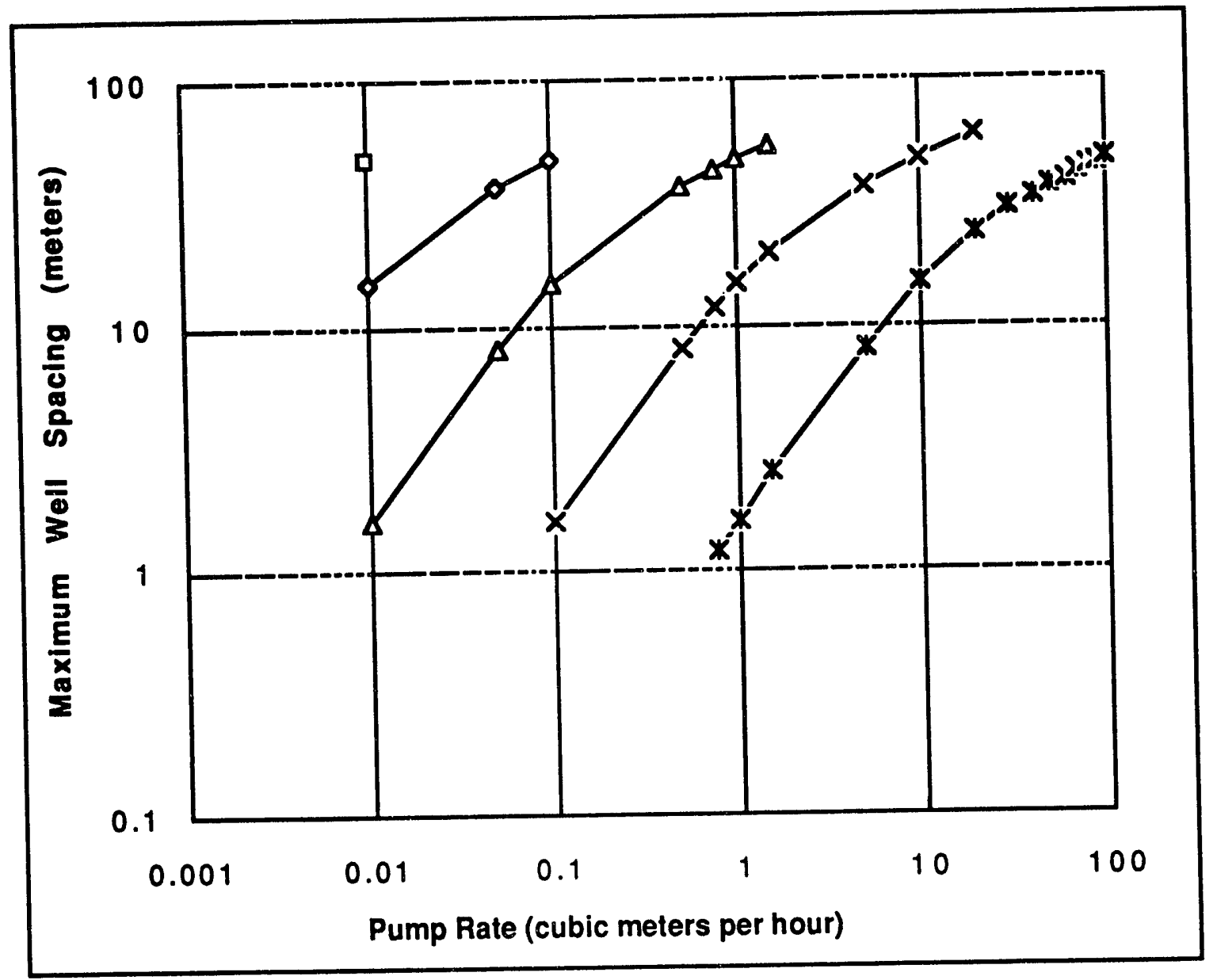

Fig. 3.5 Maximum well spacing as a function of pump rate and hydraulic conductivity for an aquifer thickness of $10 \mathrm{~m}$. Horizontal conductivities are indicated by the following symbols, a $K_{h}=0.0001 \mathrm{~m} / \mathrm{h}, \diamond K_{h}=0.001 \mathrm{~m} / \mathrm{h}, \Delta K_{h}=0.01 \mathrm{~m} / \mathrm{h}, \times K_{h}=0.1 \mathrm{~m} / \mathrm{h}, \approx K_{h}=$ $1.0 \mathrm{~m} / \mathrm{h}, \circ K_{h}=10.0 \mathrm{~m} / \mathrm{h}$. (ORNL Drawing 93-10201)

(Note: $K_{k} / K_{v}=10 ; 4.4 \mathrm{gal} / \mathrm{min}$ is approximately equal to $1 \mathrm{~m}^{3} /$ hour). 


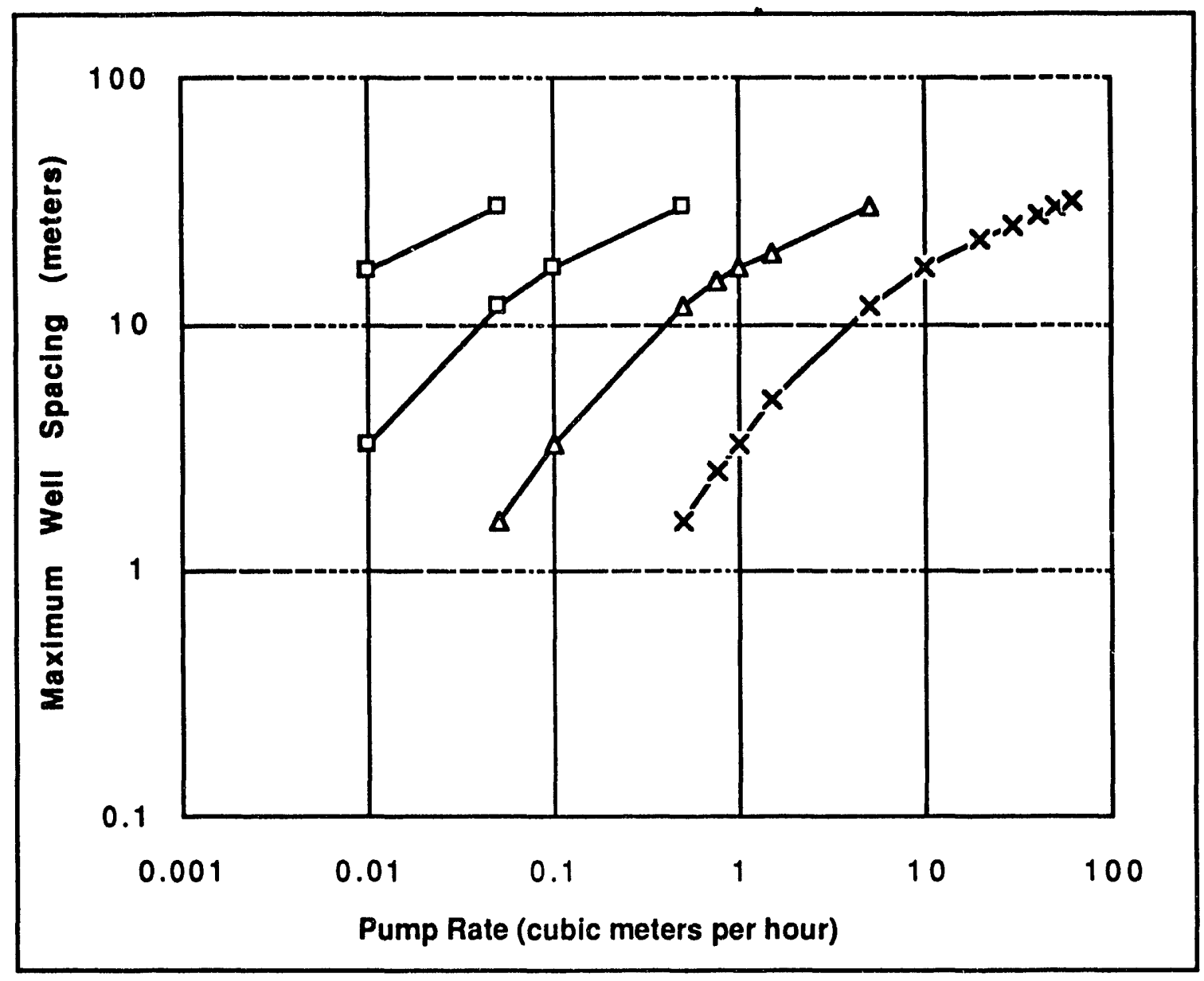

Fig. 3.6 Maximum well spacing as a function of pump rate and hydraulic conductivity for an aquifer thickness of $5 \mathrm{~m}$. Horizontal conductivities are indicated by the following symbols, $\square K_{h}=0.0001 \mathrm{~m} / \mathrm{h}, \diamond K_{h}=0.001 \mathrm{~m} / \mathrm{h}, \Delta K_{h}=0.01 \mathrm{~m} / \mathrm{h}, \times K_{h}=0.1 \mathrm{~m} / \mathrm{h}, \times K_{h}=$ $1.0 \mathrm{~m} / \mathrm{h}, \circ K_{h}=10.0 \mathrm{~m} / \mathrm{h}$. (ORNL Drawing 93-10202)

(Note: $K_{h} / K_{v}=10 ; 4.4 \mathrm{gal} / \mathrm{min}$ is approximately equal to $1 \mathrm{~m}^{3} / \mathrm{hour}$ ). 


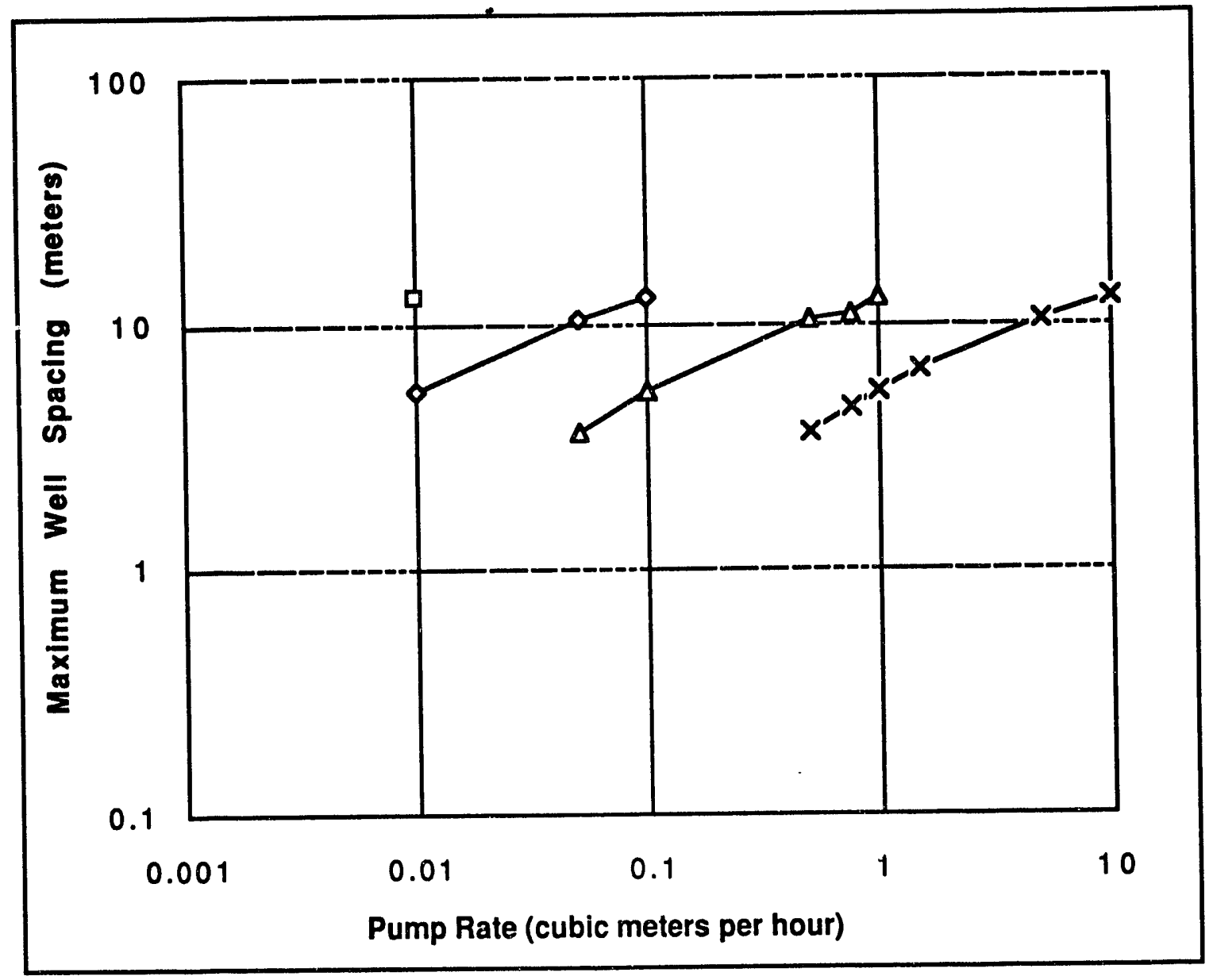

Fig. 3.7 Maximum well spacing as a function of pump rate and hydraulic conductivity for an aquifer thickness of $2 \mathrm{~m}$. Horizontal conductivities are indicated by the following symbols, $\square K_{h}=0.0001 \mathrm{~m} / \mathrm{h}, \diamond K_{h}=0.001 \mathrm{~m} / \mathrm{h}, \Delta K_{h}=0.01 \mathrm{~m} / \mathrm{h}, \times K_{h}=0.1 \mathrm{~m} / \mathrm{h}, \times K_{h}=$ $1.0 \mathrm{~m} / \mathrm{h}$, $\circ K_{h}=10.0 \mathrm{~m} / \mathrm{h}$. (ORNL Drawing 93-10203)

(Note: $K_{h} / K_{v}=10 ; 4.4 \mathrm{gal} / \mathrm{min}$ is approximately equal to $1 \mathrm{~m}^{3} /$ hour). 
It is interesting to note that the maximum allowable pumping rates that produce the maximum allowable drawdowns are, in general, the same as the maximum pumping rates that can be used on the nomographs. The dimensionless parameter, $Q /\left(B^{2 *} v_{f}\right)$ when equal to 50 , indicates the maximum pumping rates that can be sustained by the aquifer. All data presented in Figs. 3.3 through 3.7 are for pumping rates which pass the drawdown test described above.

Examination of the $Q$ versus $D$ graphs presented in Figs. 3.3 through 3.7 leads to several conclusions. In general, the well spacing at a given pumping rate is relatively insensitive to the aquifer thickness, except for the smaller values of the dimensionless parameter. For thick aquifers with high permeability, low pumping rates yield very small well spacing. This is the result of the lower and upper well sections having very little influence on one another and the lack of circulation development. Conversely, aquifers with very low permeability yield very large well spacing; however, this spacing can be achieved only with extremely slow pumping rates. The plots also suggest that the technique will not work well in thin aquifers because small well spacing will be needed, especially for the more permeable material. The main conclusion to be made based on our analysis is that the technique appears to be best suited for aquifers that are on the order of $10 \mathrm{~m}$ thick and have hydraulic conductivities that are in the range of fine to coarse sand.

Application to the Kansas City DOE and Portsmouth Plant Sites. The nomographs from Herrling et al. (1991) were used to estimate the appropriate well spacing for both the Northeast Area of the Kansas City Plant (KCP) and the X701B site at the Portsmouth Gaseous Diffusion Plant (PORTS). Geologic site characterization data are presented in Appendix B. Both sites have relatively low hydraulic conductivities $(0.019 \mathrm{~m} / \mathrm{h}$ for KCP and $0.07 \mathrm{~m} / \mathrm{h}$ for PORTS), hydraulic gradients of around 0.007 and assumed effective porosities of 0.20 . The major difference between the two sites is their aquifer thickness. The thickness of the $\mathrm{KCP}$ aquifer (the alluvial aquifer) is taken to be $10.8 \mathrm{~m}$ and that for the PORTS aquifer (the Gallia formation) is $1.5 \mathrm{~m}$. For each site, three different ratios of horizontal to vertical hydraulic conductivity were used: 1 , 5 , and 10. As done in the preceding case, the length of the screened section was one quarter of the aquifer thickness.

The nomographs were used to estimate the well spacing for the KCP site using pumping rates of $0.1,0.5$, and $0.7 \mathrm{~m}^{3} / \mathrm{h}$. The pumping rate of $0.7 \mathrm{~m}^{3} / \mathrm{h}$ was determined by setting the dimensionless term equal to 50 and solving for the pumping rate $Q$. The results are presented in Table 3.1. The well spacing can range from 19 to $70 \mathrm{~m}$, depending upon the specified parameters. The spacing as a function of pumping rate for $K_{h} / K_{v}=10$ are plotted on the graph for the aquifer thickness of $10 \mathrm{~m}$ (Fig. 3.5). It can be seen that the larger well spacing occurs at larger ratios of the horizontal to vertical conductivity.

For PORTS, only one pumping rate was used, $0.06 \mathrm{~m}^{3} / \mathrm{h}$. This rate gives a dimensionless parameter value of 50. The results are given in Table 3.2. As can be seen, the well spacing would have to be quite small $(4$ to $10 \mathrm{~m})$ because the aquifer thickness is small. The spacing for the conductivity ratio of 10 is plotted with the other curves on the graph for aquifer thickness of $2 \mathrm{~m}$ (Fig. 3.7). Again, it can be seen that the larger well spacing occurs at larger ratios of the horizontal to vertical conductivity (Table 3.2 ).

Based on the use of the nomographs (Herrling et al., 1991), a viable well spacing can be achieved for the KCP site. The main problem will be in the use of a fairly low pumping rate. It would be good to compare this pumping rate to that of other wells used on the site. 
Table 3.1. Kansas City Plant UVB/GZB well spacing for various discharge rates

Maximum well spacing at conductivity ratio shown

\begin{tabular}{cccc} 
Parameter & $K_{h} / K_{v}=1$ & $K_{h} / K_{v}=5$ & $K_{h} / K_{v}=10$ \\
\cline { 2 - 4 } Pump rate $=0.1 \mathrm{~m}^{3} / \mathrm{h}$ & & & \\
$\boldsymbol{B}_{T}(\mathrm{~m})$ & 10 & 12 & 12 \\
$\boldsymbol{B}_{\boldsymbol{B}}(\mathrm{m})$ & 28 & 49 & 63 \\
$\boldsymbol{A}\left(\mathrm{m}^{2}\right)$ & 245 & 410 & 510 \\
$\boldsymbol{D}(\mathrm{m})$ & $\mathbf{1 9}$ & $\mathbf{3 5}$ & $\mathbf{4 0}$ \\
\hline Pump rate $=0.5 \mathrm{~m}^{3} / \mathrm{h}$ & & & \\
$\boldsymbol{B}_{T}(\mathrm{~m})$ & 16 & 27 & 31 \\
$\boldsymbol{B}_{\boldsymbol{B}}(\mathrm{m})$ & 36 & 68 & 88 \\
$\boldsymbol{A}\left(\mathrm{m}^{2}\right)$ & 315 & 583 & 746 \\
$\boldsymbol{D}(\mathrm{m})$ & $\mathbf{5 7}$ & $\mathbf{5 1}$ & $\mathbf{6 4}$ \\
\hline Pump rate $=0.7 \mathrm{~m}^{3} / \mathrm{h}$ & & & 38 \\
$\boldsymbol{B}_{T}(\mathrm{~m})$ & 19 & 31 & 95 \\
$\boldsymbol{B}_{\boldsymbol{B}}(\mathrm{m})$ & 40 & 73 & $\mathbf{8 1 6}$ \\
$\boldsymbol{A}\left(\mathrm{m}^{2}\right)$ & 350 & 642 & $\mathbf{7 0}$ \\
$\boldsymbol{D}(\mathrm{m})$ & 30 & 55 &
\end{tabular}

Note: The hydraulic gradient of the natural groundwater system at Kansas City Plant is taken to be $5.0 \times 10^{-3}$. The Darcy velocity of the groundwater flow is $3 \times 10^{-3} \mathrm{~m} / \mathrm{d}$. The horizontal conductivity is taken to be $5.3 \times$ $10^{-6} \mathrm{~m} / \mathrm{s}$. Aquifer thickness is estimated to be 10.8 meters. Screened section lengths are taken to be a quarter of the aquifer thickness.

$B T=$ upstream capture zone at the top of the aquifer, $B_{B}=$ upstream capture zone at the bottom of the aquifer, $A=$ influx area of the upstream capture zone, $D=$ maximum well spacing.

Table 3.2. Portsmouth Plant UVB/GZB well spacing for a well discharge rate of $0.06 \mathrm{~m}^{3} / \mathrm{h}$.

Maximum well spacing at conductivity ratio shown

\begin{tabular}{cccc} 
& & & \\
\cline { 2 - 4 } Parameter & $K_{h} / K_{v}=1$ & $K_{h} / K_{v}=5$ & $K_{h} / K_{v}=10$ \\
\hline Pump rate $=0.06 \mathrm{~m}^{3} / \mathrm{h}$ & & 4 & 5 \\
\hline$B_{T}(\mathrm{~m})$ & 3 & 10 & 13 \\
$B_{B}(\mathrm{~m})$ & 6 & 13 & 16 \\
$A\left(\mathrm{~m}^{2}\right)$ & 7 & 8 & 10 \\
$D(\mathrm{~m})$ & 4 & 8
\end{tabular}

Note: The hydraulic gradient of the natural groundwater system at Portsmouth Plant is taken to be $7.0 \times 10^{-3}$. The Darcy velocity of the groundwater flow is $1.2 \times 10^{-2} \mathrm{~m} / \mathrm{d}$. The horizontal conductivity is taken to be $7.0 \times 10^{-2}$ $\mathrm{m} / \mathrm{h}$. Aquifer thickness is estimated to be 1.5 meters. Screened section lengths are taken to be a quarter of the aquifer thickness.

$B T=$ upstream capture zone at the top of the aquifer, $B_{B}=$ upstream capture zone at the bottom of the aquifer, $A=$ influx area of the upstream capture zone, $D=$ maximum well spacing. 
The PORTS site appears to be a questionable location for the application of a typical UVB/GZB technology. This is because of the small thickness of the contaminated aquifer coupled with the low permeability of the overlying formation.

\subsubsection{VOC Stripping Treatment Efficiency}

This section discusses UVB/GZB stripping efficiency. VOC removal efficiency by air stripping depends on the method of contacting and equilibrium partitioning between liquid and vapor phases. The quality of phase mixing depends on the contacting method. Phases may be mixed countercurrently or cocurrently. Phases may also be mixed in a continuous or staged method. The Henry's constant quantitatively describes partitioning and is defined as the ratio of solute chemical activity in the vapor phase to solute in the aqueous phase. The Henry's Law value is a thermodynamic property that is unique for each solute-solvent system. VOCs with high Henry's constant generally show good recovery by air stripping.

\subsubsection{Methods}

The potential stripping efficiency of the UVB/GZB process was assessed by using analytical process modeling methods as described in the following. Solute transport must occur across an interfacia! surface. Mass transfer depends on interface surface area, mass transfer resistance (resistance of movement in individual phases), and the driving force (difference between actual and equilibrium concentrations). The interfacial area depends on the volume and physical distribution of gas and liquid within the stripping chamber.

Liquid and gas phases are mixed cocurrently and continuously in the UVB/GZB stripping chamber. A more efficient method would include a countercurrent treatment that uses a high surface area packing material. Packing materials reduce back mixing and increase surface area for mass transfer. Improvements by countercurrent contacting are described in Section 4.

The stripper air and contaminated groundwater mix in the UVB/GZB in a cocurrent fashion (Fig. 2.4 and Fig. 3.8). The process is schematically depicted in Fig. 3.8 along with symbols for flow rates and concentrations. The total mass balance on the stripper section (Fig. 3.8) is

$$
L_{A}+V_{A}=L_{B}+V_{B}
$$

The solute mass balance (Fig. 3.13) is

$$
L_{A} x_{A}+V_{A} y_{A}=L_{B} x_{B}+V_{B} y_{B}
$$

The dimensionless Henry's Law relation is

$$
H=\frac{y_{i}}{x_{i}}
$$

Because solute is transferred from the liquid to the gas phase, the liquid-phase concentration decreases to the equilibrium concentration. The effective Henry's law constant is a function of a number of variables and is less than or equal to the equilibrium Henry's law constant

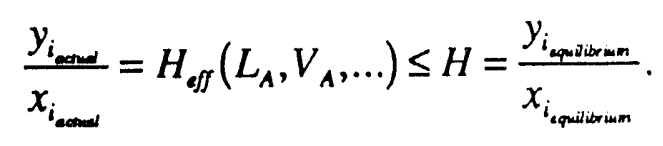




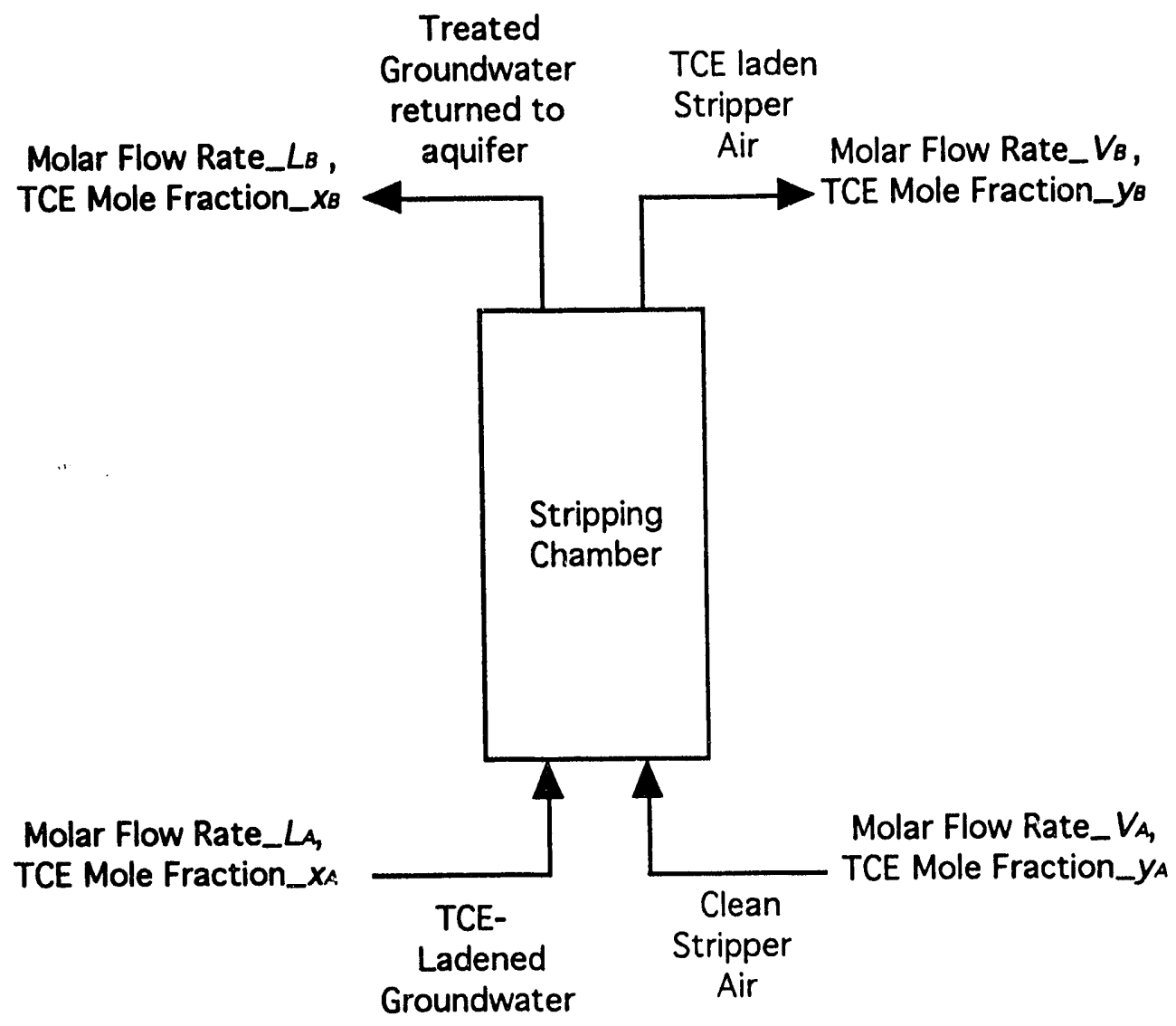

Fig. 3.8. Block diagram and symbols for a stripper section representative of the UVB/GZB. (ORNL Drawing 93-10204) 
The stripping section of the UVB/GZB is not packed and might better be modeled as a simple mixing chamber. Entering concentrations of stripper gas and contaminated groundwater are known. The stripper gas is initially free of contaminant. The effluent concentration may be determined by using the effective Henry's law relation

$$
x_{B}=\frac{L_{A} x_{A}}{L_{B}+V_{B} H_{C S}}
$$

If we assume that the gas phase is relatively insoluble in the liquid phase and that the liquid phase does not change the mass flow rate of the effluent gas phase appreciably, then equation (3.5) simplifies to

$$
x_{B}=\frac{L_{A} x_{A}}{L_{A}+V_{A} H_{\text {eff }}} .
$$

Equation (3.6) indicates the relationship between entrance flow rates, feed concentrations, and the liquid effluent concentration. For systems where significant phase change occurs, these assumptions may not be valid.

\subsubsection{Results}

The objective of the stripping process is to decrease the effluent concentration by transferring as much of the contaminant to the gas phase as possible. Inspection of equation (3.6) indicates that the effluent concentration decreases as the stripper gas flow increases. Keeping $V_{A}$ constant and decreasing $L_{A}$ also reduces the effluent concentration. To reduce the effluent concentration, $H_{c f f}$

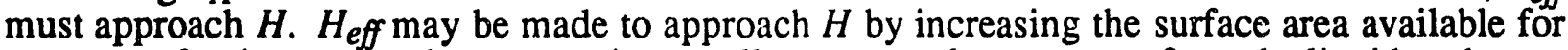
mass transfer, increasing the contact time to allow more solute to move from the liquid to the gas phase, or to increase the mass transfer driving force (this depends upon the amount of back mixing and whether the fluids are contacted in a countercurrent or cocurrent fashion).

Using fluid phase flow rates as reported by B. Herrling (1992) $\left(82 \mathrm{~m}^{3} / \mathrm{h}\right.$ at 1 atm and $298 \mathrm{~K} ; 5$ $\mathrm{m}^{3} / \mathrm{h}$ of water) and the equilibrium Henry's law constant, equation (3.6) predicts that under ideal conditions (negligible mass transfer and dispersion), one pass through the stripper removes $90 \%$ of the contaminants. Thus under equilibrium conditions, two passes are required to remove 99 percent of the contaminants. Gvirtzman \& Gorelich (1992), assuming similar flow patterns and conditions and overestimating mass transfer resistance, indicated that approximately 10 passes through the stripper would be required to remove greater than 99 percent of TCE from the aquifer plume. Efficient removal of contaminants becomes very important when low recirculation flow rates are taken into account.

\subsubsection{Geochemical Precipitates}

Precipitation can occur as a result of the chemical and biological characteristics of aquifers and as a result of changes caused by recirculation and treatment. Precipitates are may foul equipment, reduce the permeability of the well-aquifer interface and/or the aquifer sediments themselves. Precipitates can adversely impact operation and performance, resulting in higher maintenance and operating costs. The objective of this section is to investigate some possible precipitates formed as a result of recirculation processes and to investigate ways of preventing their formation. 


\subsubsection{Methods}

Precipitate formation is a function of available reactants, $\mathrm{pH}$, and redox conditions. An extensive compilation of possible reactions, published as Pourbaix diagrams (Garrels \& Christ, 1965; Stumm \& Morgan, 1970; Guenther, 1975) may be utilized for analysis. Pourbaix diagrams may also be produced by plotting individual reactions as a function of $\mathrm{pH}$ and $\mathrm{Eh}$. Observation of the Gibbs free energy for various reactions indicate equilibrium conditions when subsurface conditions are changed; however, reactions may proceed at greatly varying rates. Subsurface bacteria may also make the system dynamic, that is shift ionic species by using native substances as substrates. Thus, the presence or absence of various ionic compounds depends on a number of factors including the $\mathrm{pH}$, reducing conditions, subsurface microbiology, and subsurface environmental changes. Specific reactions of iron compounds with associated Gibbs free energy values are listed in Appendix C.

\subsubsection{Results}

Pourbaix diagrams indicate dominant species as a function of $\mathrm{pH}$ and $\mathrm{Eh}$. Decreasing $\mathrm{pH}$ values indicate that an aqueous system is becoming more acidic. Decreasing Eh values indicate that the system is becoming more reductive. Precipitate formation rates depend on a number of variables and may be difficult to predict.

Stable native iron oxides are $\mathrm{Fe}_{2} \mathrm{O}_{3}$ (hematite) and $\mathrm{Fe}_{3} \mathrm{O}_{4}$ (magnetite). Iron compounds are common in aquifers and may be a significant source of precipitates. For example, $\mathrm{Fe}^{2+}$ concentrations in the groundwater at the Kansas City Plant varied from 0.2 to $40 \mathrm{mg} / \mathrm{L}$ in a study by Korte (1989).

It is important to consider the effect of stripping with various gases because stripping and aquifer gases will exchange. Addition of an oxidizer will drive the system to higher Eh values causing $\mathrm{Fe}_{2} \mathrm{O}_{3}$ to precipitate. For example, stripping with air might increase the Eh value of an anoxic aquifer because oxygen absorbs from the stripping fluid into the aquifer water. Exchange of carbon dioxide between the aquifer and the stripping gas will shift the aquifer $\mathrm{pH}$ (Appendix $\mathrm{C}$ ).

Aquifer $\mathrm{pH}$ and Eh values depend on the natural buffering tendency of the aquifer, levels and types of microbial activity, age of the aquifer water, and recharge water characteristics. Respective ranges of $\mathrm{pH}$ and Eh values at DOE sites typically vary from 4 to 9 and - 200 to + $200 \mathrm{mV}$ (Phelps, 1993). Figures 3.9 through 3.11 show the effect of carbonate and dissolved sulfur concentrations on the formation of iron carbonates, sulfides, and oxides. Carbonate is formed by the absorption of carbon dioxide in water. Carbonate concentrations is also a function of calcium ion concentration. Sulfide is a common ion and maybe found at high concentrations.

The Pourbaix plots indicate that, if ferrous ion is present, changes in $\mathrm{pH}$ and Eh may quickly shift the iron species from a soluble to insoluble state. Several gases and combination of gases are possible for stripping. Use of air for stripping relatively anoxic aquifer water will shift the Eh toward more oxidizing conditions by increasing oxygen concentrations. An increase in Eh value tends to shift ferrous species from a soluble to an insoluble state. Stripping of carbon dioxide from the aquifer would shift the $\mathrm{pH}$ upward, pushing the equilibrium toward more insoluble ferrous species. An alternative to using fresh air for stripping would be to recycle the aquifer gases for stripping (including a purge stream). This recycle option would tend to shift the equilibrium less and might tend to mitigate precipitation. Use of nitrogen or other inert gas would tend to strip carbon dioxide from the aquifer but might shift the aquifer toward more anoxic conditions that might reduce the quality of the aquifer. 
In summary, Pourbaix plots indicate that changes in $\mathrm{Eh}$ and $\mathrm{pH}$ may significantly increase precipitate formation, resulting in premature fouling of equipment and the well-aquifer interface. Recycling of the stripping gas (with a purge stream) might be effective in reducing detrimental precipitates caused by recirculation processes. 


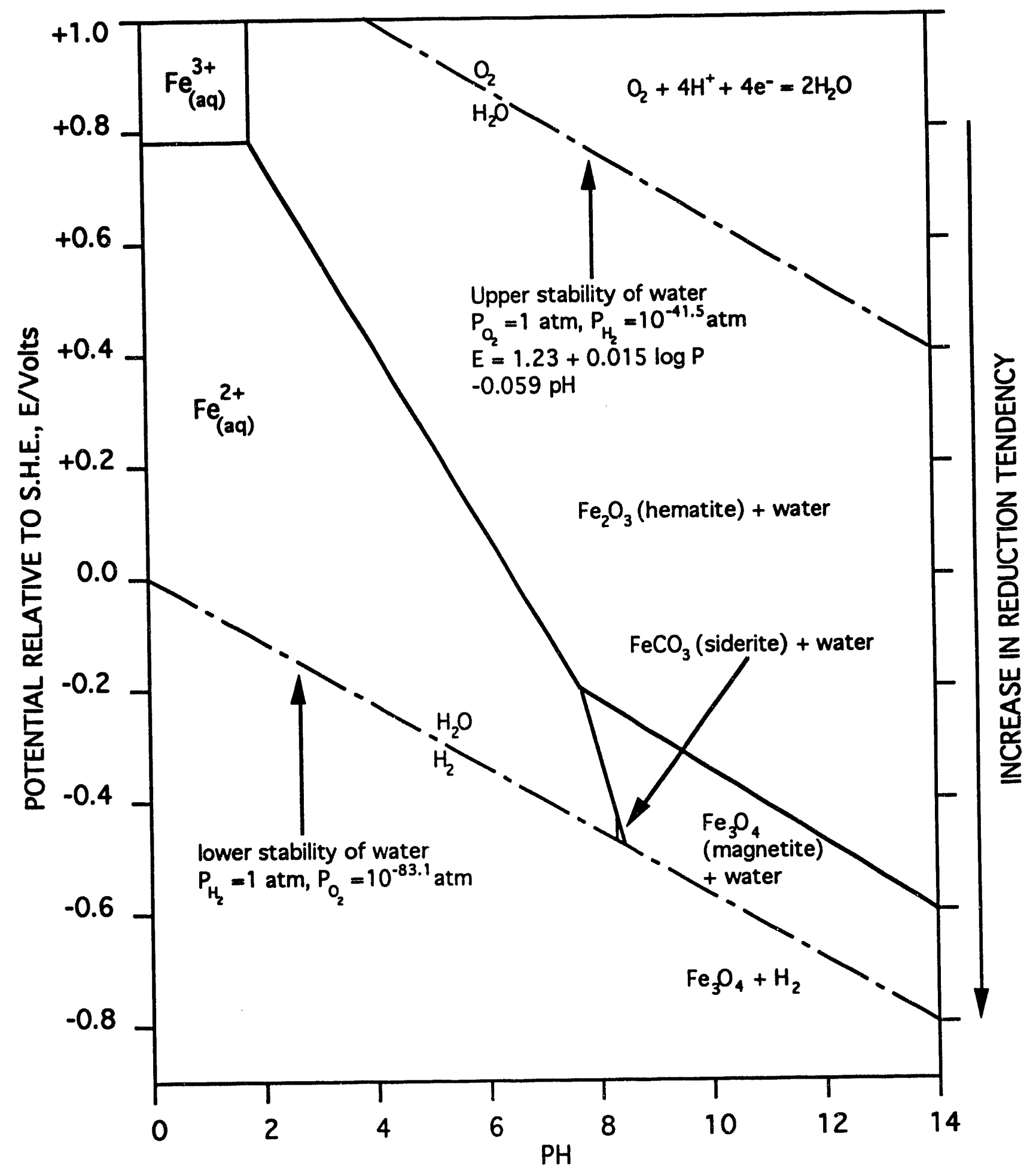

Fig. 3.9. Predominance of hematite, magnetite, and siderite in aqueous solution under equilibrium conditions containing total dissolved carbonate species of $10^{-3} \mathrm{M}$ at $25^{\circ} \mathrm{C}$ and $1 \mathrm{~atm}$. (ORNL Drawing 93-10205) 


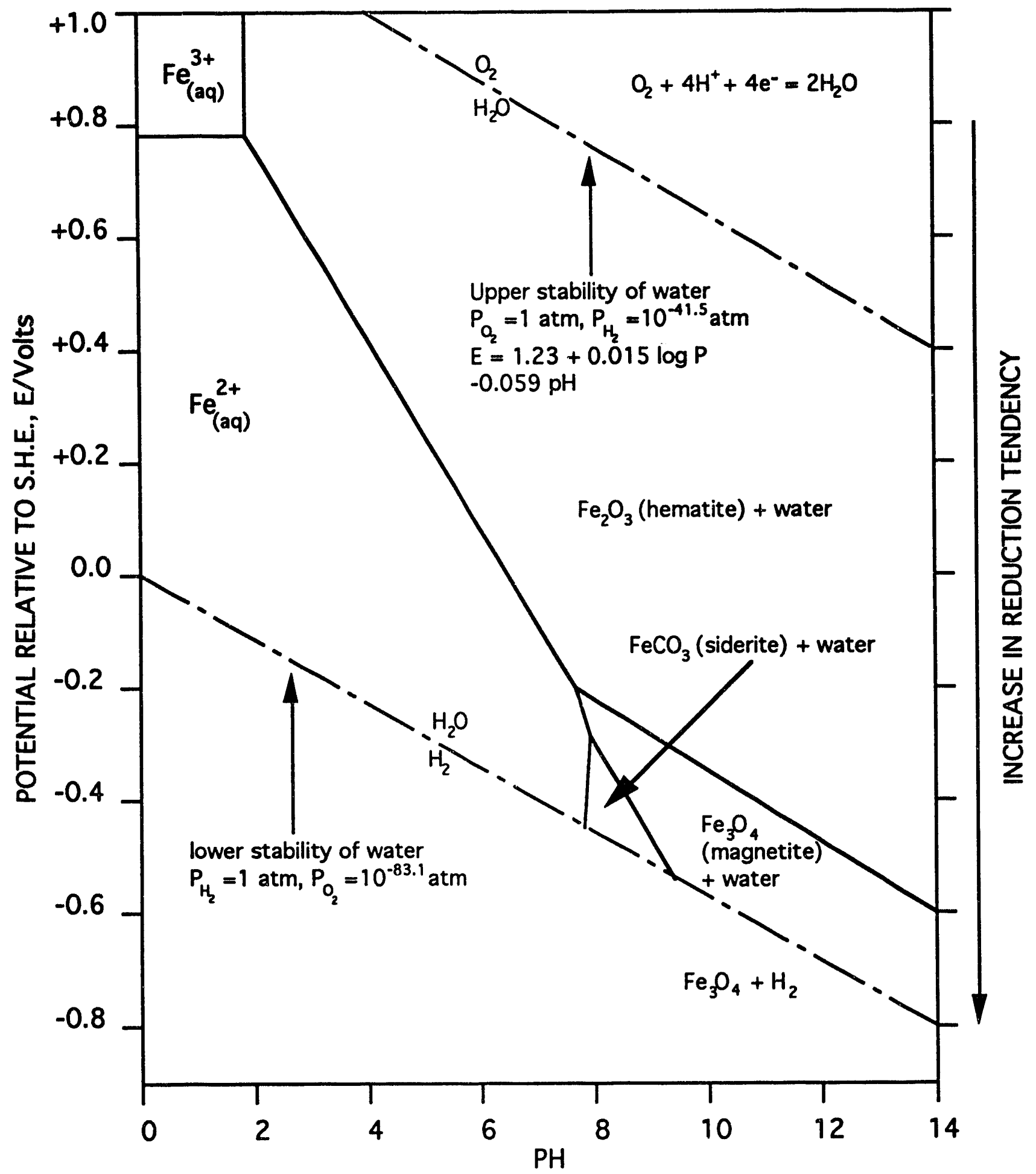

Fig. 3.10. Predominance of hematite, magnetite, and siderite in aqueous solution under equilibrium conditions containing total dissolved carbonate species of $10^{-2} \mathrm{M}$ at $25^{\circ} \mathrm{C}$ and $1 \mathrm{~atm}$. (ORNL Drawing 93-10206) 


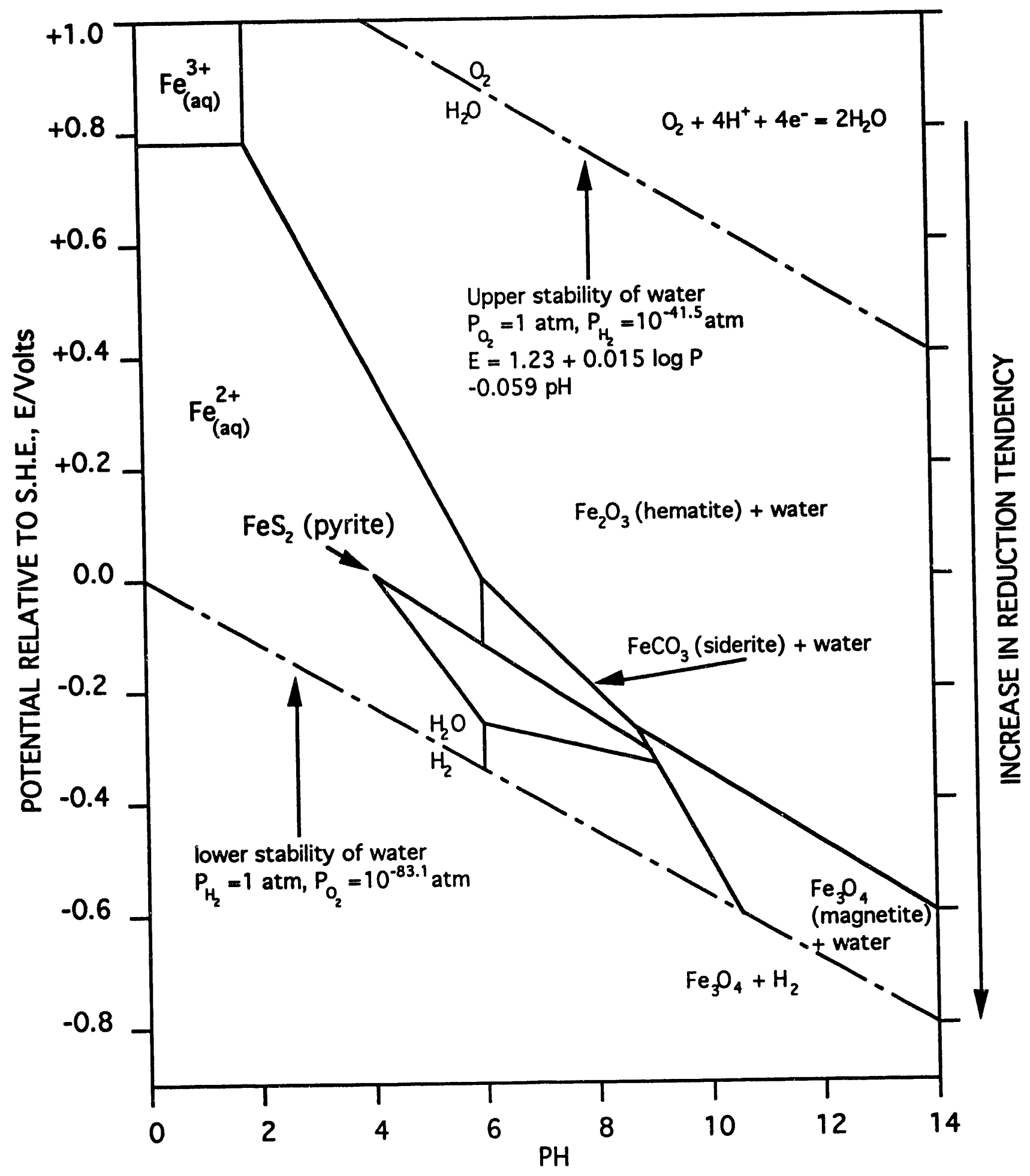

Fig. 3.11. Predominance of hematite, magnetite, and siderite in aqueous solution under equilibrium conditions containing total dissolved carbonate of 1.0 molar, dissolved sulfide at $10^{-6} \mathrm{M}$, at $25^{\circ} \mathrm{C}$ and $1 \mathrm{~atm}$. (ORNL Drawing 93-10207) 


\subsection{PROCESS MODIFICATIONS}

\subsection{INTRODUCTION}

The assessment of process operation and performance for the in situ recirculation processes suggested some potential modifications as described in this section.

\subsection{IMPROVING VOC TREATMENT EFFICIENCY}

\subsubsection{Improving Stripper Efficiency with a Countercurrent Flow Pattern}

\subsubsection{Methods}

The removal of dissolved gases and volatile compounds from water by air stripping is a proven and reliable method, widely practiced by industry and in municipal water treatment plants. The EPA has identified air-stipping as one of the best available technologies for the removal of VOCs from water (EPA, 1984). The efficiency of VOC removal by air stripping in the UVB/GZB depends on the contacting pattern, interfacial mass transfer area, and solute partitioning between aqueous and vapor phases. The case of countercurrent flow is discussed to illustrate improvements in efficiency by changing gas and liquid phase contact.

Values of Henry's Constant in the literature are usually reported in atm- $\mathrm{m}^{3} / \mathrm{mol}$. Experimentally, the Henry's constant is determined by

$$
p_{i}=H_{c} \frac{c_{i}}{M_{i}}
$$

In dimensionless form, Henry's constant is represented by the equation

$$
y_{i}=H x_{i}
$$

Dividing equation (4.1) by equation (4.2) gives

$$
\frac{p_{i}}{y_{i}}=\frac{H_{c} c_{i}}{H M_{i} x_{i}}
$$

It can be shown that for dilute systems the dimensionless Henry's Law constant is related to the dimensional Henry's Law constant by

$$
H=\frac{H_{c} \rho}{P M_{1} 10^{-6}}
$$

For TCE, $H_{C}=0.0117 \mathrm{~m}^{3}$-atm $/ \mathrm{gmol}$ (Fang \& Khor, 1989). Substituting this value in equation (4.4) yields $H=649.4$. Values of Henry's constant calculated in this manner and those reported in the literature (Fang \& Khor, ibid.) are tabulated in Table 4.1.

Stripper size and air flow requirements are determined from material balances and the solute Henry's Law constant. Fig. 4.1 depicts a stripper with entering and exiting streams. The air 
stream at any point in the stripper consists of $V$ total mol s-1 $\mathrm{m}^{-2}$ and the contaminant. The liquid phase is made up of made up of $V_{s}$ mol s-1 $\mathrm{m}^{-2}$ and dissolved contaminant. Contaminant concentrations are given in either mole fraction or mole ratio. The relation between mole ratio and mole fraction is

$$
\begin{aligned}
& X_{1}=\frac{x_{1}}{1-x_{1}} ; \quad X_{2}=\frac{x_{2}}{1-x_{2}} ; \\
& Y_{1}=\frac{y_{1}}{1-y_{1}} ; \quad Y_{2}=\frac{y_{2}}{1-y_{2}}
\end{aligned}
$$

Substitution of equation (4.5) in equation (4.2) along with the Henry's constant for TCE yields

$$
\frac{Y}{1+Y}=649.5 \frac{X}{1+X}
$$

The TCE balance about the lower part of the tower in Fig. 4.1 is

$$
V_{s}\left(Y_{1}-Y\right)=L_{s}\left(X_{1}-X\right)
$$

Equations (4.6) and (4.7) determine the equilibrium and operating lines for the stripper. The contaminated water flow rate $L_{S}$, the mole ratio of TCE in water entering the stripper, $X_{2}$ and the mole ratio of TCE in fresh air, $Y_{1}$ are known quantities. The mole ratio of TCE in the treated liquid is arbitrarily set. The equilibrium effluent air concentration is related to the entering liquid phase concentration by Henry's Law. The minimum amount of stripping gas, $V_{2}$, , may be determined because all quantities in equation (4.7) except the solute free air flow rate are known. The minimum air flow rate is the amount required to remove solute under equilibrium conditions. The actual amount of air for which the stripper is designed is taken to be eight times the minimum flow rate. In the UVB/GZB process, the amount of air used is about 6 times the minimum flow rate (Herrling, personal communication, 1992).

The required contact time for the process is dictated by Henry's constant, the sparger configuration, and flow rates. Convenient chemical engineering units that relate contact time to physical dimensions are the number of transfer units $N_{t o L}$ and the height of a transfer unit $H_{t o L}$. 
Table 4.1. Henry's Law constants for selected VOCs at $25^{\circ} \mathrm{C}$.

\begin{tabular}{llll}
\hline & \multicolumn{3}{c}{ Henry's Law constant } \\
\cline { 2 - 4 } Target VOC & $\begin{array}{l}\text { Literature } H_{c}{ }^{\mathrm{a}} \\
\left(\mathrm{m}^{3} \text {-atm/gmol) }\right.\end{array}$ & $\begin{array}{l}\text { Literature } H_{c}{ }^{\mathrm{a}} \\
\text { (dimensionless) }\end{array}$ & $\begin{array}{l}\text { Computed } H \text { b } \\
\text { (dimensionless) }\end{array}$ \\
\hline Trichloroethylene & 0.0117 & 649.5 & 649.4 \\
1,1-Dichloroethane & 0.00577 & 320.3 & 320.3 \\
Toluene & 0.00688 & 370.8 & 381 \\
Methyl ethyl ketone & $2.97 \times 10^{-5}$ & 1.64 & 1.64 \\
Chloroform & 0.00385 & 213.7 & 214 \\
1,1,2-Trichloroethane & $9.11 \times 10^{-4}$ & 50.6 & 50.6 \\
Benzene & 0.00549 & 304.7 & 305 \\
o-Xylene & 0.00527 & 292.5 & 292 \\
p-Xylene & 0.00664 & 368.6 & 369 \\
Vinyl chloride & 0.199 & 4,680 & $11046 \mathrm{c}$ \\
Carbon tetrachloride & 0.0286 & 944.8 & $1587 \mathrm{c}$ \\
1,1,1-Trichloroethane & 0.030 & 991.1 & $1665 \mathrm{c}$ \\
\hline
\end{tabular}

a Henry's Constant values reproduced from C. S. Fang \& Khor, S-L., Environmental Progress, Vol. 8, No. 4, November 1989, pp. 270-278.

b Values calculated in this work (equation 4.3).

c Values calculated in this work that are not in agreement with those reported in Fang \& Khor, 1989. 


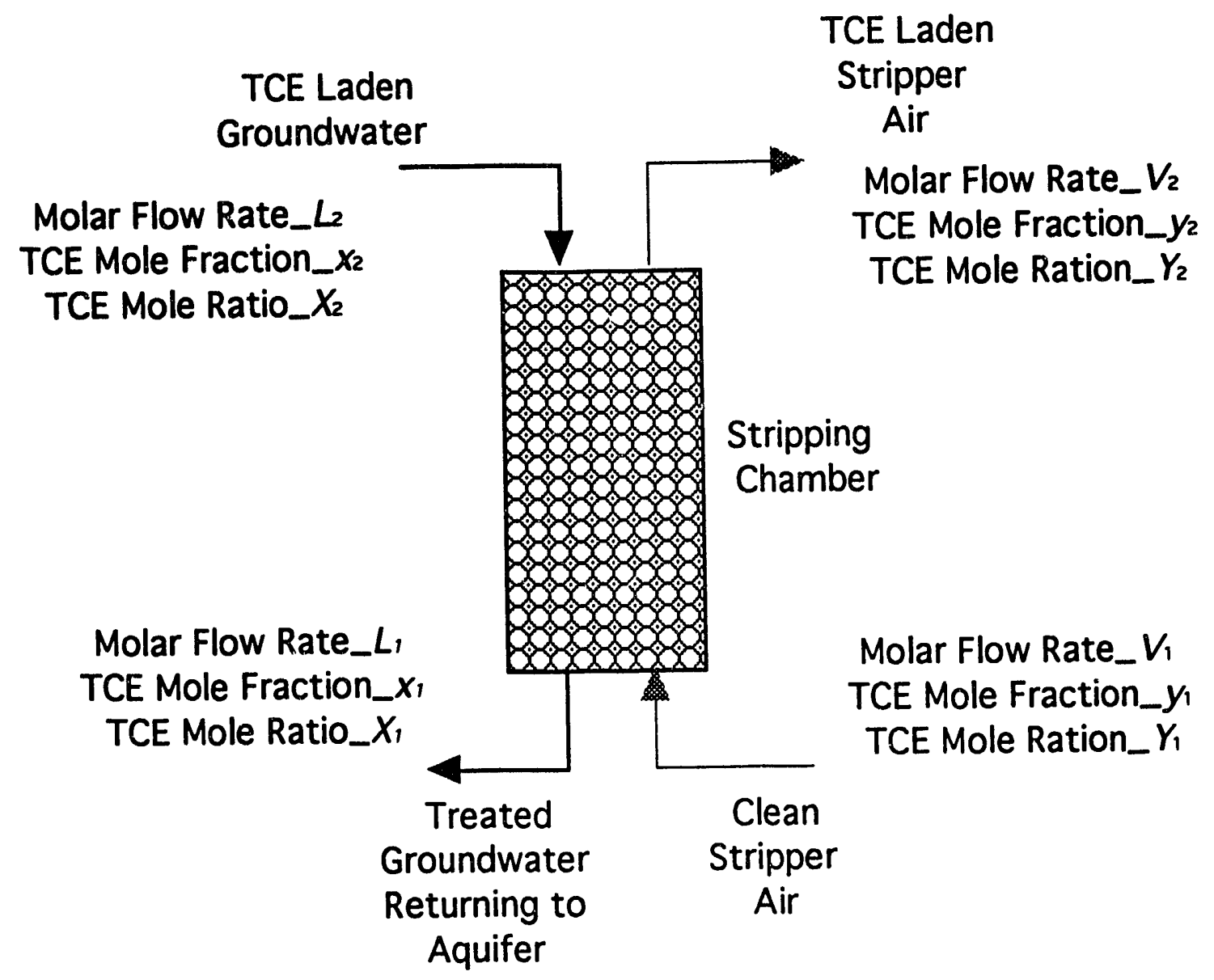

Fig. 4.1. Diagram of a countercurrent air stripper. (ORNL Drawing 93-10208) 
The $\mathrm{N}_{\text {toL }}$ is defined as

$$
N_{c L L}=\frac{\ln \left[\alpha+(1-\alpha) \frac{x_{2}-y_{1} / H}{x_{1}-y_{1} / H}\right]}{1-\alpha}
$$

where, $\alpha=L_{s} /\left(V_{s} H\right)$. The height of a transfer unit is defined as

$$
H_{t a L}=\frac{L_{s}}{F_{L} a_{m t}}
$$

Low $H_{t o L}$ and $N_{t o L}$ values are preferred because they determine capital and energy costs. The size of the stripper depends upon the number of transfer units, $N_{t o L}$ as well as the height of each transfer unit, $H_{t o L}$. The overall liquid-phase mass transfer resistance generally controls mass transfer in liquid-gas systems. The liquid-phase coefficient may be estimated to within $15 \%$ by using the empirical correlation by Hughmark (1967)

$$
S h_{L}=\frac{F_{L} d_{p}}{c_{A} D_{A B}}=2+0.0187\left(\operatorname{Re}_{g}\right)^{0.779} S c_{L}^{0.546}\left[\frac{d_{p} g^{1 / 3}}{D_{A B}^{2 / 3}}\right]^{0.116}
$$

The gas Reynolds number and Schmidt number respectively are

$$
\begin{aligned}
& \operatorname{Re}_{8}=\frac{d_{p} V_{s} \rho_{l}}{\mu_{l}} \\
& S c_{L}=\frac{\mu_{L}}{\rho_{L} D_{A B}}
\end{aligned}
$$

For dilute solutions, $c_{A}$ is approximately that of water $\left(55.506 \mathrm{kmol} / \mathrm{m}^{3}\right)$. The liquid side mass transfer coefficient, $F_{L}$ can then be estimated from equation (4.9) and (4.10) using flow conditions and physical properties of the solution. The interfacial area for mass transfer depends upon the air distribution in the stripper. We assume that the distribution of fresh air is achieved through a circular sparger, $25 \mathrm{~cm}$ in diameter, containing 50 holes (orifices $d_{o}=3 \mathrm{~mm}$ ). This configuration is based on spargers used in industry. For $10,000<R e_{0}<50,000$, the jets of air that rise from the orifice break into bubbles, with the bubble diameter given by Liebson et al. (1956)

$$
d_{p}=0.0071 \operatorname{Re}_{0}^{-0.05}
$$

where

$$
\operatorname{Re}_{o}=\frac{4 W_{o}}{\pi d_{o} \mu_{a}}
$$


The gas holdup is the volume fraction of the gas-liquid mixture in the vessel that is occupied by the gas. If a gas-liquid mixture contains a gas volume $\varphi_{G} V$ made up of $n_{G}$ bubbles of diameter $d_{p}$, then

$$
n_{G}=\frac{6 \varphi_{G} V}{\pi d_{p}^{3}}
$$

The interfacial area for mass transfer is then

$$
a_{m t}=n_{G} \pi d_{p}^{2} .
$$

Equating the two equations for $n_{G}$ provides the requisite expression for the interfacial mass transpurt area

$$
a_{m t}=\frac{6 \varphi_{G} V}{d_{p}}
$$

The gas holdup, $\varphi_{G}$, must be evaluated before the interfacial mass transfer area can be determined from equation (4.17).

If the superficial gas velocity, defined as the volume rate of gas flow divided by the crosssectional area of the vessel, is $V_{G}$, then $V_{G} / \varphi_{G}$ can be taken as the true gas velocity relative to the vessel walls. The holdup for sparged vessels is graphically represented by Hughmark (1967) with $V_{G}$ as the abscissa, $V_{G} / V_{S}$ as the ordinate, and the vessel diameter as a parameter. The fresh air flow rate and vessel diameter $(0.4 \mathrm{~m})$ are known for the UVB/GZB process, $V_{S}$ can then be determined from Hughmark (1967). The gas holdup $\varphi_{G}$ is obtained from the roots of the equation 4.18 (Treybal, 1980)

$$
V_{s} \varphi_{G}^{2}-\left(V_{G}+V_{s}+V_{L}\right) \varphi_{G}+V_{G}=0
$$

The interfacial area is approximated by substituting values of $\varphi_{G}$ and $d_{p}$ in equation (4.17).

The diffusion coefficient of TCE in water at $25^{\circ} \mathrm{C}$ is estimated from the Wilke-Chiang method (Reid et al., 1977)

$$
D_{T C E-\text { Water }}=7.4 \times 10^{-8} \frac{\left(\phi M_{\text {water }}\right)^{1 / 2} T}{\mu_{\text {water }} V_{T C E}^{0.6}} .
$$

The diffusion coefficient of TCE in water from equation (4.19) is typically $1.1 \times 10^{-9} \mathrm{~m}^{2} / \mathrm{s}$.

The overall liquid side mass transfer coefficient $F_{L}$ is approximated from equations (4.10). Typical values of $F_{L}$ are $0.027 \mathrm{kmol} \mathrm{m}^{-2} \mathrm{~s}^{-1}$. 
To allow for the passage of the required amount of fresh air into the stripping section, the pressure drop between the atmosphere and the top section of the stripper must be less than the critical pressure drop. The critical pressure relates pressure drop to air flow. If the pressure at the pipe exit is lower than the critical pressure, then the mass flux of air will be less than the specified amount. The critical pressure is given by

$$
P_{c}^{2}=\frac{G^{2} R T}{M_{i} g_{c}}
$$

The value of the critical pressure is utilized to back calculate the length of pipe that corresponds to the critical pressure from the expression

$$
\frac{2 f L_{\text {max }}}{D_{\text {pipe }}}+0.5=\ln \left(\frac{P_{c}}{P_{1}}\right)+0.5\left(\frac{P_{1}}{P_{c}}\right)^{2}
$$

The Fanning friction factor is taken to be 0.018 . The check is to ensure that the length of pipe chosen is less than $L_{\max }$, calculated from equation (4.21).

The pressure drop in the fresh air pipe is calculated from

$$
\frac{0.5 g_{c} M_{a}}{G^{2} R T}\left(P_{2}^{2}-P_{1}^{2}\right)+\ln \left(\frac{P_{1}}{P_{2}}\right)+\frac{2 f L}{D_{\text {pipe }}}=0
$$

by trial and error, assuming a initial value of $P_{1}$ and iterating until $P_{1}$ converges within the prescribed tolerance.

The pressure at the well head is equal to the atmospheric pressure minus the sum of the pressure drops in the fresh air pipe and the column of water in the stripper. This well head pressure must be greater than the critical pressure $P_{c}$ :

$$
P_{c}=\frac{p g h}{g_{c}}
$$

\subsubsection{Resuits}

Simulated Case Studies - 5 ppm TCE in water, 99\% removal. Consider a simulated case in which $99 \%$ of TCE is removed from contaminated water initially containing $5 \mathrm{ppm}$ TCE. The borehole and fresh air pipe are $40 \mathrm{~cm}$ and $5 \mathrm{~cm}$ in diameter, respectively (Table 4.2). Air flow rate is estimated at $82 \mathrm{~m}^{3} / \mathrm{h}$ (atmospheric pressure, $298 \mathrm{~K}$ ). The critical pressure is $3.89 \mathrm{kPa}$ (0.564 psia) with the pressure in the well head at $89.1 \mathrm{kPa}(12.93 \mathrm{psia})$. As mentioned in the preceding, the pressure in the well head must be greater than the critical pressure to avoid creating a shock wave that would result in a rapid decrease in air mass flow rate through the pipe. The interfacial area and the overall mass transfer coefficient are estimated to be $332 \mathrm{~m} / \mathrm{m}^{3}$ and $0.0168 \mathrm{kmol} \mathrm{m}^{-2} \mathrm{~s}^{-1}$, respectively. A stripping height of at least $0.563 \mathrm{~m}$ is needed and because the total stripping height is taken to be $1.2 \mathrm{~m}$, it exceeds the required height. 
Table 4.2. Effect of changing fresh air pipe diameter on stripping processes. ${ }^{a}$

\begin{tabular}{|c|c|c|c|c|}
\hline \multirow[b]{2}{*}{ Parameter } & \multirow[b]{2}{*}{ Units } & \multicolumn{3}{|c|}{ Fresh air inlet pipe diameter in $\mathrm{cm}$ (in.) } \\
\hline & & $\begin{array}{c}2.0 \\
(0.8) \\
\end{array}$ & $\begin{array}{c}2.5 \\
(1.0) \\
\end{array}$ & $\begin{array}{c}5.0 \\
(2.0) \\
\end{array}$ \\
\hline Pressure drop in pipe & $\underset{(\mathrm{psia})}{\mathrm{kPa}}$ & $\begin{array}{l}67.3 \\
(9.76)\end{array}$ & $\begin{array}{l}15.0 \\
(2.18)\end{array}$ & $\begin{array}{c}3.89 \\
(0.06)\end{array}$ \\
\hline Pressure at well head & $\begin{array}{c}\mathrm{kPa} \\
\text { (psia) }\end{array}$ & $\begin{array}{l}22.3 \\
(3.23)\end{array}$ & $\begin{array}{c}74.5 \\
(10.8)\end{array}$ & $\begin{array}{r}89.1 \\
(12.9)\end{array}$ \\
\hline Interfacial mass transfer area & $\mathrm{m}^{2} / \mathrm{m}^{3}$ & 534 & 359 & 332 \\
\hline $\begin{array}{l}\text { Overall liquid side mass } \\
\text { transfer coefficient }\end{array}$ & $\mathrm{mole} / \mathrm{m}^{2}$ & 27.2 & 17.9 & 16.8 \\
\hline Required stripper height & $\mathrm{cm}$ & 22 & 48 & 56 \\
\hline
\end{tabular}

a The estimated process parameters that are affected by changing the fresh air pipe diameter are (1) trichloroethylene feed concentration is $5 \mathrm{ppm}$., (2) trichloroethylene removal is 99 percent, (3) minimum gas flow rate is $3330 \mathrm{~mol} / \mathrm{m}^{2}-\mathrm{h}$, (4) fresh air flow rate is $82 \mathrm{~m}^{3} / \mathrm{h}$, (5)liquid feed rate is $5 \mathrm{~m}^{3} / \mathrm{h}$, (6) diffusion coefficient of trichloroethylene in water is $1.07 \mathrm{E}-5 \mathrm{~cm}^{2} / \mathrm{s}$, (7) pipe is submerged $1.2 \mathrm{~m}$ below working water level.

Table 4.3. Effect of changing trichloroethylene liquid feed concentration on required stripping height. $^{\text {a }}$

Parameters

Stripping parameters to yield \% removal shown

99\% TCE removal $\quad 99.975 \%$ TCE removal

Required stripper height (cm)

60

108

Trichloroethylene effluent liquid phase mole fraction

$2.74 \times 10^{-7}$

$6.89 \times 10^{-9}$

Trichloroethylene effluent vapor phase mole fraction

Note: The estimated process parameters that are affected by changing the liquid trichloroethylene feed concentration are (1) trichloroethylene feed concentration is 200 parts per million, (2) minimum gas flow rate is $3150 \mathrm{~mol} / \mathrm{m}^{2}-\mathrm{h}$, (3) fresh air flow rate is $78 \mathrm{~m}^{3} / \mathrm{h}$, (4) pressure drop in pipe is $0.4 \mathrm{kPa}$, (5) pressure at well head is 89 $\mathrm{kPa}$, (6) liquid feed rate is $5 \mathrm{~m}^{3} / \mathrm{h}$, (7) diffusion coefficient of trichionethylene in water is $1.07 \mathrm{E}-5 \mathrm{~cm}^{2} / \mathrm{s}$, (8) pipe is submerged $1.2 \mathrm{~m}$ below working water level, (9) interfacial mass transfer area is $324 \mathrm{~m}^{2} / \mathrm{m}^{3}$, (10) the overall mass transfer coefficient is $16.4 \mathrm{~mol} / \mathrm{m}^{2}$, (11) fresh air pipe ID is $5.0 \mathrm{~cm}$ inside diameter. 
If the diameter of the fresh air pipe is decreased from 5.0 to $2.5 \mathrm{~cm}$, the critical pressure increases to $15.6 \mathrm{kPa}$ (2.26 psia) and the well head pressure decreases to $74.5 \mathrm{kPa}$ (10.8 psia) for the same mass flow rate of air $\left(82 \mathrm{~m}^{3} / \mathrm{h}\right.$ at $1 \mathrm{~atm}, 298 \mathrm{~K}$ ) (Table 4.2$)$. The interfacial area and overall liquid-side mass transfer coefficient are $359 \mathrm{~m}^{2} / \mathrm{m}^{3}$ and $0.01791 \mathrm{kmol} \mathrm{m}^{-2} \mathrm{~s}^{-1}$, respectively. The slight changes in the interfacial area and mass transfer coefficient are in part due to the influence of a lower well head pressure on the bubble sizes. Because of slightly improved mass transfer characteristics, the required height of the stripper reduces from $0.56 \mathrm{~m}$ to $0.49 \mathrm{~m}$. Despite this slight improvement, the $2.5 \mathrm{~cm}$ fresh air pipe should not be the preferred alternative because the duty on the ventilator or the vacuum system will increase and because lowering the stripper height from $0.56 \mathrm{~m}$ to $0.49 \mathrm{~m}$ is of no benefit because the stripping section is taken as $1.2 \mathrm{~m}$.

If the diameter of the fresh air pipe is further decreased to $2.1 \mathrm{~cm}$, the critical pressure increases to $23.7 \mathrm{kPa}$ (3.44 psi) and the pressure in the well head decreases to $22.3 \mathrm{kPa}$ (3.23 psia) (Table 4.2). This is a case where the pressure in the well head is slightly lower than the critical pressure and is an example of a limiting case in which the required amount of air probably will not be delivered to meet the stripping requirements. However, Table 4.2 shows how the other process variables may be affected, particularly the interfacial area and the overall liquid side mass transfer coefficient, both of which increase as a result of the influence of pressure on the hydrodynamic flow conditions. The stripper height consequently decreases. Even though a stripper height is considerably reduced, a 1 in pipe should be ruled out because of the vacuum demands on the system. At this point the vacuum is removing water vapor and is not assisting in remediation. Decreasing the stripping height in this case is not crucial, whereas the pressure in the well head is.

Simulated Case Studies - 200 ppm TCE, 99 to 99.975\% removal. It is possible that at some DOE sites, TCE concentration in water may be higher than $5 \mathrm{ppm}(\mathrm{mg} / \mathrm{L})$. To examine the effect of higher concentrations on the UVB/GZB process variables, a hypothetical case of $200 \mathrm{ppm}$ TCE contamination is considered (Table 4.3). The extent of TCE removal is $99 \%$, the same as in the previous case. The actual air flow rate required is $78 \mathrm{~m}^{3} / \mathrm{h}$ at $1 \mathrm{~atm}, 298 \mathrm{~K}$. If the diameter of the fresh air pipe is $5.1 \mathrm{~cm}$, the critical pressure and the pressure at the well head are $3.68 \mathrm{kPa}$ (0.534 psia) and $89 \mathrm{kPa}$ (12.93 psia), respectively. Note that the critical and well head pressures are similar to the previous cases when the air flow rate was $82 \mathrm{~m}^{3} / \mathrm{h}$. The critical pressure and the well head pressure are dependent on the air flow rate and independent of the TCE concentration in the dilute solution range where Henry's constant is applicable. The interfacial area and the overall liquid side mass transfer coefficient are estimated as, $324 \mathrm{~m}^{2} / \mathrm{m}^{3}$ and $0.01635 \mathrm{kmol} / \mathrm{m}^{2}$, both are which are comparable to the previous case for $5 \mathrm{ppm}$ contamination.

Removing 99\% TCE from contaminated water initially containing $200 \mathrm{ppm}$ means that the residual TCE in water is still going to be $2 \mathrm{ppm}$, which may be above regulatory standards. Therefore, if the extent of removal is $99.975 \%$, the mole fraction of TCE in the cleaned water will be $6.86 \times 10^{-9}$ mole fraction, which is in the part per billion range. To consider what effect 99.975\% removal might have on the UVB/GZB process variables, consider Table 4.3. The actual gas flow rate remains the same at $78 \mathrm{~m}^{3} / \mathrm{h}$ as expected because it is practically independent of the TCE concentration in the range where Henry's law is applicable. The values for critical pressure, the pressure at the well head, interfacial area and overall liquid-side mass transfer coefficient are also similar. However, the height of the stripping section is approximately $108 \mathrm{~cm}$, almost double in value relative to the case of $5 \mathrm{ppm}$ contamination. This rapid increase in stripping height is the penalty for removing trace amounts of TCE. However, it should also be noted that increasing the TCE contamination from $5 \mathrm{ppm}$ to $200 \mathrm{ppm}$, an increase of 40 times, resulted in an increase of stripper height of only a factor of 2. 


\subsubsection{An Alternate Off-gas VOC Treatment Method}

When VOCs such as TCE partition from the water to the vapor phase, they must be removed from the air exiting the well head before the air is vented into the atmosphere. The UVB/GZB process uses activated carbon adsorption to remove the TCE fraction from the air. Use of activated carbon for this and similar adsorption process is an established albeit expensive technique The expense is caused by the subsequent processing required to rejuvenate the carbon in adsorption beds. For this reason, the removal of TCE by adsorption remains the most expensive step in the UVB/GZB process. In this report, an alternate recovery process is suggested that is based on TCE removal by refrigeration. This process may be cheaper and produce a much smaller amount of residual waste for final disposal. It has the potential for recovering TCE in a relatively pure form.

In the UVB/GZB process approximately $50 \mathrm{~m}^{3} / \mathrm{h}$ of air is used to strip TCE from $5 \mathrm{~m}^{3} / \mathrm{h}$ of recirculated water within the aquifer. The mole fraction of TCE in the gaseous mixture exiting the well head might typically vary between $10^{-5}$ to $10^{-3}$. In addition to the TCE in the exiting air, a substantial quantity of water vapor also is present as a result of the intrinsic humidity and the effect of bubbling air through the stripping section. Therefore, it is a valid assumption to consider the exiting air from the well head to be saturated with water vapor, for calculation purposes.

The exiting well head gases in the current UVB/GZB process are taken to fixed beds containing activated carbon to remove TCE by adsorption. When the beds are fully utilized, the desorbed carbon is further processed for reuse. A certain amount of carbon is expended and needs to be replenished with a fresh supply. Reactivating the carbon means removal of the adsorbed TCE by some means, usually steam stripping. This proven method produces another hazardous waste mixture, namely TCE + steam, which ultimately becomes a hazardous mixture of TCE + water when it eventually cools to ambient temperature. This mixture has to be further disposed of in a manner consistent with current laws and regulations. Incineration is another option of spent carbon disposal, but it probably costs more than desorbing with steam. The cost of TCE adsorption with carbon led ORNL to seek possible alternate cost-effective TCE removal and recovery method(s).

A definite improvement in the removal and recovery of TCE would be to find a process that is (1) less complex and costly in terms of capital and operating expenditures than the conventional activated carbon adsorption process, (2) produces a smaller volume of hazardous material for final disposal, (3) operates continuously as opposed to the semi-batchwise adsorption process and (4) recovers TCE in a relatively pure form so that further processing such as separation from water as in the case of steam stripping for activated carbon can be avoided. One possible approach is to utilize cooling rather than adsorption as a method of recuvery. This technique is described in the following.

Removal of TCE from the exiting well head gases is possible by condensation. Because humidity of the exiting air is assumed be $100 \%$, the amount of water in the air can be calculated. The gaseous mixture from the well head (air, water vapor, and TCE) can be cooled such that water vapor is condensed first. Then in a subsequent cooling step, the remaining TCE can be condense. In this way it is hoped that TCE can be removed and recovered in a relatively pure form for reuse or final disposal. Because the quantity of TCE contaminating the water is typically between 5 to $200 \mathrm{mg} / \mathrm{L}$ (ppm), the total quantity of TCE recovered per day $(24 \mathrm{~h})$ is approximately 6 to $24 \mathrm{~kg}$. This represents a small volume of hazardous material for final disposal compared with the large volume (and weight) of the activated carbon bed system. In any case, steam stripping of the desorbed carbon would involve a large quantity of water and the 
volume of contaminated condensed liquid in its 'ffermath will be much larger than that expected to result if cooling were used as an option.

\subsubsection{Methods}

In considering cooling as an alternative riethod for TCE removal and recovery, several important variables need to be specified: (1) the temperatures in each stage of the copling process, (2) an estimate of the magnitude of the individual and overall heat transfer coefficient, (3) the controlling step in the heat transfer process, (4) the quantity of heat to be removed in each stage, (5) the heat transfur surface area required, (6) the overall size of the system, and (7) the nature of the equipment to be used.

\subsubsection{Results}

Because the first step is the total removal cf water, "dry ice" temperatures are adequate to convert water vapor into ice. Dry ice temperature at one atmospheric pressure is about $-78^{\circ} \mathrm{C}$ $(195.15 \mathrm{~K})$. Because the pressures in the system are at or below atmospheric, the thickness of the tubing that carries the gaseous mixture will be small, and because of the high thermal conductivity of metal, its thermal resistance is tuken to be negligible. Hence, the resistance to heat transfer shall reside mainly on the inside (gas side) and outside (metal-cooling medium) interface. The overall heat transfer coefficient, $U$ becomes

$$
\frac{1}{U}=\frac{1}{h_{i}}+\frac{1}{h_{0}}
$$

To calculate $U$, both $h_{i}$ and $h_{o}$ have to be evaluated. The inside heat transfer coefficient is expressed as

$$
N u=\frac{h_{i} D_{C}}{k}=0.023 \operatorname{Re}^{0.8} \operatorname{Pr}^{1 / 3}
$$

If the temperature of the gaseous mixture exiting the well head is taken to be the arithmetic average of the ambient $\left(25^{\circ} \mathrm{C}\right)$ and "dry ice" temperature $\left(-78^{\circ} \mathrm{C}\right)$, the diameter of the tubing to be 2 in, the flow rate of exiting gases to be $82 \mathrm{~m}^{3} / \mathrm{h}$ and the well head pressure to be $10 \mathrm{psi}(6.89 \mathrm{x}$ $10^{4} \mathrm{~Pa}$ ), equation (4.25) yields a value of $h_{i}=40 \mathrm{~W} / \mathrm{ni}^{2} \mathrm{~K}$. The outside film heat transfer coefficient, $h_{o}$ is taken as, $h_{o}=500 \mathrm{~W} / \mathrm{m}^{2} \mathrm{~K}$ (Perry \& Chilton 1973). Combining values of $h_{o}$ and $h_{i}$ according to equation (4.24) gives $U=37 \mathrm{~W} / \mathrm{m}^{2} \mathrm{~K}$. This value of $U$ will be used to estimate the heat transfer surface area, later on.

To get an approximate idea of the temperature at which the TCE may condense out from air, it is important to look at the vapor pressure of TCE as a function of temperature (Table 4.4). The data of Table 4.4 were fit to an equation (Antoine type) of the form, $\ln (P)=A+B / T$, where $P$ is the vapor pressure of TCE in atm, $T$ is the absolute temperature in degrees Kelvin, and $A=$ 11.68959 and $B=-4183.71$ are constants obtained through a least squares curve fit of the above data. The mole fraction of TCE in the exiting air is on the order of $10^{-5}$ to $10^{-3}$ mole fraction. For the p'urposes of this calculatior. if we consider the mole fraction of TCE to be one order of magnitlive lower $\left(10^{-6}\right)$ after treatment, the partial pressure of TCE in the exiting air shall be approximately $10^{-6} \mathrm{~atm}$. Rearranging the Antoine type of equation to $\left.T=B / \ln (P)-A\right]$ gives the temperature corresponding to $10^{-6}$ atm TCE as $164 \mathrm{~K}\left(-109.1^{\circ} \mathrm{C}\right)$. At this temperature, TCE 
would start to condense out from the air, and therefore, this is the minimum temperature to which the air mixture would have to be cooled. An appropriate way to do this is to use liquid nitrogen that has a normal boiling point of $77.4 \mathrm{~K}\left(-195.8^{\circ} \mathrm{C}\right)$. However, before TCE is removed, it is better to remove the water vapor first.

Before the water vapor can be condensed out, the air + TCE mixture exiting the well head has to be cooled from $25^{\circ} \mathrm{C}$ to the freezing point of water. With a $13 \mathrm{~K}$ approach temperature between the gaseous mixture and "dry ice", the quantity of heat removed is

$$
Q_{h}=m C_{p} \Delta T
$$

where $m$ is the mass flow rate of the air + TCE + water vapor mixture. This heat duty is calculated to be $883 \mathrm{~W}$. It is assumed that further cooling of the water vapor to liquefy it does not have to await the mass transport of water from the bulk of the gas to the inside surface of the tubing. In other words, the concentration of water in the gaseous mixture is considered to be high enough so that mass transport is not limiting. If mass transport were limiting then the amount of heat removed from water would be less than $883 \mathrm{~W}$. Assuming $100 \%$ relative humidity, the ratio of the mass of dry air to the mass of wet air from psychometric charts is read as 0.954. Hence, the mass flow rate of water vapor in the exiting well head gaseous mixture is about $4.6 \times 10^{-4} \mathrm{~kg} / \mathrm{s}$. If the latent heat of condensation of water is taken as $1000 \mathrm{Btu} / \mathrm{lbm}(2.3 \times$ $10^{3} \mathrm{~J} / \mathrm{kg}$ ), the heat released by condensation of water is $1084 \mathrm{~W}$. The heat of fusion of water is $335 \mathrm{~J} / \mathrm{g}$. Therefore, the amount of heat removed to freeze the condensed water is $156 \mathrm{~W}$. The surface area required for condensing and freezing water is determined by dividing the heat load by the product of $U$ and $\Delta T$ yielding a value of $0.6 \mathrm{~m}^{2}$.

The mass flow rate of TCE is on the order of $10^{-3} \mathrm{~g} / \mathrm{s}$. Because the mass flow rate of TCE is very small compared with the mass flow rate of air, the latent heat of condensation of TCE is neglected because it will be small compared with the sensible heat. The total sensible heat is calculated as $1.25 \times 10^{3} \mathrm{~W}$. Because the concentration of TCE in air is very small, the rate determining step in condensing TCE is likely to be dependent on the rate at which TCE is transported to the heat transfer surface. In other words, the transport is taken to be diffusion controlled. The diffusion coefficient of TCE in air at an average temperature of $227.6 \mathrm{~K}$ ($45.6^{\circ} \mathrm{C}$ ) is approximated using the Wilke \& Lee (1955) modification of the Hirschfelder et al. (1949) method. The estimated diffusion coefficient of TCE in air at $227.6 \mathrm{~K}$ is $1.73 \times 10^{-5} \mathrm{~m}^{2} / \mathrm{s}$. 
Table 4.4. Vapor pressure of TCE at selected temperatures. ${ }^{\mathrm{a}}$

\begin{tabular}{ccc}
\hline $\begin{array}{c}\text { Temperature } \\
(\mathrm{K})\end{array}$ & \multicolumn{2}{c}{ Vapor pressure of TCE } \\
$(\mathrm{mm} \mathrm{Hg})$ & $(\mathrm{atm})$ \\
\hline 360 & 760 & 1 \\
340 & 400 & 0.5 \\
321 & 200 & 0.26 \\
305 & 100 & 0.13 \\
293 & 60 & 0.79 \\
285 & 40 & 0.053 \\
272 & 20 & 0.026 \\
261 & 10 & 0.013 \\
250 & 5 & 0.0066 \\
229 & 1 & 0.0012 \\
\hline
\end{tabular}

a From Perry, R. H., and C. H. Chilton (editors), Chemical Engineers Handbook. Fifth Edition. McGraw-Hill, p. 3, 1973.

For mass transfer, the Schmidt No., $S c=\mu / D_{A B}$, and the Nusselt No., $N u=K D / D_{A B}$, where $K$ is the mass transfer coefficient, and $D$ is the diameter of the tube through which the TCE and air mixture passes. The correlation for heat transfer in turbulent flow can once again be used for the case of mass transfer if the Nusselt and Schmidt numbers are appropriately defined. From these equations, the value of the mass transfer coefficient, $K=2.4 \times 10^{-4} \mathrm{kmol} \mathrm{m}^{-2} \mathrm{~s}^{-1}$. Because the mole fraction of TCE leaving the well head is $5 \times 10^{-5}$, the mass flux calculated from the relation, $N_{T C E}=K\left(y_{T C E}-0\right) 10^{3}=1.2 \times 10^{-5} \mathrm{~mol} \mathrm{~m}^{-2} \mathrm{~s}^{-1}$. This rate of mass flux is almost equal to the mass flux in the bulk stream flowing perpendicular to it. Therefore, the diffusion of TCE from the bulk stream to the heat transfer surface is not expected to be limiting under turbulent flow conditions. The surface area for removal of TCE is then the sum of the area required to bring TCE to the surface and that required to cool and condense it. The magnitude of this area is $1.6 \mathrm{~m}^{2}$.

The total surface heat exchange area therefore, is $1.6+0.6=2.2 \mathrm{~m}^{2}$. Whether a total surface area of $2.2 \mathrm{~m}^{2}$ is adequate to condense TCE depends upon how close the estimated overall heat transfer coefficient is to the true value. Errors of $30 \%$ are not infrequent. Even in that case, the analysis suggests that the surface requirements are small.

The results from the above calculations are approximations, but they do suggest that it appears reasonable to remove the TCE by cooling to temperatures that are easily made available in the field. Whether or not such a separation can be realized in practice can first be determined through simple laboratory experiments. The technology involved should facilitate scale up and estimation of capital equipment and operating costs. Such a small recovery system will not rely on incineration or combustion, produce residual waste, or need periodic regeneration. 


\subsection{CONCLUSIONS AND RECOMMENDATIONS}

As part of the ITEP within the U. S. DOE Office of Technology Development, efforts were made to identify German technologies of potential near-term benefit to DOE environmental restoration projects. During calendar year 1992, efforts were made by ORNL and its collaborators to identify processes and technologies developed in association with the UoK for enhancing the cleanup of VOC contaminated soil and groundwater at DOE sites. The objectives of this ORNL project were to (1) identify German technologies for in situ recirculation and treatment of groundwater potentially appropriate for demonstration at DOE sites, (2) assess their current performance and identify modifications for use at specific sites, and (3) provide ad hoc technical suppor: to DOE sites for planning and implementing field demonstration and testing activities. Project activities included contacts with researchers within three departments of the UoK (i.e., Applied Geology, Hydromechanics, and Soil and Foundation Engineering) during fall 1991 and subsequent site visits to UoK and private industry collaborators during February 1992. Subsequent analyses consisted of engineering computations, groundwater flow modeling, and treatment process modeling.

Based on the results of the project to date, the following conclusions have been drawn.

1. Two German technologies were identified as having near-term potential for DOE: (1) the vacuum vaporizer well/groundwater recirculation well (German: Unterdruck-VerdampferBrunnen/Grundwasser-Zirkulations-Brunnen, or UVB/GZB) and (2) the porous pipe/horizontal well (PP/HW).

2. The UVB/GZB technology has been researched and demonstrated in shallow aquiferc of amenable hydraulic properties (i.e., relatively thick, homogeneous, and hydraulically conductive); and operation and performance have been reportedly very good. Research and demonstration in the U. S. has been limited.

3. Application of the PP/HW technology to in situ recirculation of groundwater has yet to be researched or demonstrated, although it appears to have great potential for extending the application of recirculation concepts to thin, heterogeneous aquifers.

4. Nomographs to predict capture zone geometries for the UVB/GZB process are published. However, independent flow and transport models to predict aquifer capture and release zone geometries within vertical and horizontal recirculation systems are not yet readily available and need to be conducted on a site by site basis.

5. VOC stripping efficiency during in situ recirculation can be markedly enhanced by using countercurrent flow rather than the currently employed cocurrent flow regimes.

6. Coupling of in situ treatment processes other than air stripping (e.g., bioremediation and oxidation/reduction) with in situ recirculation technologies has been limited, although the potential to do so appears good. The impact of recirculation on treatment processes within the aquifer sediments away from the recirculation well(s) remains uncertain. 
7. Formation of precipitates as a result of changes in redox conditions may lead to fouling of recirculation apparatus and aquifer materials in certain groundwater systems. The rate and extent of fouling and potential for adverse operation and performance impacts remain uncertain. Recycling of the stripping gas (with a purge stream) might be effective in reducing detrimental precipitates caused by recirculation processes.

Further research and demonstration are required to fully develop the in situ recirculation technologies and document their potential benefits for application to DOE sites. Ongoing activities as part of the current ORNL project include development of a finite difference model for predicting multiphase flow and pollutant transport in three dimensions surrounding in situ recirculation systems. The model will be used to assess technology application at representative DOE sites and to facilitate design of laboratory testing and field demonstration activities. Pertinent issues that might be addressed by laboratory and field tests for both the UVB/GZB and PP/HW systems include: (1) verification of recirculation zone geometries and sensitivities to aquifer properties, (2) fouling of well materials and aquifer sediments by precipitates, (3) evaluation of VOC stripping efficiencies, (4) evaluation of alternative in situ treatment processes, and (5) direct comparison of operation and performance features with conventional pump and treat systems. Laboratory and field testing has been proposed in support of contemplated field demonstration projects at the DOE Hanford, Savannah River, and Portsmouth sites. 


\subsection{REFERENCES}

Abelson, P. H. 1990. Inefficient remediation of groundwater pollution. Science. ed., p. 733.

Bonano, E. J., International Technology Exchange Program Contractor Coordination Meeting, Albuquerque, NM, October 9-10, 1991.

Begor, K. F., M. A. Miller, and R. W. Sutch. 1989. Creation of an Artificially Produced Fracture Zone to Prevent Contaminated Ground-Water Migration, Groundwater 27(1):57-65.

Beurmann, W., "Investigation on the Circulation Flow around the Combined Withdrawal and Infiltration Well for Groundwater Remediation-Demonstrated for the Underpressure Vaporizer Well (UVB)", Contaminated Soil, F. Arendt, M. Hinsenveld, and W. J. van den Brink, Eds., p.1045, 1990.

Cannon, J. Z. 1989. Considerations in Groundwater Remediation at Superfund Sites, Text of EPA memorandum on groundwater treatment, Superfund Report, p. 9-11.

Davis, S. N. and J. M. De Wiest, Hydrogeology, Interscience, New York, 1966.

Doherty, R. E. 1992. Operating Issues in Groundwater Extraction and Treatment. Pollution Engineering, p. 61-64.

Fang, C. S., and S. L. Khor, Environmental Progress, 8, 270, 1989.

Garrels, R. M., and C. L. Christ, Solutions. Minerals, and Equilibria, Harper \& Row, NY, 1965.

Gilman, J. R. and J. R. Jargon. 1992. Evaluating horizontal vs. vertical well performance. World Oil. p. 55-60.

Guenther, W. B., Chemical Equilibrium: A Practical Introduction for the Physical and Life Sciences, Plenum press, New York, 1975.

Gvirtzman, H. and S. M. Gorelich, Transport in Porous Media, 8, 71, 1992.

Herrling, B., Personal communications, Oak Ridge, Tennessee, 1992.

Herrling, B., W. Beurmann, J. Stamm, and M. Schoen "UVB/GZB Technique for In Situ Groundwater Remediation of Strippable Contaminants: Operation and Dimensioning of Wells", Envirotech Vienna 1990, W. Pillmann and K. Zirm, Eds., p.631, 1990.

Herrling, B., W. Beurmann, and J. Stamm, "Hydraulic Circulation System for In Situ Bioreclamation and/or In Situ Remediation of Strippable Contamination", In situ Bioreclamation, Applications and Investigations for Hydrocarbon and Contaminated Site Remediation, R. E. Hinchee and R. F. Olfenbuttel, Eds., p.173, 1991.

Herrling, B., W. Beurmann, and J. Stamm, "In Situ Groundwater Remediation of Strippable or Volatile Contamination Using the UVB-Method", Proceedings of the European Conference Advances in Water Resources Technology, G. T. Tsakiris, Ed., p.315, 1991.

Herrling, B., W. Beurmann, and J. Stamm, "In Situ Remediation of Volatile Contaminants in Groundwater by a new System of 'Vacuum-Vaporizer-Wells' ", Subsurface Contamination by Immiscible Fluids, K. U. Weyer, Ed., p.315, 1991. 
Herrling, B., J. Stamm, E. J. Alesi, P. Brinnel, G. F. Hirshberger, and M. R. Sick. 1991. In situ Groundwater Remediation of Strippable Contaminants by Vacuum Vaporizer Wells (UVB): Operation of the Well and Report About Cleaned Industrial Sites, forum on Innovative Hazardous Waste Treatment Technologies, U. S. EPA, Dallas, Tex.

Hirschfelder, J. O., C. F. Curtis, and R. B. Bird, Molecular Theory of Gases and Liquids, Wiley, New York, 1954.

Hughmark, G. A., Industrial and Engineering Chemistry, Process Design and Development, 6, $218,1967$.

Kaback, D. S., B. B. Looney, J. C. Corey, L. M. Wright, III, and J. L. Steele, 1989. Horizontal Wells for In-Situ Remediation of Groundwater and Soils. National Water Well Assoc., E. I. du Pont de Nemours \& Co., Savannah River Lab., Aiken, S. C., and Sirrine Environmental Consultants, Greenville, S. C.

Keely, J. F. 1989. Performance Evaluations of Pump-and-Treat Remediations. EPA/540/489/005, U. S. Environmental Protection Agency. October.

Korte, N., 1989, Naturally-Occurring Manganese in Groundwater at the Kansas City Plant, ORNL Report. Oak Ridge National Laboratory, Oak Ridge, TN.

Lepore, J. V., L. H. Turner, D. S. Kosson, and R. C. Ahlert. 1990. Process Development for In Situ Remediation of a Highly Contaminated Groundwater Plume. Journal of Hazardous Materials 25:289-307.

Liebson, L., E. G. Holcomb, A. G. Cosco, and J. J. Jamie, AIChE Journal, 2, 296, 1956.

Looney, B. B., T. C. Hazen, D. S. Kaback, and C. A. Eddy, "Full Scale Field Test of the In Situ Air Stripping Process at the Savannah River Integrated Demonstration Test Site", WSRCRD-91-22, 1991.

Lund, N.-Ch., H. Wuerdemann, J. Swinianski, and G. Gudehus, "Experiences from a Field test for a Biological In Situ Remediation of Contaminated Gasworks Subsoils", BIOMEC/COMMETT Conference: Soil and Groundwater Cleaning, November, 1991, Hindsgavl Castle, Denmark.

Mercer, J. W., D. C. Skipp, and D. Giffin. 1990. "Basics of Pump-and-Treat Ground-Water Remediation Technology", EPA-600/8-90/003, U. S. Environmental Protection Agency.

Nirmalakhandan, N., W. Jang, and R. E. Speece, "Cascade Air-Stripping-A New Technology for Cost Effective Removal of Semi and Low Volatile Organics form Groundwater", Fourth National Outdoor Action Conference on Aquifer Restoration, Groundwater Monitoring and Geophysical Methods, May 1990, Publisher: Dublin, Ohio National Water Well Association.

Nordstrom, D. K. and J. L. Mu 10z, Geochemical thermodynamics, The Benjamin/Cummings Publishing Company, Inc., 1985.

Nyer, E. 1990. One Small Voice for Pump-and-Treat. Groundwater Monitoring Review, p. 7072.

Palmer, C. D. and W. Fish. 1992. Chemical Enhancements to Pump-and-Treat Remediation. EPA/540/S-92/001, U. S. Environmental Protection Agency. January. 
Perry, R. H., and C. H. Chilton (editors), Chemical Engineers Handbook. Fifth Edition. McGraw-Hill, 1973.

Phelps, T. J., Personal communication, Oak Ridge National Laboratory, 1993.

Philip, R. D. and G. R. Walter. 1992. Prediction of Flow and Hydraulic Heal Fields for Vertical Circulation Wells, Groundwater 30(5):765-773.

Reid, R. C., J. M. Prausnitz, and T. K. Sherwood, The Properties of Gases and Liquids, McGrawHill, 1977.

Russell, H. H., J. E. Mathews, and G. W. Sewell. 1992. TCE Removal from Contaminated Soil and Groundwater. EPA/540/S-92/002, U. S. Environmental Protection Agency. January.

Siegrist, R. L. 1992. Report of foreign travel of Robert L. Siegrist, Environmental Sciences Division; Tom J. Phelps, Center for Environmental Biotechnology, The University of Tennessee; and Jack C. Parker, Center for Environmental and Hazardous Materials Studies, Virginia Polytechnic Institute. ORNL/FTR-4194. Oak Ridge National Laboratory, Oak Ridge, TN 37830.

Sims, J. L., J. M. Suflita, and H. H. Russell. 1992. In-Situ Bioremediation of Contaminated Groundwater. EPA/540/S-92/003, U. S. Environmental Protection Agency.

Stumm, W., and J. J. Morgan, Aquatic Chemistry, John Wiley \& Sons, New York, 1970.

Swinianski, J., Lund, N.-Ch., H. Wuerdemann, and G. Gudehus, Laboratory Test for a Biological In Situ Remediation of Contaminated Gasworks Soils, BIOMEC/COMMETT Conference: Soil and Groundwater Cleaning, November, 1991, Hindsgavl Castle, Denmark.

Taber and Seright. 1992. Horizontal Wells Inject New Life Into Mature Field. Petroleum Engineer International. p. 49-50.

Thomsen, K. O., M. A. Chaudhry, K. Dovantzis, and R. R. Riesing. 1989. Groundwater Remediation Using an Extraction, Treatment, and Recharge System. Groundwater Monitoring Review, p. 92-99.

Travis, C. C. and C. B. Doty. 1990. Inefficient Remediation of Ground-Water Pollution, Science 250(4982):733.

Treybal, R. E., Mass Transfer Operations, McGraw-Hill, 1980.

EPA, 1984, Research Outlook for 1984, EPA/600/9/84-004, U. S. Environmental Protection Agency.

EPA, 1991, Stabilization Technologies for RCRA Corrective Actions, EPA/625/6-91/026, U. S. Environmental Protection Agency.

Wilke, C. R. and C. Y. Lee, Industrial and Chemical Engineering, 47, 1253, 1955. 


\subsection{APPENDICES}


Appendix A. HYDROLOGIC COMPUTATIONS FOR THE UVB/GZB PROCESS 
Table A.1. Maximum well spacing as a function of pump rate, aquifer thickness, and hydraulic conductivity. (Aquifer thickness held constant at $30 \mathrm{~m}$ ).

\begin{tabular}{|c|c|c|c|}
\hline$Q\left(\mathrm{~m}^{3} / \mathrm{h}\right)$ & $V(\mathrm{~m} / \mathrm{h})$ & $K_{h \mathrm{~m} / \mathrm{h}}$ & $D(\mathrm{~m})$ \\
\hline 0.01 & $5.00 \mathrm{E}-07$ & 0.0001 & 147 \\
\hline $\begin{array}{c}0.01 \\
0.05 \\
0.1\end{array}$ & $\begin{array}{l}5.00 \mathrm{E}-06 \\
5.00 \mathrm{E}-06 \\
5.00 \mathrm{E}-06\end{array}$ & $\begin{array}{l}0.001 \\
0.001 \\
0.001\end{array}$ & $\begin{array}{l}57 \\
117 \\
147\end{array}$ \\
\hline $\begin{array}{c}0.01 \\
0.05 \\
0.1 \\
0.5 \\
0.75 \\
1 \\
1.5\end{array}$ & $\begin{array}{l}5.00 \mathrm{E}-05 \\
5.00 \mathrm{E}-05 \\
5.00 \mathrm{E}-05 \\
5.00 \mathrm{E}-05 \\
5.00 \mathrm{E}-05 \\
5.00 \mathrm{E}-05 \\
5.00 \mathrm{E}-05\end{array}$ & $\begin{array}{l}0.01 \\
0.01 \\
0.01 \\
0.01 \\
0.01 \\
0.01 \\
0.01\end{array}$ & $\begin{array}{l}5.5 \\
27 \\
57 \\
117 \\
135 \\
147 \\
174\end{array}$ \\
\hline $\begin{array}{c}0.01 \\
0.05 \\
0.1 \\
0.5 \\
0.75 \\
1 \\
1.5 \\
5 \\
10 \\
20\end{array}$ & $\begin{array}{l}5.00 \mathrm{E}-04 \\
5.00 \mathrm{E}-04 \\
5.00 \mathrm{E}-04 \\
5.00 \mathrm{E}-04 \\
5.00 \mathrm{E}-04 \\
5.00 \mathrm{E}-04 \\
5.00 \mathrm{E}-04 \\
5.00 \mathrm{E}-04 \\
5.00 \mathrm{E}-04 \\
5.00 \mathrm{E}-04\end{array}$ & $\begin{array}{l}0.1 \\
0.1 \\
0.1 \\
0.1 \\
0.1 \\
0.1 \\
0.1 \\
0.1 \\
0.1 \\
0.1\end{array}$ & $\begin{array}{c}0.55 \\
2.7 \\
5.5 \\
27 \\
39 \\
57 \\
66 \\
117 \\
147 \\
186\end{array}$ \\
\hline $\begin{array}{c}0.5 \\
0.75 \\
1 \\
1.5 \\
5 \\
10 \\
20 \\
30 \\
40 \\
50 \\
60 \\
70 \\
80 \\
90 \\
100\end{array}$ & $\begin{array}{l}5.00 \mathrm{E}-03 \\
5.00 \mathrm{E}-03 \\
5.00 \mathrm{E}-03 \\
5.00 \mathrm{E}-03 \\
5.00 \mathrm{E}-03 \\
5.00 \mathrm{E}-03 \\
5.00 \mathrm{E}-03 \\
5.00 \mathrm{E}-03 \\
5.00 \mathrm{E}-03 \\
5.00 \mathrm{E}-03 \\
5.00 \mathrm{E}-03 \\
5.00 \mathrm{E}-03 \\
5.00 \mathrm{E}-03 \\
5.00 \mathrm{E}-03 \\
5.00 \mathrm{E}-03\end{array}$ & $\begin{array}{l}1 \\
1 \\
1 \\
1 \\
1 \\
1 \\
1 \\
1 \\
1 \\
1 \\
1 \\
1 \\
1 \\
1 \\
1\end{array}$ & $\begin{array}{l}2.7 \\
4.1 \\
5.5 \\
8.2 \\
27 \\
57 \\
75 \\
96 \\
105 \\
117 \\
123 \\
129 \\
138 \\
144 \\
147\end{array}$ \\
\hline $\begin{array}{c}5 \\
5 \\
10 \\
20 \\
30 \\
40 \\
50 \\
60 \\
70 \\
80 \\
90 \\
100 \\
\end{array}$ & $\begin{array}{l}5.00 \mathrm{E}-02 \\
5.00 \mathrm{E}-02 \\
5.00 \mathrm{E}-02 \\
5.00 \mathrm{E}-02 \\
5.00 \mathrm{E}-02 \\
5.00 \mathrm{E}-02 \\
5.00 \mathrm{E}-02 \\
5.00 \mathrm{E}-02 \\
5.00 \mathrm{E}-02 \\
5.00 \mathrm{E}-02 \\
5.00 \mathrm{E}-02\end{array}$ & $\begin{array}{l}10 \\
10 \\
10 \\
10 \\
10 \\
10 \\
10 \\
10 \\
10 \\
10 \\
10\end{array}$ & $\begin{array}{c}2.7 \\
5.5 \\
10.9 \\
16.4 \\
21.8 \\
27 \\
33 \\
36 \\
42 \\
48 \\
57 \\
\end{array}$ \\
\hline
\end{tabular}


Table A.2. Maximum well spacing as a function of pump rate, aquifer thickness, and hydraulic conductivity. (Aquifer thickness was constant at $20 \mathrm{~m}$ ).

\begin{tabular}{|c|c|c|c|}
\hline$Q\left(\mathrm{~m}^{3} / \mathrm{h}\right)$ & $V(\mathrm{~m} / \mathrm{h})$ & $K_{h \mathrm{~m} / \mathrm{h}}$ & $D(\mathrm{~m})$ \\
\hline 0.01 & $5.00 \mathrm{E}-07$ & 0.0001 & 130 \\
\hline 0.01 & $5.00 \mathrm{E}-06$ & 0.001 & 54 \\
\hline 0.05 & $5.00 \mathrm{E}-06$ & 0.001 & 104 \\
\hline 0.1 & $5.00 \mathrm{E}-06$ & 0.001 & 130 \\
\hline 0.01 & $5.00 \mathrm{E}-05$ & 0.01 & 8.2 \\
\hline 0.05 & $5.00 \mathrm{E}-05$ & 0.01 & 36 \\
\hline 0.1 & $5.00 \mathrm{E}-05$ & 0.01 & 54 \\
\hline 0.5 & $5.00 \mathrm{E}-05$ & 0.01 & 104 \\
\hline 0.75 & $5.00 \mathrm{E}-05$ & 0.01 & 114 \\
\hline 1 & $5.00 \mathrm{E}-05$ & 0.01 & 130 \\
\hline 0.01 & $5.00 \mathrm{E}-04$ & 0.1 & 4.1 \\
\hline 0.05 & $5.00 \mathrm{E}-04$ & 0.1 & 8.2 \\
\hline 0.1 & $5.00 \mathrm{E}-04$ & 0.1 & 36 \\
\hline 0.5 & $5.00 \mathrm{E}-04$ & 0.1 & 46 \\
\hline 0.75 & $5.00 \mathrm{E}-04$ & 0.1 & 54 \\
\hline 1 & $5.00 \mathrm{E}-04$ & 0.1 & 66 \\
\hline 1.5 & $5.00 \mathrm{E}-04$ & 0.1 & 104 \\
\hline 5 & $5.00 \mathrm{E}-04$ & 0.1 & 130 \\
\hline 0.5 & $5.00 \mathrm{E}-03$ & 1 & 4.1 \\
\hline 0.75 & $5.00 \mathrm{E}-03$ & 1 & 6.1 \\
\hline 1 & $5.00 \mathrm{E}-03$ & 1 & 8.2 \\
\hline 1.5 & $5.00 \mathrm{E}-03$ & 1 & 12 \\
\hline 5 & $5.00 \mathrm{E}-03$ & 1 & 36 \\
\hline 10 & $5.00 \mathrm{E}-03$ & 1 & 54 \\
\hline 20 & $5.00 \mathrm{E}-03$ & 1 & 74 \\
\hline 30 & $5.00 \mathrm{E}-03$ & $i$ & 86 \\
\hline 40 & $5.00 \mathrm{E}-03$ & $i$ & 96 \\
\hline 50 & $5.00 \mathrm{E}-03$ & 1 & 104 \\
\hline 60 & $5.00 \mathrm{E}-03$ & 1 & 110 \\
\hline 70 & $5.00 \mathrm{E}-03$ & 1 & 116 \\
\hline 80 & $5.00 \mathrm{E}-03$ & 1 & 120 \\
\hline 90 & $5.00 \mathrm{E}-03$ & 1 & 124 \\
\hline 100 & $5.00 \mathrm{E}-03$ & 1 & 130 \\
\hline 1.5 & $5.00 \mathrm{E}-02$ & 10 & 1.2 \\
\hline 5 & $5.00 \mathrm{E}-02$ & 10 & 4.1 \\
\hline 10 & $5.00 \mathrm{E}-02$ & 10 & 8.2 \\
\hline 20 & $5.00 \mathrm{E}-02$ & 10 & 16 \\
\hline 30 & $5.00 \mathrm{E}-02$ & 10 & 24 \\
\hline 40 & $5.00 \mathrm{E}-02$ & 10 & 30 \\
\hline 50 & $5.00 \mathrm{E}-02$ & 10 & 36 \\
\hline 60 & $5.00 \mathrm{E}-02$ & 10 & 40 \\
\hline 70 & $5.00 \mathrm{E}-02$ & 10 & 46 \\
\hline 80 & $5.00 \mathrm{E}-02$ & 10 & 48 \\
\hline 90 & 5.00E-02 & 10 & 52 \\
\hline 100 & $5.00 \mathrm{E}-02$ & 10 & 54 \\
\hline
\end{tabular}


Table A.3. Maximum well spacing as a function of pump rate, aquifer thickness, and hydraulic conductivity. (Aquifer thickness was constant at $10 \mathrm{~m}$ ).

\begin{tabular}{|c|c|c|c|}
\hline$Q\left(\mathrm{~m}^{3} / \mathrm{h}\right)$ & $V(\mathrm{~m} / \mathrm{h})$ & $K_{h} \mathrm{~m} / \mathrm{h}$ & $D(\mathrm{~m})$ \\
\hline 0.01 & $5.00 \mathrm{E}-06$ & 0.001 & 48 \\
\hline 0.01 & $5.00 \mathrm{E}-05$ & 0.01 & 15 \\
\hline 0.05 & $5.00 \mathrm{E}-05$ & 0.01 & 37 \\
\hline 0.1 & $5.00 \mathrm{E}-05$ & 0.01 & 48 \\
\hline 0.01 & $5.00 \mathrm{E}-04$ & 0.1 & 1.6 \\
\hline 0.05 & $5.00 \mathrm{E}-04$ & 0.1 & 8 \\
\hline 0.1 & $5.00 \mathrm{E}-04$ & 0.1 & 15 \\
\hline 0.5 & $5.00 \mathrm{E}-04$ & 0.1 & 37 \\
\hline 0.75 & $5.00 \mathrm{E}-04$ & 0.1 & 43 \\
\hline 1 & $5.00 \mathrm{E}-04$ & 0.1 & 48 \\
\hline 1.5 & $5.00 \mathrm{E}-04$ & 0.1 & 55 \\
\hline 0.1 & $5.00 \mathrm{E}-03$ & 1 & 1.6 \\
\hline 0.5 & $5.00 \mathrm{E}-03$ & 1 & 8 \\
\hline 0.75 & $5.00 \mathrm{E}-03$ & 1 & 12 \\
\hline 1 & $5.00 \mathrm{E}-03$ & 1 & 15 \\
\hline 1.5 & $5.00 \mathrm{E}-03$ & 1 & 20 \\
\hline 5 & $5.00 \mathrm{E}-03$ & 1 & 37 \\
\hline 10 & $5.00 \mathrm{E}-03$ & 1 & 48 \\
\hline 20 & $5.00 \mathrm{E}-03$ & 1 & 60 \\
\hline 0.75 & $5.00 \mathrm{E}-02$ & 10 & 1.2 \\
\hline 1 & $5.00 \mathrm{E}-02$ & 10 & 1.6 \\
\hline 1.5 & $5.00 \mathrm{E}-02$ & 10 & 2.5 \\
\hline 5 & $5.00 \mathrm{E}-02$ & 10 & 8 \\
\hline 10 & $5.00 \mathrm{E}-02$ & 10 & 15 \\
\hline 20 & $5.00 \mathrm{E}-02$ & 10 & 24 \\
\hline 30 & $5.00 \mathrm{E}-02$ & 10 & 30 \\
\hline 40 & $5.00 \mathrm{E}-02$ & 10 & 33 \\
\hline 50 & $5.00 \mathrm{E}-02$ & 10 & 37 \\
\hline 60 & $5.00 \mathrm{E}-02$ & 10 & 39 \\
\hline 70 & $5.00 \mathrm{E}-02$ & 10 & 42 \\
\hline 80 & $5.00 \mathrm{E}-02$ & 10 & 44 \\
\hline 90 & $5.00 \mathrm{E}-02$ & 10 & 46 \\
\hline 100 & $5.00 \mathrm{E}-02$ & 10 & 48 \\
\hline
\end{tabular}


Table A.4. Maximum well spacing as a function of pump rate, aquifer thickness, and hydraulic conductivity. (Aquifer thickness was constant at $5 \mathrm{~m}$ ).

\begin{tabular}{|c|c|c|c|}
\hline$Q\left(\mathrm{~m}^{3} / \mathrm{h}\right)$ & $V(\mathrm{~m} / \mathrm{h})$ & $K_{h} \mathrm{~m} / \mathrm{h}$ & $D(\mathrm{~m})$ \\
\hline $\begin{array}{l}0.01 \\
0.05\end{array}$ & $\begin{array}{l}5.00 \mathrm{E}-05 \\
5.00 \mathrm{E}-05\end{array}$ & $\begin{array}{l}0.01 \\
0.01\end{array}$ & $\begin{array}{c}16.5 \\
30\end{array}$ \\
\hline 0.01 & $5.00 \mathrm{E}-04$ & 0.1 & 3.3 \\
\hline 0.05 & $5.00 \mathrm{E}-04$ & 0.1 & 12 \\
\hline 0.1 & $5.00 \mathrm{E}-04$ & 0.1 & 17 \\
\hline 0.5 & $5.00 \mathrm{E}-04$ & 0.1 & 30 \\
\hline 0.05 & $5.00 \mathrm{E}-03$ & 1 & 1.6 \\
\hline 0.1 & $5.00 \mathrm{E}-03$ & 1 & 3.3 \\
\hline 0.5 & $5.00 \mathrm{E}-03$ & 1 & 12 \\
\hline 0.75 & $5.00 \mathrm{E}-03$ & 1 & 15 \\
\hline 1 & $5.00 \mathrm{E}-03$ & 1 & 17 \\
\hline 1.5 & $5.00 \mathrm{E}-03$ & 1 & 19.5 \\
\hline 5 & $5.00 \mathrm{E}-03$ & 1 & 30 \\
\hline 0.5 & $5.00 \mathrm{E}-02$ & 10 & 1.6 \\
\hline 0.75 & $5.00 \mathrm{E}-02$ & 10 & 2.5 \\
\hline 1 & $5.00 \mathrm{E}-02$ & 10 & 3.3 \\
\hline 1.5 & $5.00 \mathrm{E}-02$ & 10 & 5 \\
\hline 5 & $5.00 \mathrm{E}-02$ & 10 & 12 \\
\hline 10 & $5.00 \mathrm{E}-02$ & 10 & 17 \\
\hline 20 & $5.00 \mathrm{E}-02$ & 10 & 22 \\
\hline 30 & $5.00 \mathrm{E}-02$ & 10 & 25 \\
\hline 40 & $5.00 \mathrm{E}-02$ & 10 & 28 \\
\hline 50 & $5.00 \mathrm{E}-02$ & 10 & 30 \\
\hline 60 & $5.00 \mathrm{E}-02$ & 10 & 32 \\
\hline
\end{tabular}


Tab'e A.5. Maximum well spacing as a function of pump rate, aquifer thickness, and hydraulic conductivity. (Aquifer thickness was constant at $2 \mathrm{~m}$ ).

\begin{tabular}{cccc}
\hline$Q\left(\mathrm{~m}^{3} / \mathrm{h}\right)$ & $V(\mathrm{~m} / \mathrm{h})$ & $K_{h} \mathrm{~m} / \mathrm{h}$ & $D(\mathrm{~m})$ \\
\hline 0.01 & $5.00 \mathrm{E}-05$ & 0.01 & 13 \\
\hline 0.01 & $5.00 \mathrm{E}-04$ & 0.1 & 5.4 \\
0.05 & $5.00 \mathrm{E}-04$ & 0.1 & 10.4 \\
0.1 & $5.00 \mathrm{E}-04$ & 0.1 & 13 \\
\hline 0.05 & & & 3.6 \\
0.1 & $5.00 \mathrm{E}-03$ & 1 & 5.4 \\
0.5 & $5.00 \mathrm{E}-03$ & 1 & 10.4 \\
0.75 & $5.00 \mathrm{E}-03$ & 1 & 11 \\
1 & $5.00 \mathrm{E}-03$ & 1 & 13 \\
\hline 0.5 & $5.00 \mathrm{E}-03$ & 1 & 3.6 \\
0.75 & & & 4.6 \\
1 & $5.00 \mathrm{E}-02$ & 10 & 5.4 \\
1.5 & $5.00 \mathrm{E}-02$ & 10 & 6.6 \\
5 & $5.00 \mathrm{E}-02$ & 10 & 10.4 \\
10 & $5.00 \mathrm{E}-02$ & 10 & 13 \\
\hline
\end{tabular}


Table A.6. Estimation of possible pumping rates based on drawdown calculations for $H=$ $30 \mathrm{~m}(97 \mathrm{ft})$, maximum allowable drawdown $=72 \mathrm{ft}, l=24 \mathrm{ft}, r=1 \mathrm{ft}, t=30$ days.

\begin{tabular}{|c|c|c|c|c|c|c|c|}
\hline \multirow[b]{4}{*}{$\underset{\left(\mathrm{m}^{3} / \mathrm{h}\right)}{Q}$} & \multirow[t]{3}{*}{$K_{h}=$} & $\begin{array}{c}0.00787 \\
(\mathrm{ft} / \mathrm{d})\end{array}$ & $\begin{array}{c}0.0787 \\
(\mathrm{ft} / \mathrm{d})\end{array}$ & $\begin{array}{l}0.787 \\
(\mathrm{ft} / \mathrm{d})\end{array}$ & $\begin{array}{l}7.87 \\
(\mathrm{ft} / \mathrm{d})\end{array}$ & $\begin{array}{l}78.7 \\
(\mathrm{ft} / \mathrm{d})\end{array}$ & $\begin{array}{c}787 \\
(\mathrm{ft} / \mathrm{d})\end{array}$ \\
\hline & & $\begin{array}{c}\mathrm{I} \\
8.82 \mathrm{E}-3\end{array}$ & $\begin{array}{c}\mathrm{I} \\
8.82 \mathrm{E}-4\end{array}$ & $\underset{8.82 \mathrm{E}-5}{u}$ & $\begin{array}{c}\mathrm{I} \\
8.82 \mathrm{E}-6\end{array}$ & 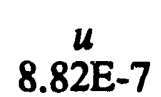 & $\stackrel{u}{8.82 \mathrm{E}-8}$ \\
\hline & & $\begin{array}{l}W(u) \\
4.17\end{array}$ & $\begin{array}{l}W(u) \\
6.47\end{array}$ & $\begin{array}{l}W(u) \\
8.77\end{array}$ & $\begin{array}{l}W(u) \\
11.07\end{array}$ & $\begin{array}{c}W(u) \\
13.37\end{array}$ & $\begin{array}{l}W(u) \\
15.68\end{array}$ \\
\hline & $\underset{(\mathrm{gal} / \mathrm{min})}{Q}$ & $\underset{(\mathrm{ft})}{S}$ & $\underset{(\mathrm{ft})}{s}$ & $\underset{(\mathrm{ft})}{s}$ & $\stackrel{s}{(\mathrm{ft})}$ & $\stackrel{S}{(\mathrm{ft})}$ & $\stackrel{S}{S}$ \\
\hline 0.01 & 0.044 & 14.89 & 2.310 & 0.313 & 0.008 & 0.004 & 0.001 \\
\hline 0.05 & 0.221 & 74.47 & 11.09 & 1.500 & 0.189 & 0.022 & 0.002 \\
\hline 0.10 & 0.440 & 148.9 & 22.18 & 3.007 & 0.380 & 0.046 & 0.005 \\
\hline 0.50 & 2.201 & 744.7 & 110.9 & 15.03 & 1.897 & 0.229 & 0.026 \\
\hline 0.75 & 3.303 & 1117. & 166.3 & 22.55 & 2.846 & 0.343 & 0.040 \\
\hline 1.00 & 4.403 & 1489. & 221.8 & 30.07 & 3.795 & 0.458 & 0.053 \\
\hline 1.50 & 6.605 & 2234 & 332.7 & 45.11 & 5.693 & 0.687 & 0.080 \\
\hline 5.00 & 22.01 & 7447 & 1109. & 150.4 & 18.98 & 2.292 & 0.268 \\
\hline 10.0 & 44.03 & 14894 & 2218 & 300.7 & 37.96 & 4.584 & 0.537 \\
\hline 20.0 & 88.06 & 29788 & 4436. & 601.4 & 75.92 & 9.168 & 1.075 \\
\hline 30.0 & 132.1 & 44682 & 6555 & 902.1 & 113.8 & 13.75 & 1.612 \\
\hline 40.0 & 176.1 & $59 \searrow 76$ & 8873. & 1202. & 151.8 & 18.33 & 2.150 \\
\hline 50.0 & 220.1 & 74470 & 11092 & 1503. & 189.8 & 22.92 & 2.688 \\
\hline 60.0 & 264.2 & 89364 & 13310 & 1804. & 227.7 & 27.51 & 3.225 \\
\hline 70.0 & 308.2 & 104259 & 15529 & 2104. & 265.7 & 32.09 & 3.763 \\
\hline 80.0 & 352.2 & 119153 & 17747 & 2405 & 303.6 & 36.67 & 4.301 \\
\hline 90.0 & 396.3 & 134047 & 19966 & 2706. & 341.6 & 41.26 & 4.838 \\
\hline 100. & 440.3 & 148941 & 22184 & 3007. & 379.5 & 45.84 & 5.376 \\
\hline
\end{tabular}


Table A.7. Estimation of possible pumping rates based on drawdown calculations for $H=$ $20 \mathrm{~m}(97 \mathrm{ft})$, maximum allowable drawdown $=49 \mathrm{ft}, l=16 \mathrm{ft}, r=1 \mathrm{ft}, t=30$ days.

\begin{tabular}{|c|c|c|c|c|c|c|c|}
\hline & $K_{h}=$ & $\begin{array}{c}0.00787 \\
(\mathrm{ft} / \mathrm{d})\end{array}$ & $\begin{array}{c}0.0787 \\
\text { (ft/d) }\end{array}$ & $\begin{array}{l}0.787 \\
(\mathrm{ft} / \mathrm{d})\end{array}$ & $\begin{array}{l}7.87 \\
(\mathrm{ft} / \mathrm{d})\end{array}$ & $\begin{array}{l}78.7 \\
(\mathrm{ft} / \mathrm{d})\end{array}$ & $\begin{array}{l}787 \\
(\mathrm{ft} / \mathrm{d})\end{array}$ \\
\hline & & $\begin{array}{c}u \\
1.32 \mathrm{E}-2 \\
W(u) \\
3.84\end{array}$ & $\begin{array}{c}u \\
1.32 \mathrm{E}-3 \\
W(u) \\
6.13\end{array}$ & $\begin{array}{c}u \\
1.32 \mathrm{E}-4 \\
W(u) \\
8.43\end{array}$ & $\begin{array}{c}u \\
1.32 \mathrm{E}-5 \\
W(u) \\
10.74\end{array}$ & $\begin{array}{c}u \\
1.32 \mathrm{E}-6 \\
W(u) \\
13.04\end{array}$ & $\begin{array}{c}u \\
1.32 \mathrm{E}-7 \\
W(u) \\
15.344\end{array}$ \\
\hline$\underset{\left(\mathrm{m}^{3} / \mathrm{h}\right)}{Q}$ & $\underset{(\mathrm{gal} / \mathrm{min})}{Q}$ & $\begin{array}{c}S \\
(\mathrm{ft})\end{array}$ & $\begin{array}{c}S \\
(\mathrm{ft})\end{array}$ & $\begin{array}{c}S \\
(\mathrm{ft})\end{array}$ & $\underset{(\mathrm{ft})}{S}$ & $\begin{array}{c}S \\
(\mathrm{ft})\end{array}$ & $\begin{array}{c}\boldsymbol{S} \\
(\mathrm{ft})\end{array}$ \\
\hline 0.01 & 0.044 & 20.57 & 3.284 & 0.451 & 0.057 & 0.006 & 0.00 \\
\hline 0.05 & 0.220 & 102.8 & 16.42 & 2.258 & 0.287 & 0.034 & 0.004 \\
\hline 0.10 & 0.440 & 205.7 & 32.84 & 4.516 & 0.575 & 0.069 & 0.008 \\
\hline 0.50 & 2.201 & 1028. & 164.2 & 22.58 & 2.877 & 0.349 & 0.041 \\
\hline 0.75 & 3.302 & 1542. & 246.3 & 33.87 & 4.315 & 0.523 & 0.061 \\
\hline 1.00 & 4.403 & 2057. & 328.4 & 45.16 & 5.574 & 0.698 & 0.082 \\
\hline 1.50 & 6.605 & 3085. & 492.6 & 67.74 & 8.631 & 1.047 & 0.123 \\
\hline 5.00 & 22.01 & 10286 & 1642. & 225.8 & 28.77 & 3.493 & 0.410 \\
\hline 10.0 & 44.03 & 20573 & 3284. & 451.6 & 57.54 & 6.986 & 0.821 \\
\hline 20.0 & 88.06 & 41146 & 6568. & 903.2 & 115.0 & 13.97 & 1.643 \\
\hline 30.0 & 132.1 & 61719 & 9852. & 1354. & 172.6 & 20.95 & 2.465 \\
\hline 40.0 & 176.1 & 82292 & 13136 & 1806. & 230.1 & 27.94 & 3.287 \\
\hline 50.0 & 220.1 & 102866 & 16421 & 2258. & 287.7 & 34.93 & 4.109 \\
\hline 60.0 & 264.2 & 123439 & 19705 & 2709. & 345.2 & 41.91 & 4.931 \\
\hline 70.0 & 308.2 & 144012 & 22989 & 3161. & 402.7 & 48.90 & 5.753 \\
\hline 80.0 & 352.2 & 164585 & 26273 & 3613. & 460.3 & 55.89 & 6.574 \\
\hline 90.0 & 396.3 & 185159 & 29557 & 4064. & 517.8 & 62.87 & 7.396 \\
\hline 100. & 440.3 & 205732 & 32842 & 4516. & 575.4 & 69.86 & 8.218 \\
\hline
\end{tabular}


Table A.8. Estimation of possible pumping rates based on drawdown calculations for $H=$ $10 \mathrm{~m}(33 \mathrm{ft})$, maximum allowable drawdown $=24 \mathrm{ft}, l=8 \mathrm{ft}, r=1 \mathrm{ft}, t=30$ days.

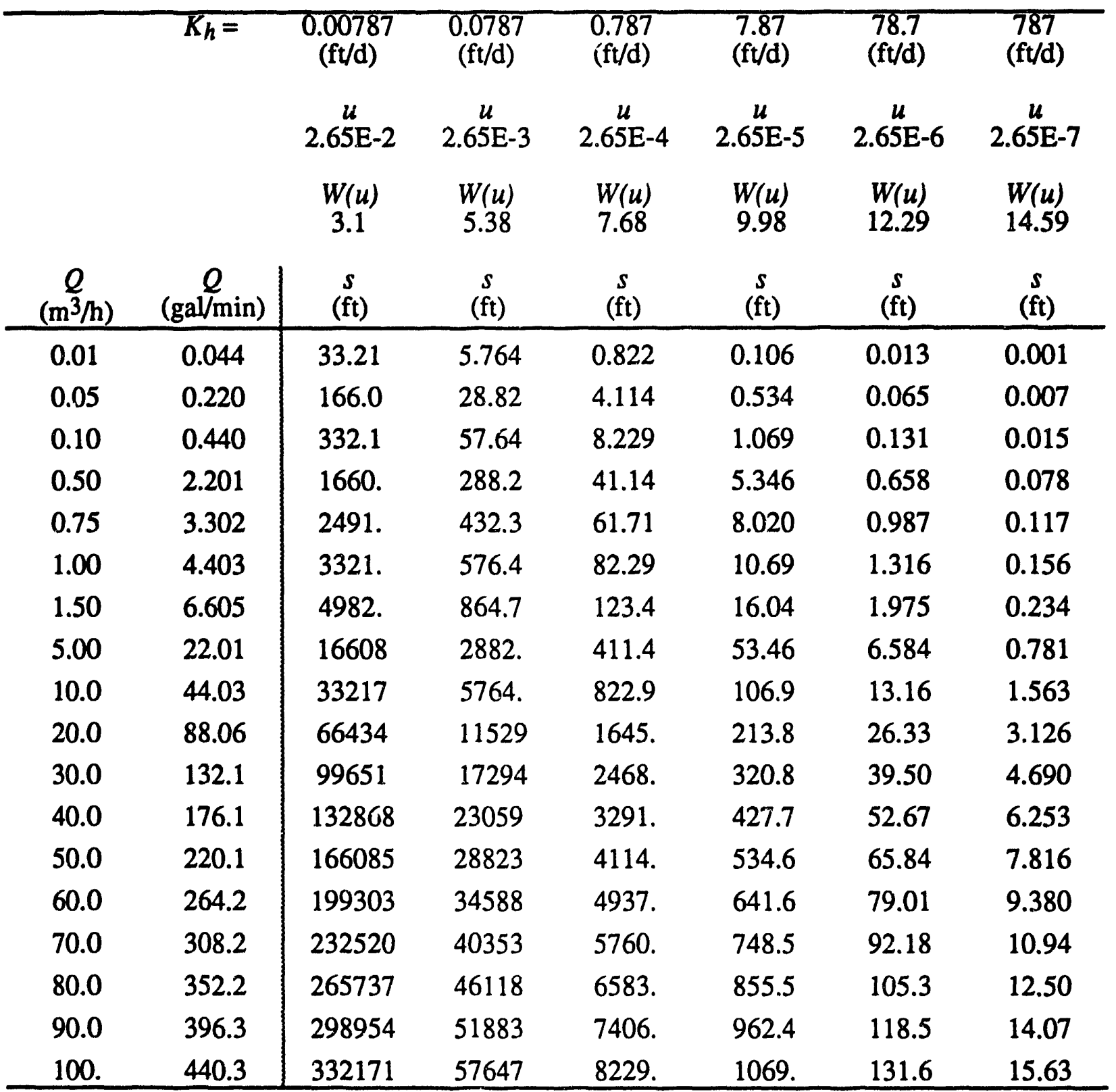


Table A.9. Estimation of possible pumping rates based on drawdown calculations for $H=$ $5 \mathrm{~m}(16 \mathrm{ft})$, maximum allowable drawdown $=11 \mathrm{ft}, l=4 \mathrm{ft}, r=1 \mathrm{ft}, t=30$ days.

\begin{tabular}{|c|c|c|c|c|c|c|c|}
\hline & $K_{h}=$ & $\begin{array}{c}0.00787 \\
(\mathrm{ft} / \mathrm{d})\end{array}$ & $\begin{array}{c}0.0787 \\
\text { (ft/d) }\end{array}$ & $\begin{array}{l}0.787 \\
(\mathrm{ft} / \mathrm{d})\end{array}$ & $\begin{array}{l}7.87 \\
\text { (ft/d) }\end{array}$ & $\begin{array}{l}78.7 \\
(\mathrm{ft} / \mathrm{d})\end{array}$ & $\begin{array}{c}787 \\
(\mathrm{ft} / \mathrm{d})\end{array}$ \\
\hline & & $\underset{5.29 \mathrm{E}-2}{u}$ & $\begin{array}{c}u \\
5.29 \mathrm{E}-3\end{array}$ & $\begin{array}{c}u \\
5.29 \mathrm{E}-4\end{array}$ & $\underset{5.29 \mathrm{E}-5}{u}$ & $\underset{5.29 \mathrm{E}-6}{u}$ & $\stackrel{\substack{u \\
5.29 \mathrm{E}-7}}{.}$ \\
\hline & & $\begin{array}{l}W(u) \\
2.42\end{array}$ & $\begin{array}{c}W(u) \\
4.67\end{array}$ & $\begin{array}{l}W(u) \\
6.97\end{array}$ & $\begin{array}{l}W(u) \\
9.27\end{array}$ & $\begin{array}{l}W(u) \\
11.58\end{array}$ & $\begin{array}{l}W(u) \\
13.88\end{array}$ \\
\hline$\underset{\left(m^{3} / h\right)}{Q}$ & $\underset{(\mathrm{gal} / \mathrm{min})}{Q}$ & $\underset{(\mathrm{ft})}{S}$ & $\stackrel{s}{(\mathrm{ft})}$ & $\underset{(\mathrm{ft})}{s}$ & $\underset{(\mathrm{ft})}{S}$ & $\underset{(\mathrm{ft})}{s}$ & $\begin{array}{c}S \\
(\mathrm{ft})\end{array}$ \\
\hline 0.01 & 0.044 & 51.86 & 10.00 & 1.493 & 0.198 & 0.024 & 0.002 \\
\hline 0.05 & 0.220 & 259.3 & 50.04 & 7.468 & 0.993 & 0.124 & 0.014 \\
\hline 0.10 & 0.440 & 518.6 & 100.0 & 14.93 & 1.986 & 0.248 & 0.029 \\
\hline 0.50 & 2.201 & 2593. & 500.4 & 74.68 & 9.933 & 1.240 & 0.148 \\
\hline 0.75 & 3.302 & 3889. & 750.6 & 112.0 & 14.89 & 1.861 & 0.223 \\
\hline 1.00 & 4.403 & 5186. & 1000. & 149.3 & 19.86 & 2.481 & 0.297 \\
\hline 1.50 & 6.605 & 7779. & 1501. & 224.0 & 29.79 & 3.722 & 0.446 \\
\hline 5.00 & 22.01 & 25930 & 5004. & 746.8 & 99.33 & 12.40 & 1.487 \\
\hline 10.0 & 44.03 & 51861 & 10008 & 1493. & 198.6 & 24.81 & 2.974 \\
\hline 20.0 & 88.06 & 103723 & 20016 & 2987. & 397.3 & 49.63 & 5.949 \\
\hline 30.0 & 132.1 & 155585 & 30024 & 4481. & 595.9 & 74.44 & 8.923 \\
\hline 40.0 & 176.1 & 207446 & 40032 & 5974. & 794.6 & 99.26 & 11.89 \\
\hline 50.0 & 220.1 & 259308 & 50040 & 7468. & 993.3 & 124.0 & 14.87 \\
\hline 60.0 & 264.2 & 311170 & 60048 & 8962. & 1191. & 148.8 & 17.84 \\
\hline 70.0 & 308.2 & 363031 & 70056 & 10455 & 1390. & 173.7 & 20.82 \\
\hline 80.0 & 352.2 & 414893 & 80064 & 11949 & 1589. & 198.5 & 23.79 \\
\hline 90.0 & 396.3 & 466755 & 90072 & 13443 & 1787. & 223.3 & 26.77 \\
\hline 100 & 440.3 & 518616 & 100080 & 14937 & 1986. & 248.1 & 29.74 \\
\hline
\end{tabular}


Table A.10. of possible pumping rates based on drawdown calculations for $H=2 \mathrm{~m}$ (6.5 $\mathrm{ft}$ ), maximum allowable drawdown $=4 \mathrm{ft}, l=1.6 \mathrm{ft}, r=1 \mathrm{ft}, t=30$ days.

\begin{tabular}{|c|c|c|c|c|c|c|c|}
\hline & $\overline{K_{h}}=$ & $\begin{array}{c}0.00787 \\
(\mathrm{ft} / \mathrm{d})\end{array}$ & $\begin{array}{l}0.0787 \\
(\mathrm{ft} / \mathrm{d})\end{array}$ & $\begin{array}{l}0.787 \\
(\mathrm{ft} / \mathrm{d})\end{array}$ & $\begin{array}{l}7.87 \\
\text { (ft/d) }\end{array}$ & $\begin{array}{l}78.7 \\
(\mathrm{ft} / \mathrm{d})\end{array}$ & $\begin{array}{l}787 \\
(\mathrm{ft} / \mathrm{d})\end{array}$ \\
\hline & & $\begin{array}{c}u \\
1.32 \mathrm{E}-1\end{array}$ & $\begin{array}{c}u \\
1.32 \mathrm{E}-2\end{array}$ & 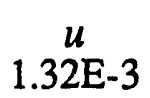 & 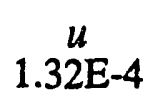 & $\begin{array}{c}u \\
1.32 \mathrm{E}-5\end{array}$ & $\begin{array}{c}u \\
1.32 \mathrm{E}-6\end{array}$ \\
\hline & & $\begin{array}{l}W(u) \\
1.64\end{array}$ & $\begin{array}{l}W(u) \\
3.84\end{array}$ & $\begin{array}{l}W(u) \\
6.13\end{array}$ & $\begin{array}{l}W(u) \\
8.43\end{array}$ & $\begin{array}{l}W(u) \\
10.74\end{array}$ & $\begin{array}{l}W(u) \\
13.04\end{array}$ \\
\hline$\underset{\left(\mathrm{m}^{3} / \mathrm{h}\right)}{Q}$ & $\underset{(\mathrm{gal} / \mathrm{min})}{Q}$ & $\underset{(\mathrm{ft})}{S}$ & $\underset{(\mathrm{ft})}{S}$ & $\underset{(\mathrm{ft})}{S}$ & $\underset{(\mathrm{ft})}{S}$ & $\underset{(\mathrm{ft})}{S}$ & $\begin{array}{c}S \\
\text { (ft) }\end{array}$ \\
\hline 0.01 & 0.044 & 0.044 & 0.044 & 0.044 & 0.044 & 0.044 & 0.044 \\
\hline 0.05 & 0.220 & 0.220 & 0.220 & 0.220 & 0.220 & 0.220 & 0.220 \\
\hline 0.10 & 0.440 & 0.440 & 0.440 & 0.440 & 0.440 & 0.440 & 0.440 \\
\hline 0.50 & 2.201 & 2.201 & 2.201 & 2.201 & 2.201 & 2.201 & 2.201 \\
\hline 0.75 & 3.302 & 3.302 & 3.302 & 3.302 & 3.302 & 3.302 & 3.302 \\
\hline 1.00 & 4.403 & 4.403 & 4.403 & 4.403 & 4.403 & 4.403 & 4.403 \\
\hline 1.50 & 6.605 & 6.605 & 6.605 & 6.605 & 6.605 & 6.605 & 6.605 \\
\hline 5.00 & 22.01 & 22.01 & 22.01 & 22.01 & 22.01 & 22.01 & 22.01 \\
\hline 10.0 & 44.03 & 44.03 & 44.03 & 44.03 & 44.03 & 44.03 & 44.03 \\
\hline 20.0 & 88.06 & 88.06 & 88.06 & 88.06 & 88.06 & 88.06 & 88.06 \\
\hline 30.0 & 132.1 & 132.1 & 132.1 & 132.1 & 132.1 & 132.1 & 132.1 \\
\hline 40.0 & 176.1 & 176.1 & 176.1 & 176.1 & 176.1 & 176.1 & 176.1 \\
\hline 50.0 & 220.1 & 220.1 & 220.1 & 220.1 & 220.1 & 220.1 & 220.1 \\
\hline 60.0 & 264.2 & 264.2 & 264.2 & 264.2 & 264.2 & 264.2 & 264.2 \\
\hline 70.0 & 308.2 & 308.2 & 308.2 & 308.2 & 308.2 & 308.2 & 308.2 \\
\hline 80.0 & 352.2 & 352.2 & 352.2 & 352.2 & 352.2 & 352.2 & 352.2 \\
\hline 90.0 & 396.3 & 396.3 & 396.3 & 396.3 & 396.3 & 396.3 & 396.3 \\
\hline 100. & 440.3 & 440.3 & 440.3 & 440.3 & 440.3 & 440.3 & 440.3 \\
\hline
\end{tabular}


Appendix B. HYDROLOGY OF SELECTED DOE SITES 
This appendix discusses the hydrogeology at selected facilities across the DOE complex. Each site has unique features that affect the selection and design of the recirculation techniques discussed in this report. The variety and complexity of the selected sites may indicate that one technique will have a distinct advantage or perhaps limited application.

\section{B.1. DOE KANSAS CITY PLANT}

The Kansas City Plant (KCP) is located within the city limits of Kansas City, Missouri. The plant has been in operation since 1943. Several spills have occurred at the facility, including chlorinated solvents, PCBs, and plating wastes.

The geology at the KCP can be divided into two major units, the unconsolidated alluvium and the underlying bedrock. Three identifiable units are present within the alluvium: an upper sandyclayey-silt unit, a middle blue-green-clayey-silt unit, and a basal clayey-gravel unit. The upper unit consists of a thin-bedded sequence of sand and clayey silt, with minor amounts of gravel fragments near the shale and limestone bluff located north of the site. The upper unit truncates near the Blue River at the eastern end of the site. The middle blue-green-clayey-silt unit, commonly referred to as the green clay, is not found everywhere at the KCP. The basal gravel unit consists of angular limestone and chert gravel in a clayey-silt matrix.

The bedrock underlying the KCP consists of Paleozoic shales and sandstones of the Pleasanton Group. Within the Pleasanton Shale are two sandstone units, the Knobtown and Hepler Sandstones. The sandstones are typically fine-grained and well cemented.

The local flow system exists within sediments of the unconsolidated alluvial deposits and, to a lesser extent, the underlying bedrock shales and sandstones (Table C.1). Specific units of hydrologic importance are:

1. Upper Clayey-Silt Unit - consists of the uppermost alluvial sediments. Total thickness of this unit is approximately $26 \mathrm{ft}$. Depth to the water table is approximately $10 \mathrm{ft}$.

2. Green Clay Unit - consists of dense silty-clay, blocky in structure and containing less water than either the overlying clayey-silt or the underlying clayey-gravel. This unit is not found at all areas at the KCP. Total thickness of the Green Clay Unit varies from 0 to $6 \mathrm{ft}$. An aquifer pump test concluded that the Green Clay Unit has similar hydraulic properties of the overlying Clayey-Silt Unit.

3. Basal Gravel Unit - comprised of limestone and chert gravel in a clayey-silt matrix. This unit is considered the greatest water producer of the three alluvial units. Thickness of the Basal Gravel Unit varies from 0.5 to $5 \mathrm{ft}$.

4. Pleasanton Shale Group - consists of dense indurated shale lacking secondary permeability features (fractures). Within the Pleasanton Shale are two sandstone units, the Knobtown and the Hepler Sandstones. Packe: and bail tests in the Knobtown and hydraulic conductivity tests from core samples suggest that the hydraulic conductivity of the bedrock aquifer is at least two orders of magnitude less than the hydraulic conductivity of the alluvial aqiifer.

The KCP receives an average of 34 in. of precipitation per year. Approximately $46 \%$ of the KCP is covered with either grass or gravel and is available for recharge. The actual percentage of precipitation that recharges the aquifer is not known. Assuming the precipitation is the predominant recharge mechanism at the $\mathrm{KCP}$, the volume of recharge to the alluvial aquifer from precipitation must be approximately equal to the volume of groundwater discharging from the 
alluvial aquifer. Estimated discharge volume for the alluvial aquifer is approximately 11,300 $\mathrm{ft}^{3} / \mathrm{d}$.

Table B.1. Range of hydraulic conductivities for aquifer units at the DOE Kansas City Plant.

\begin{tabular}{cccc}
\hline Geologic unit & Units & $\begin{array}{c}\text { Horizonal hydraulic } \\
\text { conductivity }\end{array}$ & $\begin{array}{c}\text { Vertical hydraulic } \\
\text { conductivity }\end{array}$ \\
\hline Upper Clayey-Silt Unit & $\mathrm{ft} / \mathrm{d}$ & 0.2 to 1.0 & 0.02 to 0.1 \\
Green Clay Unit & $\mathrm{ft} / \mathrm{d}$ & 0.2 to 1.0 & 0.02 to 0.1 \\
Basal Gravel Unit & $\mathrm{ft} / \mathrm{d}$ & 1.0 to 14 & 0.1 to 1.4 \\
\hline
\end{tabular}

\section{B.2. DOE PORTSMOUTH GASEOUS DIFFUSION PLANT}

Five geologic units ranging from Mississippian age shale to Quaternary unconsolidated sands and clays control the groundwater flow at the Portsmouth facility. These units, which total approximately $100 \mathrm{~m}(330 \mathrm{ft})$, are described as follows:

The Mississippian age Bedford Shale consists of thinly bedded shale with interbeds of hard, gray, fine-grained sandstone and siltstone. The unit is approximately $30 \mathrm{~m}(100 \mathrm{ft})$ thick and is continuous beneath the Berea Sandstone. Three boreholes that penetrated the Besford, encountered sandstone lenses saturated with crude oil.

The Mississippian age Berea Sandstone is continuous across the Portsmouth facility, and underlies the Sunbury Shale on the eastern portion of the reservation and unconsolidated deposits (i.e., the Minford and Gallia ) on the western portion of the reservation. The unit is approximately $9 \mathrm{~m}(30 \mathrm{ft})$ thick, the upper $6 \mathrm{~m}(20 \mathrm{ft})$ of which is composed of a light gray, hard, thickly bedded, fine-grained sandstone; the lower portion, approximately $3 \mathrm{~m}$ (10 ft), has numerous interlayered shale laminations and is very similar to the underlying Bedford Shale.

The is a Mississippian age bedrock unit composed of a competent, black, carbonaceous, fissile shale that is approximately $6 \mathrm{~m}(20 \mathrm{ft})$ thick on the eastern portion of the reservation and absent on the western portion. In outcrops the Sunbury is highly fractured; however, in cores, it is competent and semiplastic. A thin 2.5 to $7.6 \mathrm{~cm}$ ( 1 to 3 in.) zone of sulfide mineralization occurs at the interface between the Sunbury and the Berea.

The youngest and uppermost bedrock unit found on the reservation, the Cuyahoga, is composed of gray, thinly bedded shale and fine-grained sand lenses. Locally, the unit reaches a maximum thickness of approximately $49 \mathrm{~m}(160 \mathrm{ft})$. This unit does not underlie the active portion of the Portsmouth facility.

The Gallia, an unconsolidated Quaternary deposit of the Teays Formation, is approximately 7.6 $\mathrm{m}(25 \mathrm{ft})$ below ground surface, at the plant site, and varies in thickness fiom 1 to $1.5 \mathrm{~m}(3$ to 5 $\mathrm{ft}$ ). The Gallia is composed of clay, sand, and gravel (channel lag or point bar deposits) that were accumulated as alluvium in the meandering channel of the ancient Portsmouth River. Deposits are generally poorly sorted and often contain silt, clay, and numerous pebble-size rock 
fragments. The fine to medium-grained sand deposits probably originated as over-bank deposits; coarse sand and gravel, near the base of the unit probably resulted from channel lab or point bar deposits. The Gallia is locally discontinuous across the site; where present, it directly overlies bedrock.

The Minford is divided into two units of unconsolidated Quaternary deposits of the Teays Formation that accumulated as a lacustrine deposit in a glacial lake (Lake Tight). The uppermost $4.5 \mathrm{~m}(15 \mathrm{ft})$ of this unit is predominantly clay, whereas the lowermost $3 \mathrm{~m}(10 \mathrm{ft})$ is predominantly silt.

The primary aquifers at the Portsmouth reservation are found in the Berea Sandstone and the Gallia Sands with the unconsolidated sands of the Gallia comprising the principal water bearing unit underlying the Portsmouth facility. Figs. 1 and 2 show the potentiometric surface contours for both the Gallia Sand and Berea Sandstone at Portsmouth.

The primary pattern of groundwater movement in the Minford Silt and Clay, is vertical; approximately $80 \%$ of the water entering the Minford moves down to the Gallia. The primary pattern of groundwater movement in the Gallia is horizontal with calculated mean flow velocities of $1.24 \mathrm{ft} / \mathrm{day}$, and a thickness of approximately 3 to $5 \mathrm{ft}(1$ to $1.5 \mathrm{~m})$. The hydraulic gradient of the Gallia is approximately 0.007 and the assumed effective porosity is approximately 0.20 . The Gallia is generally recognized as the "contaminated aquifer" at the Portsmouth facility.

Approximately $2.4 \%$ of the water entering the Gallia migrates vertically through the much less permeable Sunbury Shale (mean calculated flow velocity of $8.84 \times 10^{-8}$ ) to the Berea Sandstone. Calculated groundwater flow velocities for the Berea Sandstone range from $5.18 \times 10^{-2}$ to 0.35 $\mathrm{ft} / \mathrm{d}$, with a mean of $0.24 \mathrm{ft} /$ day. The thickness of the Berea Sandstone is approximately $9 \mathrm{~m}$ (30 $\mathrm{ft})$, with only the upper $6 \mathrm{~m}(20 \mathrm{ft})$ of which is composed of a thickly bedded, fine-grained sandstone. The lower $3 \mathrm{~m}(10 \mathrm{ft})$ is composed of interbedded shales, and is often indistinguishable from the underlying Bedford Shale.

\section{B.3. DOE SAVANNAH RIVER SITE}

The Savannah River Site (SRS) was acquired by the U. S. Government in 1950. The facility has been contracted to support national defense and space exploration. During these activities, several million gallons of wastewater containing spent process chemicals, including volatile organic compounds (TCE and 1,2-DCE).

The SRS is underlain 180 to $370 \mathrm{~m}$ of Coastal Plain Sediments ranging in age from Late Cretaceous to Recent overlying basement Paleozoic metamorphic and igneous rocks. The Coastal Plain Sediments are divided into several groups based on age and lithology.

The Late Cretaceous sediments constitute the Lumbee Group, which includes, from oldest to youngest, the Cape Fear, Middendorf, Black Creek, and Peedee Formations. This group has also been referred to as the Tuscaloosa Formation. The Cape Fear Formation consists of silty-toclayey quartz sands and interbedded clays. Thickness of the Cape Fear Formation varies from 9 $\mathrm{m}$ to $55 \mathrm{~m}$. Overlying the Cape Fear is the Middendorf Formation. The Middendorf Formation is composed of medium and coarse grained quartz sand overlain by clay. Thickness of the sand unit varies from 16 to $31 \mathrm{~m}$. Thickness of the clay unit is approximately $24 \mathrm{~m}$. Overlying the Middendorf Formation is the Black Creek Formation, consisting of quartz sands, silts, and clays. Thickness of the Black Creek Formation ranges from 34 to $76 \mathrm{~m}$. The uppermost formation in the Lumbee Group is the Peedee Formation, which consists of fine-grained sandstone and siltstone with marine fossils. The Peedee Formation varies in thickness from 34 to $40 \mathrm{~m}$. 
The Tertiary sediments of the Ellenton, Congaree, Santee, and Barnwell overlay the Lumbee Group. The Ellenton Member (a.k.a. Rhems Formation) consists of gray, poorly sorted, micaceous, lignitic, silty and clayey quartz sand interbedded with gray clays. Thickness of this member varies from 12 to $30 \mathrm{~m}$. The Congaree Formation consists of fine- to coarse-grained quartz sand. Thin clay laminae occur throughout with pebbly layers, clay casts, and glauconite present in places. The well-sorted sands, glauconite, and few fossils indicate the Congaree is a shallow marine deposit. The formation varies in thickness from 18 to $26 \mathrm{~m}$. The overlying Santee Formation consists of quartz sands and clays. Three members comprise the Santee Formation. The lowest member, referred to as the Warley Hill Member, is a fine-grained sandstone. Overlying the Warley Hill Member in a gradational contact is the Caw Member consisting of green clay. The remainder of the Santee Formation is assigned to the Mcbean Member, a micritic, calcarenitic, and shelly limestone with calcareous quartz sand.

The Late Eocene sediments comprise the Barnwell Group. The Barnwell consists of quartz sands of the Clinchfield Formation, dark brown to tan clays of the Dry Branch Formation, and poorly sorted quartz sands of the Tobacco Road Formation.

Three distinct geologic and hydrologic systems underlay the SRS: Paleozoic metamorphic and igneous rocks; lithified mudstones, sandstones, and conglomerates of Triassic age; and unconsolidated Costal Plain sediments of Late Cretaceous and Tertiary age.

Inside the SRS boundaries, the Paleozoic bedrock is not utilized as a source of water. However, within the Piedmont province, Paleozoic rocks can serve as a source of domestic water. Hydraulic conductivities in the Paleozoic rocks vary from $1.4 \times 10^{-10} \mathrm{~m} / \mathrm{s}$ in unfractured rock to $3.8 \times 10^{-7} \mathrm{~m} / \mathrm{s}$ in transmissive rocks.

Water is not pumped from the Triassic sediments due to its extremely low hydraulic conductivity $\left(4.7 \times 10^{-11}\right.$ to $\left.4.7 \times 10^{-14}\right)$, poor quality and great depth. The water quality is poor, due to a high concentration of dissolved solids, most of which is sodium chloride.

The Coastal Plain Sediments constitute a multilayered hydrologic system in which low permeability beds are interlayered with beds that transmit water more readily. Groundwater flow is governed by the hydraulic properties and geometry of each unit, and the distribution of recharge and discharge areas.

Eight hydrologic zones its have been designated based on hydrologic characteristics (Table B.2), rather than to stratigraphic names. The zones include:

Zone 1: lowermost hydrologic unit of the Coastal Plain. It corresponds to the Cape Fear Formation and consists of clay layers and semiconsolidated, clayey-silty sands.

Zone 2: comprised of three subzones: 2a, 2b, 2c. Zone $2 \mathrm{a}$ corresponds to the Middendorf Formation which consists of fine- to coarse-grained sands. Zone $2 \mathrm{~b}$ is a discontinuous clay layer which is hydrologically connected to $2 \mathrm{a}$. Zone $2 \mathrm{c}$ is a clay layer which acts as a confining layer.

Zone 3: comprised of two subzones: $3 a, 3 b$. Zone $3 a$ is the lower sand aquifer and includes the upper part of the Black Creek Formation and most of the Peedee Formation. Zone 3b is the uppermost part of the Peedee.

Zone 4: consists of the Rhems and Williamsburg Formations. This zone contains lignitic clay interbedded with sand layers. The sand at the base of Zone 4 may be wate: bearing, but is only a minor part of the unit, the rest of which is virtually impermeable material. 
Zone 5: consists of clastic sediments of the Congaree Formation (Zone 5a) and glauconite-bearing sands and clays of the lowermost Santee Limestone Formation (Zone $5 b$ ).

Zone 6: consists of clastic and carbonate sediments of the Santee Formation that lie above the green clay layer of Zone 5b. Porosity and permeability of Zone 6 vary greatly, depending on the lithology and amount of clay present.

Zone 7: is comprised of three zones: 7a, 7b, and 7c. Zone 7a (Griffins Landing and Irwinton Sand Members) and 7c (Tobacco Road Sand Formation) are aquifers whereas Zone $7 \mathrm{~b}$ is locally an aquitard.

Zone 8: consists of the upper gravels, sands, and clays of the Tobacco Road Sand and "Upland" unit. Zone 8 is commonly water bearing. The water-table often occurs in this zone.

\section{B.4 . DOE PADUCAH GASEOUS DIFFUSION PLANT}

The Paducah Gaseous Diffusion Plant (PGDP) is a Department of Energy facility that enriches uranium for commercial nuclear power reactors. Past operating and waste management procedures have contaminated the shallowest groundwater aquifer at the facility. Volatile Organic Compounds (VOCs) contamination trichloroethylene (TCE) and 1,2-dichloroethylene (DCE) has been detected at several areas at the plant in the form of dissolved phase and dense nonaqueous phase liquid (DNAPL).

The subsurface at the PGDP site consists of Cretaceous, Tertiary, and Quaternary sediments unconformably overlying Paleozoic bedrock. 
Table B.2. Summary of hydraulic conductivities reported for hydrologic units of the Coastal Plain Sediments (horizontal unless otherwise stated) at the DOE Savannah River Site.

\begin{tabular}{|c|c|c|c|c|}
\hline $\begin{array}{c}\text { Hydrologic } \\
\text { units }\end{array}$ & $\begin{array}{l}\text { Sub- } \\
\text { units }\end{array}$ & $\begin{array}{l}\text { Field-determined } \\
\text { hydraulic conductivity } \\
\left(\mathrm{m} \mathrm{s}^{-1}\right)\end{array}$ & $\begin{array}{c}\text { Hydraulic } \\
\text { conductivity from soil } \\
\text { cores } \\
\left(\mathrm{m} \mathrm{s}^{-1}\right) \\
\end{array}$ & $\begin{array}{c}\text { Hydraulic } \\
\text { conductivity from } \\
\text { sieve analysis } \\
\left(\mathrm{m} \mathrm{s}^{-1}\right)\end{array}$ \\
\hline Zone 8 & & --- & $10^{-5} \mathrm{a}$ & --- \\
\hline \multirow[t]{3}{*}{ Zone 7} & $7 c$ & $2 \times 10^{-7}-10^{-4} b, c$ & $10^{-6} \mathrm{a}, \mathrm{d}$ & $\overline{-\cdots}$ \\
\hline & $7 b$ & $\begin{array}{c}2 \times 10^{-9}-8 \times 10^{-9} \mathrm{c} \\
(\text { vertical) }\end{array}$ & $10^{-8 d}$ & $\cdots$ \\
\hline & $7 a$ & $10^{-8}-10^{-4} \mathrm{~b}, \mathrm{c}, \mathrm{e}$ & --- & $\cdots$ \\
\hline Zone 6 & & $6 \times 10^{-7}-2 \times 10^{-5} \mathrm{~b}, \mathrm{c}$ & $\cdots$ & --- \\
\hline \multirow[t]{2}{*}{ Zone 5} & $5 b$ & $\begin{array}{c}1 \times 10^{-9}-2 \times 10^{-8} \\
\text { (vertical) }\end{array}$ & $\cdots$ & --- \\
\hline & $5 a$ & $10^{-7}-5 \times 10^{-4} \mathrm{~b}, \mathrm{c}, \mathrm{e}$ & $\cdots-$ & $3 \times 10^{-5}-2 \times 10^{-3} \mathrm{~h}$ \\
\hline Zone 4 & & $\cdots$ & $\begin{array}{c}1 \times 10^{-10-4 \times 10^{-9} \mathrm{~g}} \\
\text { (vertical) }\end{array}$ & $2 \times 10^{-5}-3 \times 10^{-4} \mathrm{~h}$ \\
\hline \multirow[t]{2}{*}{ Zone 3} & $3 b$ & $\cdots$ & $\cdots$ & $-\cdots$ \\
\hline & $3 \mathrm{a}$ & $\cdots$ & $\cdots$ & $3 \times 10^{-4} \mathrm{~h}$ \\
\hline \multirow[t]{2}{*}{ Zone 2} & $2 c$ & $\cdots$ & $\cdots$ & $4 \times 10^{-4} \mathrm{~h}$ \\
\hline & $\frac{2 b}{2 a}$ & & & \\
\hline Zone 1 & & $\cdots$ & $\begin{array}{c}2 \times 10^{-9}-6 \times 10^{-8} \mathrm{~h} \\
\text { (vertical) }\end{array}$ & $\cdots$ \\
\hline
\end{tabular}

Notes:

a Dennehy et al. 1989; Z-Area vicinity

b Christensen and Gordon 1983; regional data

c Parizek and Root 1986; SRS data, near Z-Area

d Cook 1986; Z-Area vicinity

e INTERA 1986; Z-Area vicinity

f Root 1981; near H-Area

8 Bledsoe 1987; central and southeastern SRS

h WSRC 1992b; regional data 
The Upper Cretaceous McNairy Formation overlies the bedrock at PGDP. The McNairy Formation consists of interbedded and interlensing sand, silt, and clay. Very fine to medium grained, well sorted sand accounts for 40 to $50 \%$ of the McNairy Formation. The thickness of the McNairy Formation is approximately $225 \mathrm{ft}$.

Miocene, Pliocene, and Pleistocene continental deposits unconformably overlie the McNairy Formation. The continental deposits are subdivided into the lower gravel unit and the upper clay unit. The lower gravel unit consists of chert gravel in a matrix of poorly sorted sand and silt. The thickness of the lower gravel unit averages $30 \mathrm{ft}$ and ranges up to $50 \mathrm{ft}$.

The upper clay unit consists of clayey silt with thin zones of sand and occasional gravel. The clayey silt is light gray with reddish- to yellowish-brown, massive to finely laminated. The clay unit varies in thickness from 15 to $55 \mathrm{ft}$.

Loess overlies the continental deposits throughout the site. Thickness of loess deposits varies from 5 to $25 \mathrm{ft}$ with an average of $15 \mathrm{ft}$.

No distinguishing sedimentary structures are evident in either the sand or gravel lithofacies to allow further subdivision. PGDP geologists primarily correlate soil borings using recognized trends in lithofacies. Geologists have not yet defined any widespread marker beds.

The local flow system exists within sediments of the continental deposits and the McNairy Formation. Specific members of the flow system include:

1. Upper Continental Recharge System - Applies to the sand and gravel dominated facies found at different elevations throughout the upper continental deposits. The most prevalent sand and gravel deposits occur at an elevation of approximately 345 to 351 amsl.

2. Regional Gravel Aquifer (RGA) - Applies to the Quaternary sand and gravel facies of the lower continental deposits of sufficient thickness and saturation to constitute an aquifer. The RGA is the primary aquifer utilized locally.

3. McNairy Flow System - Applies to the McNairy Formation, which consists of interbedded and interlensing sand, silt, and clay.

The major conduit of flow is the RGA (Table B.3). The RGA lies at depth and receives recharge via underflow from the terrace gravels and infiltration through the upper continental deposits. The conductivity ratio between the RGA and overlying sediments ranges from 2 to 5 orders of magnitude. Measured hydraulic gradients in the upper continental deposits are downward (1 $\mathrm{ft} / \mathrm{ft}$ ). Results from analytical and numerical analysis indicate most of the water entering the shallow system flows vertically into RGA. The lateral gradient within the RGA is nearly stagnant $\left(1 \times 10^{-4} \mathrm{ft} / \mathrm{ft}\right)$. 


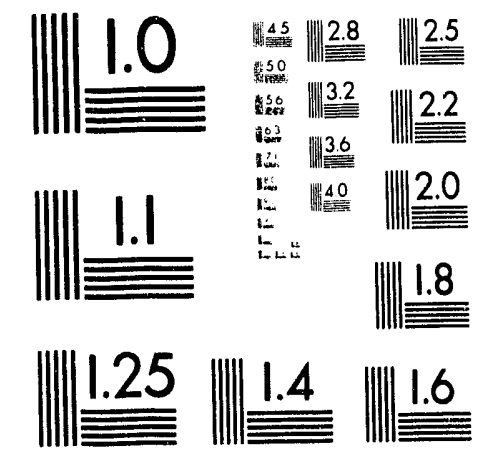



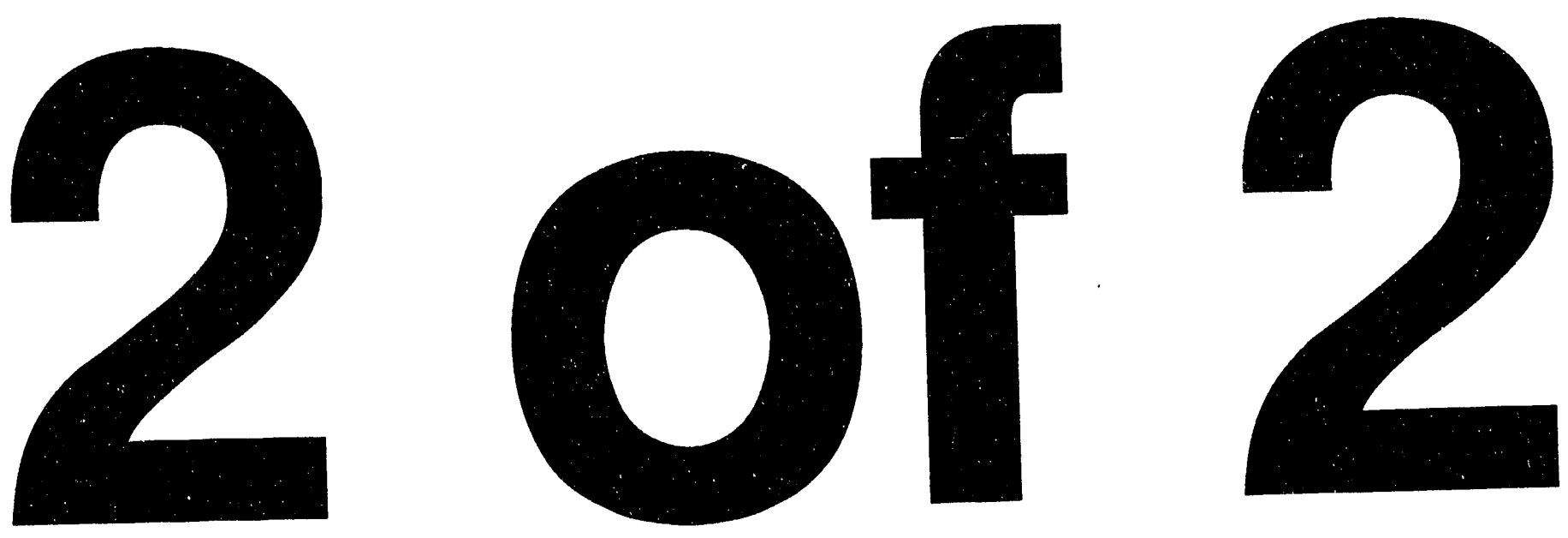
The RGA receives recharge via surface infiltration of rainwater. The role of the upper continental recharge system (UCRS) is to transmit water to the RGA, which acting as the major conduit of flow, transports water laterally to areas of discharge. Significant lateral flow within the shallow groundwater system (SGS) does not appear to occur. This is the result of the conductivity contrast that exists between the RGA and overlying sediments within the upper continental deposits.

HU 5: Unit 5 is the RGA and is predominantly gravel with silt and sand but found locally as all sand or as a cobbley gravel.

HU 4: Unit 4 is the sand which overlies the RGA. This sand is discontinuous over the PGDP area. Unit 4 hydraulically connects to the RGA and exhibits nearly identical hydraulic heads in locations with nested well completions in both Unit 4 and Unit 5 .

HU 3: Unit 3 is the confining layer for the RGA. It is composed of all sediments from the base of Unit 2 to the top of Unit 4, when present, or Unit 5 (RGA), when Unit 4 is absent. It is predominantly clay, silt, or clayey silt.

HU 2: Unit 2 is the shallow groundwater system (SGS). The unit is a discontinuous but correlatable sand body.

HU 1: Unit 1 is the overlying loess which covers the site.

As mentioned above, recharge to the RGA is controlled by the overlying sediments. Increases in recharge rates are attributed to thinning of HU 3 which represents areas of higher leakage into the RGA. Additional recharge to the RGA is from "windows" within the aquitard (HU 3). These windows are areas which contain greater than $40 \%$ sand and gravel.

Horizontal gradients within the UCRS are on the order of $1 \times 10^{-3}$. Flow directions within this system is $0.0059 \mathrm{ft} / \mathrm{d}$ directed west-northwest and oriented downward approximately 50 degrees from horizontal. Assumed flow through HU 3 is vertical; estimated leakage is on the order of $0.003 \mathrm{gpd} / \mathrm{ft}^{2}$. The average vertical hydraulic conductivity of $\mathrm{HU} 3 \mathrm{is} 0.0092 \mathrm{gpd} / \mathrm{ft}^{2}$.

The RGA is the main zone of saturation and is the primary aquifer utilized locally. The RGA varies in thickness from 10 to $40 \mathrm{ft}$.

The RGA resembles a leaky or semiconfined aquifer, bounded above by HU 3 and below by the McNairy Formation. Measured values of the storage coefficient vary from $5.57 \times 10^{-6}$ to 0.5904. No vertical gradients have been measured in nested RGA -21 wells, suggesting flow is lateral, trending north-north-northeast. The hydraulic gradient is on the order of $1 \times 10^{-4}$ to $1 \mathrm{x}$ $10^{-3} \mathrm{ft} / \mathrm{ft}$. Estimated groundwater recharge is approximately 10 to $15 \%$ of precipitation, or about 4.7 to 7.0 in. per year. 
Table B.3. Range of hydraulic conductivity values for major lithologies near the DOE Paducah Gaseous Diffusion Plant.

\begin{tabular}{cc}
\hline Geologic unit & Hydraulic conductivity (cm/s) \\
\hline Loess & $10^{-7}$ to $10^{-4}$ \\
Upper Continental Deposits (clay) & $10^{-8}$ to $10^{-3}$ \\
Upper Continental Deposits (sand) & $10^{-5}$ to $10^{-2}$ \\
Regional Gravel Aquifer (RGA) & $10^{-4}$ to 1 \\
McNairy Formation & $<10^{-6}$ to $10^{-3}$ \\
\hline
\end{tabular}


Appendix C. INORGANIC REACTIONS 


\section{C.1. REACTIONS OF IRON}

$$
\begin{aligned}
& \mathrm{Fe}(\mathrm{OH})_{2}+\mathrm{H}_{2} \mathrm{O} \rightarrow \mathrm{Fe}(\mathrm{OH})_{3}+\mathrm{H}_{(a q)}^{+}+e^{-} \\
& \Delta \mathrm{G}=24.8 \mathrm{~kJ} / \mathrm{gmol} \\
& 3 \mathrm{Fe}(\mathrm{OH})_{2} \stackrel{\mathrm{K}}{\longrightarrow} \mathrm{Fe}_{3} \mathrm{O}_{4}+\mathrm{H}_{2}+2 \mathrm{H}_{2} \mathrm{O} \\
& \Delta \mathrm{G}=-27.16 \mathrm{~kJ} / \mathrm{gmol} \\
& 2 \mathrm{Fe}(\mathrm{OH})_{3 p p t} \rightarrow \mathrm{Fe}_{2} \mathrm{O}_{3}+3 \mathrm{H}_{2} \mathrm{O} \\
& \Delta \mathrm{G}=-55.0 \mathrm{~kJ} / \mathrm{gmol} \\
& \mathrm{Fe}_{2} \mathrm{O}_{3}+6 \mathrm{H}^{+} \rightarrow 2 \mathrm{Fe}^{3+}+3 \mathrm{H}_{2} \mathrm{O} \\
& \Delta \mathrm{G}=20.3 \mathrm{~kJ} / \mathrm{gmol} \\
& \mathrm{Fe}_{3} \mathrm{O}_{4}+8 \mathrm{H}^{+} \rightarrow 3 \mathrm{Fe}^{3+}+4 \mathrm{H}_{2} \mathrm{O}+e^{-} \\
& \Delta \mathrm{G}=50.10 \mathrm{~kJ} / \mathrm{gmol} \\
& \left.3 \mathrm{FeSiO}_{3}+\mathrm{H}_{2} \mathrm{O}=\mathrm{Fe}_{3} \mathrm{O}_{4}+3 \mathrm{SiO}_{2} \text { (glass, cristobolitelI }\right)+2 \mathrm{H}_{(a q)}^{+}+2 e^{-} \\
& \Delta \mathrm{G}=97.6 \mathrm{~kJ} / \mathrm{gmol} \\
& \mathrm{E}=0.2-0.059 \mathrm{pH} \\
& \left.2 \mathrm{FeSiO}_{3}+\mathrm{H}_{2} \mathrm{O}=\mathrm{Fe}_{2} \mathrm{O}_{3}+2 \mathrm{SiO}_{2} \text { (glass, cristoboliteII }\right)+2 \mathrm{H}_{(a q)}^{+}+2 e^{-} \\
& \Delta \mathrm{G}=39.3 \mathrm{~kJ} / \mathrm{gmol} \\
& \mathrm{E}=0.21-0.059 \mathrm{pH} \\
& \mathrm{FeSiO}_{3}+2 \mathrm{H}^{+}=\mathrm{Fe}^{2+}+\mathrm{SiO}_{2}(\text { glass, cristobolitell })+2 \mathrm{H}_{2} \mathrm{O} \\
& \Delta \mathrm{G}=-50.63 \mathrm{~kJ} / \mathrm{gmol} \\
& \log \left[\mathrm{Fe}^{2+}\right]=4.43-\mathrm{pH}
\end{aligned}
$$

\section{C.2. CHANGE OF pH BY ABSORPTION OF $\mathrm{CO}_{2}$}

The atmospheric partial pressure of $\mathrm{CO}_{2}$ is

$$
P_{\mathrm{CO}_{2}}=10^{-3.5} \mathrm{~atm} \text {. }
$$

The relationship between the partial pressure of dissolved $\mathrm{CO}_{2}$ and the activity of $\mathrm{H}_{2} \mathrm{CO}_{3}$ is

$$
\left[\mathrm{H}_{2} \mathrm{CO}_{3((4))}\right]=10^{-1.47} \mathrm{P}_{\mathrm{CO}_{2}}
$$

$\mathrm{H}_{2} \mathrm{CO}_{3}$ is then a known quantity by including the atmospheric concentration of $\mathrm{CO}_{2}$. The relationship between $\mathrm{H}_{2} \mathrm{CO}_{3}$ and it's dissociation products, $\mathrm{HCO}_{3}^{-}$and $\mathrm{H}^{+}$, is

$$
\frac{\left[\mathrm{H}^{+}\right]\left[\mathrm{HCO}_{3}^{-}\right]}{\left[\mathrm{H}_{2} \mathrm{CO}_{3}\right]}=10^{-6.4} \text {. }
$$


The relationship between $\mathrm{HCO}_{3}^{-}$and it's dissociation products, $\mathrm{CO}_{3}^{2-}$ and $\mathrm{H}^{+}$, is

$$
\frac{\left[\mathrm{H}^{+}\right]\left[\mathrm{CO}_{3}^{2-}\right]}{\left[\mathrm{HCO}_{3}^{-}\right]}=10^{-10.3}
$$

The relationship between water and it's dissociation products is

$$
\left[H^{+}\right]\left[O H^{-}\right]=10^{-14}
$$

The unknown species are

$$
\left[\mathrm{H}^{+}\right],\left[\mathrm{HCO}_{3}^{-}\right],\left[\mathrm{CO}_{3}^{2-}\right] \text {, and }\left[\mathrm{OH}^{-}\right]
$$

The electro-neutrality condition dictates that

$$
\left[\mathrm{H}^{+}\right]=\left[\mathrm{HCO}_{3}^{-}\right]+2\left[\mathrm{CO}_{3}^{2-}\right]+\left[\mathrm{OH}^{-}\right]
$$

Substituting in the above conditions for $\left[\mathrm{H}^{+}\right]$in the above system of equations yields

$$
\left[H^{+}\right]^{3}=10^{-11.4}\left[H^{+}\right]+10^{-21.4}
$$

The above equation is solved by trial and error giving $\left[\mathrm{H}^{+}\right]=10^{-5.7}$.

The activities of each individual carbonate species are, $\left[\mathrm{H}^{+}\right]=10^{-5.7},[\mathrm{HCO}]=10^{-5.7}$, giving the total dissolved carbonates as: $\left[\mathrm{CO}_{3}^{-}\right]=10^{-10.3},\left[\mathrm{H}_{2} \mathrm{CO}_{3}\right]=10^{-5},\left[\mathrm{OH}^{-}\right]=10^{-8.3}\left[\mathrm{CO}^{-}\right]+$ $\left[\mathrm{H}_{2} \mathrm{CO}_{3}(\mathrm{aq})\right]+[\mathrm{HCO}]=10^{-4.9}$. When atmospheric $\mathrm{CO}_{2}$ and $\mathrm{CaCO}_{3}$ are in equilibrium with water then $\left[\mathrm{H}^{+}\right]=10^{-8.4} ;\left[\mathrm{Ca}^{2+}\right]=10^{-3.4} ;\left[\mathrm{CO}_{3}\right]=10^{-4.9} ;[\mathrm{HCO}]=10^{-3.0} ;\left[\mathrm{OH}^{-}\right]=10^{-5.6}$; $\left[\mathrm{H}_{2} \mathrm{CO}_{3}\right]=10^{-5.0}$. Therefore, the $\mathrm{pH}$ of water in equilibrium with $\mathrm{CaCO}_{3}$ and with atmospheric $\mathrm{CO}_{2}$ is 8.4. The total dissolved carbonates or alkalinity of the system is $10^{-2.99}$. 


\section{INTERNAL DISTRIBUTION}

1. M. R. Ally

2. L. D. Bates

3. D. A. Bell

4. C. H. Brown

5. J. H. Cushman

6. N. H. Cutshall

7. T. L. Donaldson

8. T. O. Early

9. W. Fulkerson

10. D. D. Gates

11. C. W. Gehrs

12. S. G. Hildebrand

13. P. Kanciruk

14.. A. P. Malinauskas

15. T. L. Mayfield

16. T. J. Phelps

17. D. E. Reichle
18
19.
W. E. Sanford
20.
F. E. Sharples
21-25. R. L. Siegrist
26.
S. H. Stow
27. R. I. Van Hook
28. J. S. Watson
29. O. F. Webb
30. O. R. West
31. Central Research Library
32-34. ESD Library
35. ORNL Y-12 Technical Library
36-37. Laboratory Records
38. Laboratory Records, RC
39. ORNL Patent Section

\section{EXTERNAL DISTRIBUTION}

40. D. T. Davenport, Environmental Restoration Division, Martin Marietta Energy Systems, Portsmouth Gaseous Diffusion Plant, MS 5025, Piketon, OH 45661.

41. R. N. Farvolden, Professor, Department of Earth Sciences, University of Water, Ontario N2L 3G1 Canada.

42. J. S. Gierke, Assistant Professor, Michigan Technological University, 1400 Townsend Drive, Houghton, MI 49931-1295.

43. D. Geiser, Office of Technology Development, International Technology Exchange Program, EM-53, U. S. Department of Energy, Washington, D. C. 20585

44. R. C. Harriss, Institute for the Study of Earth, Oceans, and Space, Science and Engineering Research Building, University of New Hampshire, Durham, NH 03824.

45. G. Y. Jordy, Director, Office of Program Analysis, Office of Energy Research, ER-30, G226, U. S. Department of Energy, Washington, D. C. 20545.

46. P. M. Kearl, ORNL Grand Junction Office, 2597 B 3/4 Road, Grand Junction, Colorado 81502.

47. Dave Mentzer, SAIC, Portsmouth Gaseous Diffusion Plant, Piketon, OH 45661.

48. A. Patrinos, Director, Environmental Sciences Division, Office of Health and Environmental Research, ER-74, U. S. Department of Energy, Washington, D. C. 20585.

49. F. J. Wobber, Environmental Sciences Division, Office of Health and Environmental Research, ER-74, U. S. Department of Energy, Washington, D. C. 20585.

50. J. Zutman, ORNL Grand Junction Office, 2597 B 3/4 Road, Grand Junction, Colorado 81502.

51. Office of Assistant Manager for Energy Research and Development, U. S. Department of Energy Oak Ridge Field Office, P.O. Box 2001, Oak Ridge, TN 37831-8600.

52-53. Office of Scientific and Technical Information, P.O. Box 62, Oak Ridge, Tennessee 37831 

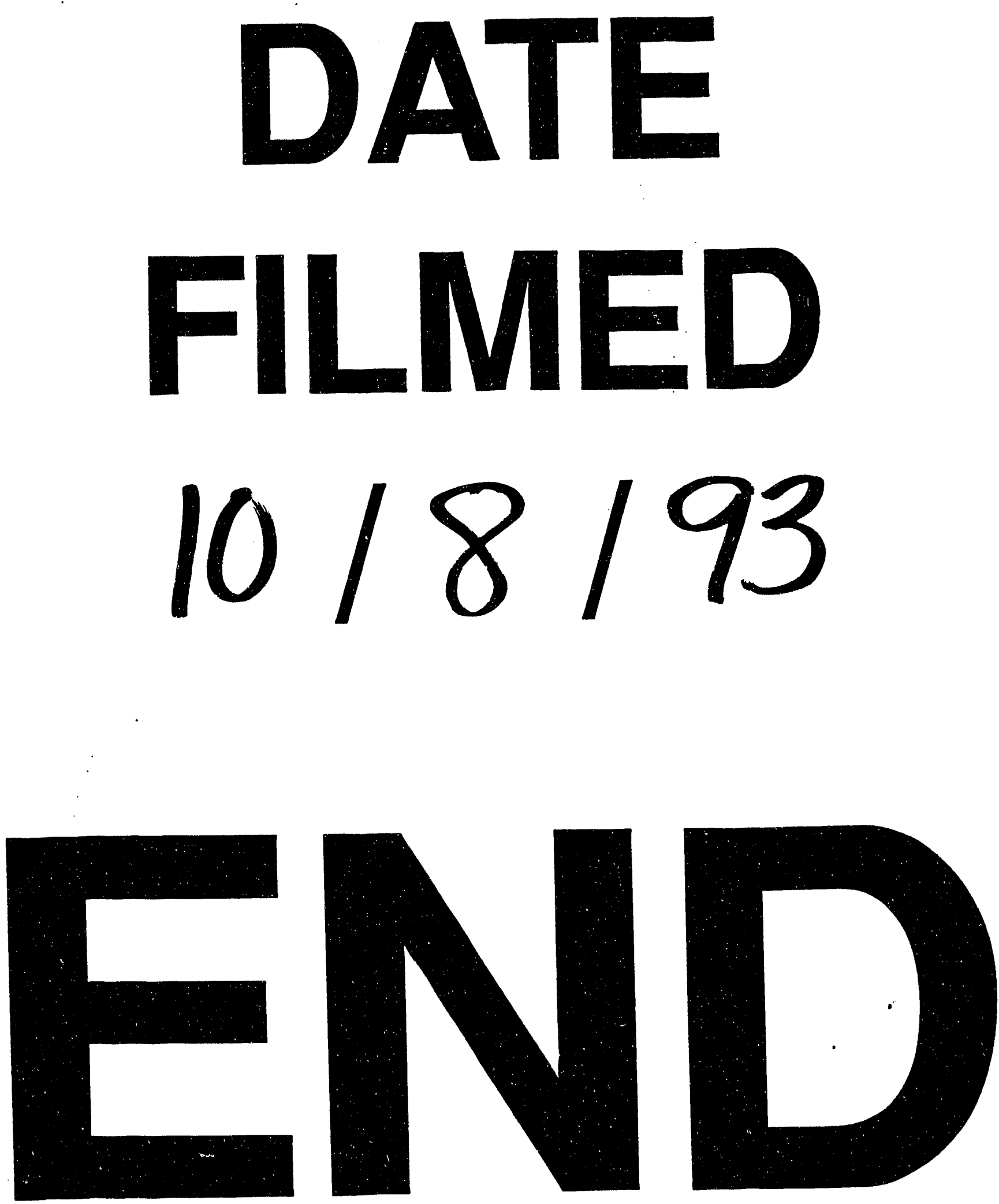
